Florida International University FIU Digital Commons

$11-9-2009$

\title{
Characterizations of the Major Coral Diseases of the Philippines: Ulcerative White Spot Disease and Novel Growth Anomalies of Porites
}

Longin T. Kaczmarsky

Florida International University, solonnie@hotmail.com

DOI: $10.25148 /$ etd.FI09120804

Follow this and additional works at: https://digitalcommons.fiu.edu/etd

\section{Recommended Citation}

Kaczmarsky, Longin T., "Characterizations of the Major Coral Diseases of the Philippines: Ulcerative White Spot Disease and Novel Growth Anomalies of Porites" (2009). FIU Electronic Theses and Dissertations. 118.

https://digitalcommons.fiu.edu/etd/118 


\section{FLORIDA INTERNATIONAL UNIVERSITY}

Miami, Florida

\section{CHARACTERIZATIONS OF THE MAJOR CORAL DISEASES \\ OF THE PHILIPPINES: \\ ULCERATIVE WHITE SPOT DISEASE \\ AND NOVEL GROWTH ANOMALIES OF PORITES}

A dissertation submitted in partial fulfillment of the

requirements for the degree of

DOCTOR OF PHILOSOPHY

in

BIOLOGY

by

Longin Kaczmarsky

2009 


\section{To: Dean Kenneth Furton}

College of Arts and Sciences

This dissertation, written by Longin Kaczmarsky, and entitled Characterizations of the Major Coral Diseases of The Philippines: Ulcerative White Spot Disease and Novel Growth Anomalies of Porites, having been approved in respect to style and intellectual content, is referred to you for judgment.

We have read this dissertation and recommend that it be approved.

Esther Peters

Charles Bigger

Joseph Boyer

Laurie L. Richardson, Major Professor

Date of Defense: November 9, 2009

The dissertation of Longin Kaczmarsky is approved.

\begin{tabular}{r} 
Dean Kenneth Furton \\
College of Arts and Sciences \\
\hline Dean George Walker \\
University Graduate School
\end{tabular}

Florida International University, 2009 


\section{DEDICATION}

This work is dedicated to my wife, Sonia, without whom none of this would have been possible. 


\section{ACKNOWLEDGMENTS}

With much gratitude, I would like to acknowledge all the folks that helped me complete this dissertation, especially my major professor Laurie Richardson and my committee members, Esther Peters, Joseph Boyer, and Charles Bigger. I would also like to acknowledge all the people who inspired me to pursue the path I've taken:

I foremost would like to thank all the thousands of students and their teachers who visited me for over 10 years and listened to my talks about coral reef conservation at the St. Croix Aquarium and Marine Education Center in the Virgin Islands. Their excitement and enthusiasm was inspirational to me and provided me the motivation to dedicate my efforts in doing my part to save the coral reefs for future generations. I would also like to thank my aquarium staff, board members, supporters and countless volunteers who so strongly believed in our mission and gave generously of themselves.

I would also like to recognize my parents, Orest and Helen, and grandparents who taught me in many ways to appreciate the wonders of the natural world and to always be open to learning new things. I am also grateful to the friends and family who supported me in this effort including Dutchy Hendrickson, Desi Gandolfo, Rhonda Pessin, Cary Nelson, Lenore Koch (who reminded me many times over the years that "if a $\mathrm{PhD}$ was easy to get, then everyone would have one"), my wife's family, and Dr. Ken Haines.

I would like to thank all the people who took time out of their busy lives to spend time meeting with me and who inspired me to take on this task of pursuing a $\mathrm{PhD}$ and follow my dream of making the world a better place by educating myself to educate others about the value of coral reefs. Most inspirational and helpful were Dr. Matt Draud, 
Dr. Ernest Williams, and Dr. DeEtta Mills. I especially would like to thank Dr. David Steinberg (President of Long Island University), Dr. Maithili Schmidt-Raghavan (Fulbright advisor), who both encouraged me to apply for and helped me win a Fulbright scholarship to do research in the Philippines.

I am grateful for the help I received from advisors and colleagues at Florida International University, Silliman University Marine Laboratory, University of the Virgin Islands, and University of Miami including Dr. Raju Sekar, Dr. Walter Goldberg, Dr. Maureen Donnelly, Dr. Lidia Kos, Elizabeth Remily, Kristin Kuehl, Dina Stanic, Dr. Miro Gantar, Beth Zimmer, Dr. Josh Voss, Dr. Roman Garcia, Dr. James Valdes, Dr. Paul Sharp, Lorenzo Menzel, Emily Broderick, Aaron Miller, Dr. Nida Calumpong, Dr. Janet Estacion, Kathryn Rosell, Dr. Dan Lindstrom, Dr. Laurie Raymundo, Dr. Paulina Aspilla, Dr. Pat Blackwelder, and Husain AlSayegh.

I also appreciate the financial support from the Florida International University Dissertation Year Fellowship, Judith Parker Travel Scholarship, Project AWARE, J. William Fulbright Foreign Scholarship Board, The Philippine-American Educational Foundation, and equipment donations from the St. Croix Aquarium and Marine Education Center. 


\author{
ABSTRACT OF THE DISSERTATION \\ CHARACTERIZATIONS OF THE MAJOR CORAL DISEASES \\ OF THE PHILIPPINES: \\ ULCERATIVE WHITE SPOT DISEASE \\ AND NOVEL GROWTH ANOMALIES OF PORITES \\ by \\ Longin Kaczmarsky
}

Florida International University, 2009

Miami, Florida

Professor Laurie Richardson, Major Professor

Coral reefs are in decline worldwide and coral disease is a significant contributing factor. However, etiologies of coral diseases are still not well understood. In contrast with the Caribbean, extremely little is known about coral diseases in the Philippines.

In 2005, off Southeast Negros Island, Philippines, I investigated relationships between environmental parameters and prevalence of the two most common coral diseases, ulcerative white spot (UWS) and massive Porites growth anomalies (MPGAs). Samples were collected along a disease prevalence gradient $40.5 \mathrm{~km}$ long. Principal component analyses showed prevalence of MPGAs was positively correlated with water column nitrogen, organic carbon of surface sediments, and colony density. UWS was positively correlated with water column phosphorus. This is the first quantitative evidence linking anthropogenically-impacted water and sediment to a higher prevalence of these diseases. 
Histological and cytological alterations were investigated by comparing tissues from two distinct types of MPGA lesions (types 1 and 2) and healthy coral using light and electron microscopy. Skeletal abnormalities and sloughing, swelling, thinning, and loss of tissues in MPGAs resembled tissues exposed to bacterial or fungal toxins. Both lesion types had decreases in symbiotic zooxanthellae, which supply nutrients to corals. Notable alterations included migrations of chromophore cells (amoebocytes) (1) nocturnally to outer epithelia to perform wound-healing, including plugging gaps and secreting melanin in degraded tissues, and (2) diurnally to the interior of the tissue possibly to prevent shading zooxanthellae in order to maximize photosynthate production. Depletion of melanin (active in wound healing) in type 2 lesions suggested type 2 tissues were overtaxed and less stable. MPGAs contained an abundance of endolithic fungi and virus-like particles, which may result from higher nutrient levels and play roles in disease development. Swollen cells and mucus frequently blocked gastrovascular canals (GVCs) in MPGAs. Type 1 lesions appeared to compensate for impeded flow of wastes and nutrients through these canals with proliferation of new GVCs, which were responsible for the observed thickened tissues. In contrast, type 2 tissues were thin and more degraded. Dysplasia and putative neoplasia were also observed in MPGAs which may result from the tissue regeneration capacity being overwhelmed. 


\section{TABLE OF CONTENTS}

CHAPTER

PAGE

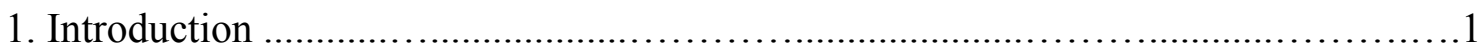

References.................................................. 16

2. Correlation of coral disease prevalence on reefs of the Philippines with high colony

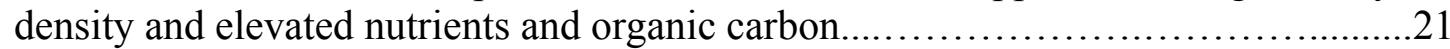

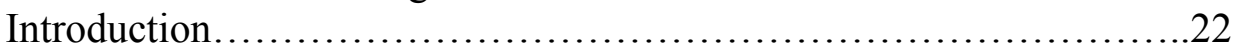

Material and methods...............................................26

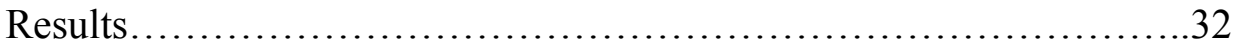

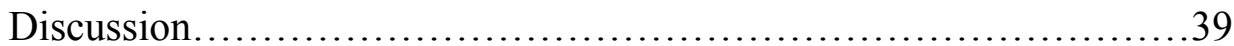

References....................................................... 45

3. Histopathology of growth anomalies of the massive coral, Porites lutea, from the

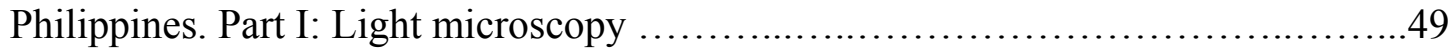

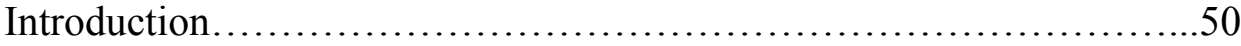

Material and methods...............................................54

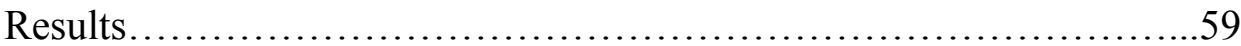

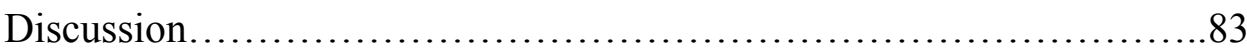

References........................................................ 90

4. Histopathology of growth anomalies of the massive coral, Porites lutea, from the Philippines. Part II: Ultrastructure ...........................................95

Introduction........................................................ 96

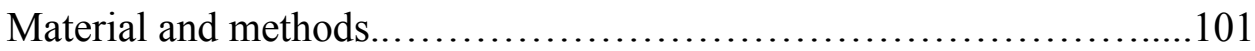

Results..........................................................

Discussion..........................................................

References........................................................

5. Summary and future directions............................................... 135

References..................................................... 147

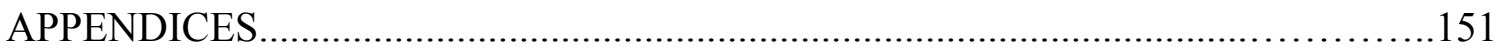

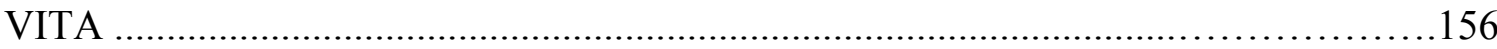




\section{LIST OF TABLES}

TABLE

PAGE

Chapter 2.

Table 1. Water quality along an environmental impact gradient in the Philippines and corresponding environmental parameters used in correlation analyses.....32

Table 2. Results of correlation analyses...................................... 33

Chapter 3.

Table 1. Summary of general histopathogical characteristics of massive Porites growth anomalies of $P$. lutea as compared to healthy $P$. lutea ......................84

Table 2. Histological comparisons of GAs in Porites lutea (Philippines) and $P$. compressa (Hawaii)................................................... 86

Chapter 4.

Table 1. MPGA associated chromophore cell alterations.........................107

Table 2. MPGA associated zooxanthellae alterations............................... 110 


\section{LIST OF FIGURES}

FIGURE

PAGE

Chapter 2.

Figure 1. Map of coral disease study sites along an environmental gradient......27

Figure 2. Results of statistical tests comparing sites........................33

Figure 3. Disease prevalence of MPGAs and UWS in relation to sites............37

Figure 4. Principal component analyses of correlations between environmental parameters and sampling site location........................... 38

Chapter 3.

Figure 1. Gross morphology of massive Porites growth anomalies...............54

Figure 2. Generalized diagram of coral anatomy...........................58

Figure 3. Alterations in $P$. lutea thickness and architecture. Longitudinal sections of decalcified coral.....................................60

Figure 4. Major tissue alterations associated with MPGAs ......................62

Figure 5. Type 2 MPGA lesion calicodermal tissue..........................63

Figure 6. Alterations in the basal tissue regions in association with MPGAs.......64

Figure 7. Alterations in the surface epithelia associated with MPGAs...........66

Figure 8. Alterations in type 1 and 2 MPGAs...........................67

Figure 9. Chromophore cell distribution and skeletal thickness patterns in MPGAs.......................................................69

Figure 10. Type 2 MPGA lesion at night............................... 71

Figure 11. Alterations in chromophore cells in association with MPGAs.........72

Figure 12. Alterations in chromophore cell behavior in association with type 1 MPGAs..................................................73

Figure 13. Chromophore cell secretions in association with MPGAs............75 
Figure 14. Dispersal of melanin-like substance in association with MPGAs.......76

Figure 15. Alterations in mucocytes in association with type 2 MPGAs..........78

Figure 16. Abnormal mass associated with a type 2 lesion.....................79

Figure 17. Protuberant surface epidermal hyperplasia........................80

Figure 18.Tissue abnormalities and aberrant growths in MPGAs..............81

Figure 19. Type 1 lesion with putative neoplasia............................83

\section{Chapter 4.}

Figure 1. Alterations in chromophore cells in MPGAs........................... 106

Figure 2. Alterations in zooxanthellae in MPGAs. ............................ 109

Figure 3. Abnormal calicodermal cells of type 2 MPGA.....................111

Figure 4. Bacteria and virus-like particles associated with $P$. lutea $\ldots \ldots \ldots \ldots . . .113$ 
CHAPTER 1

INTRODUCTION 
Coral reefs are in decline throughout the world and coral disease is a significant contributing factor (Wilkinson, 2002; Hughes et al., 2003; Pandolfi et al., 2003; Rosenberg and Loya, 2004). In the past two decades the numbers of coral diseases, disease events, and host species affected have all increased (Harvell et al., 1999; Sutherland et al., 2004). Yet, the etiologies of many coral diseases are still poorly understood (Rosenberg et al., 2007). Not much is known about coral diseases of the Philippines or South Asia in general, when compared to more intensively studied Caribbean and Australian coral diseases. Many anthropogenic factors have been considered as contributing to coral disease and coral reef degradation, such as soil erosion, global warming, over-fishing, introduced organisms, sewage effluent, and other pollutants, but it is has been exceedingly difficult to determine the individual contribution each of these makes in order to take remedial action. By identifying microorganisms and environmental and histopathologic correlates associated with a particular disease, researchers will better understand some of the factors and mechanisms that may be important in the disease process. Understanding the dynamics and progression of coral diseases will give direction for future research and management actions.

Reefs of the Philippines and Indonesia are considered the center of coral reef biodiversity (Veron, 2000; Hughes et al., 2002; Carpenter and Springer, 2005). Before the recent epizootics described by Kaczmarsky (2006), there were few reports of coral disease on Philippine reefs. These included relatively low levels of black band disease and white band disease observed in 1981 (Antonius, 1985) and ulcerative white spots disease (UWS) observed in 1996 (Raymundo et al., 2003). In the wider Indo-Pacific, 
however, the reports of white plague-like diseases and black band disease have been numerous (reviewed by Sutherland, 2004).

In 2002, epizootics of lethal growth anomalies (GAs) and ulcerative white spot disease (UWS), which affected most species of the dominant reef-building corals in the genus Porites, were discovered in the Philippines. Observations suggested that the diseases were widespread and estimated to affect $>10,000$ colonies (pers. obs.). From a survey that began in 2002 it was determined that these two diseases occurred at high prevalence values $("$ prevalence" $=$ the number of affected colonies divided by the total number of colonies of the susceptible species or population under investigation). Growth anomalies as high as 39\% occurred among massive Porites and prevalence of UWS was as high as $54 \%$ among massive and branching Porites (Kaczmarsky, 2006). Widespread epizootics involving these two diseases had not been previously reported.

These discoveries were made during a general baseline survey of coral disease prevalence (Kaczmarsky, 2004, 2006). Because of the occasional difficulty distinguishing among some Porites species in situ (Veron, 1995 and 2000), and the impracticality of sampling and identifying each colony in the laboratory, during the original disease surveys species were placed in the category "massive" or "branching" for disease prevalence analyses. Microscopy later confirmed the presence in my study sites of several large ( $>1 \mathrm{~m}$ diameter) massive species: Porites lutea, P. lobata, P. solida, P. mayeri, and P. australiensis and several small massive species (Veron, 2000), $P$. murrayensis, $P$. stephensoni, and $P$. densa. Therefore all these species were included in the "massive" group, and all were determined to be susceptible to both of the focal diseases. Two massive Porites species, Porites lutea and Porites lobata, structurally 
dominated the affected reefs. Microscopic confirmation was used to estimate the relative dominance of Porites lutea and P. lobata, (data not shown).

Porites is a very common, ecologically important genus on many Indo-Pacific reefs (Veron, 2000). Many members of the genus Porites, including the species affected by GAs, are major reef-builders and are considered hardy and long-lived ( $>200$ years). Porites was found to comprise $30 \%$ of hard coral colonies on many reefs in the Philippines (Raymundo et al., 2005) and up to $65 \%$ on some central Philippine reefs (Calumpong et al., 1997). Starting in 2002, an extensive quantitative coral disease survey of 27 reef sites in the central Philippines (Kaczmarsky, 2006) revealed a high prevalence of disease among populations of massive Porites but very few coral colonies in other genera exhibited signs of disease. The fact that species in this dominant genus appear to be targeted by lethal growth anomalies and UWS in the Philippines makes an urgent case for further investigation into the causes of these epizootics.

While growth anomalies were observed to only affect massive Porites, UWS affected both massive and branching Porites as well as several other genera (Kaczmarsky, 2004, 2006). Ulcerative white spot disease was recorded for the first time in 1996 on transplanted fragments of branching Porites in Bais Bay, SE Negros Island. Bais Bay heavily impacted by fish farms and agriculture (Raymundo et al., 2003). The UWS was originally termed "Porites" ulcerative white spot (PUWS) because it was first observed only on Porites (Raymundo et al., 2003), but since then it has been observed on many other taxa (Kaczmarsky, 2006). The disease UWS is characterized by discrete, round foci, 3 to $5 \mathrm{~mm}$ in diameter, of denuded skeleton. Multiple UWS lesions can coalesce, leading to colony mortality (Raymundo et al., 2003). 
In contrast to UWS, growth anomalies are patchy pale protuberances and/or swollen tissues of various sizes. Two distinct growth anomaly morphologies were observed affecting massive Porites; For purposes of the GA prevalence assessment these growth morphologies were combined. However, for histological and ultrastructural assessments they were treated separately. The first morphological type ("type 1") forms skeletal protuberances, is rounded, and tends to have a well-delineated margin. The other type ("type 2") tends to have diffuse margins, does not usually form skeletal protuberances (although the tissue has a swollen appearance), is usually paler than type 1, and frequently has sloughing tissues. During an initial characterization of the GAs (using microscopically confirmed $P$. lutea and $P$. lobata specimens), a laboratory disease transmission experiment resulted in transmission of the disease between colonies and thus indicated the possible involvement of a pathogen (Kaczmarsky and Richardson, 2007). The experiment produced the first evidence for transmission of coral growth anomalies.

To date, no studies have successfully established the involvement of an infectious agent associated with either coral growth anomalies (Breitbart et al., 2005) or UWS. Earlier published studies did not detect correlations between coral growth anomalies and environmental factors and did not demonstrate transmission between colonies (Peters et al., 1986; Gateño et al., 2003; Breitbart et al., 2005). However, a positive correlation with anthropogenic impact was described by Kaczmarsky $(2004,2006)$ and transmission between colonies has been demonstrated (Kaczmarsky and Richardson, 2007). In addition, Kaczmarsky (2006) detected positive associations between warmer sea temperatures and prevalence of both GAs and UWS. Although not quantitative in terms 
of correlations with human impact, a study by Raymundo et al. (2003), which first described UWS, described the sites that had least impact (marine preserves) as having the lowest prevalence of UWS while the most impacted sites (near aquacultural and agricultural run-off) had the highest levels of UWS. In addition, they presented evidence that the disease might be contagious and that it was more prevalent in warm summer months. Most recently, McClanahan et al. (2009) documented a link between an outbreak of GAs that affected massive Porites off the coast of Kenya and a bleaching event that preceded it.

Global databases report coral growth anomalies on a worldwide basis (Bruckner, 2002). Veron (2000) described "neoplasms" (or coral growth anomalies) in most coral species and considered them common. However, "neoplasm" is an inappropriately used term unless there have been histological examinations to support its use. In addition, the widely used term "tumor" should also be interpreted cautiously because it has been used to describe a wide array of anomalies; for example, a "tumor" could be a gall containing a parasite. Recently, coral growth anomalies have been observed to occur at high prevalence among dominant reef species on reefs of Australia, Hawaii, Japan, W. Costa Rica, and E. Africa (Uwins et al., 1996; Hunter, 1999; Yamashiro et al., 2000; Gateño et al., 2003; McClanahan et al., 2009, respectively). However, observations in those studies indicated the epizootics were much less widespread than the coral disease now seen in the Philippines (Kaczmarsky, 2004 and 2006). The other epizootics of coral growth anomalies affected Platygyra spp. (Loya et al., 1984) and Acropora spp. (Uwins et al., 1996) in Australia, Porites lobata in Hawaii (Hunter 1999), Montipora in Japan (Yamashiro et al., 2000), Pavona in Costa Rica (Gateño et al., 2003), and massive Porites 
(mostly P. lutea) in Kenya (McClanahan et al. 2009). Prevalence values reported in these studies ranged from 15 to $55 \%$. The presence of GAs has been reported to cause partial to whole colony mortality on massive Porites (Hunter, 1999; Kaczmarsky, 2006) and other species (Peters et al., 1986; Yamashiro et al., 2000; Work et al., 2008).

The two types of new GAs discovered in the Philippines are now referred to as MPGAs (massive Porites growth anomalies) to distinguish them from GAs with different morphologies that affect species in other coral genera. Because gross morphologies of coral GAs associated with epizootics of GAs are quite varied, it is possible that they have different etiologies.

While coral GAs, often referred to as "tumors", have been widely observed (Sutherland et al., 2004), almost nothing is known about their etiologies (Kaczmarsky, 2006). Literally, a tumor is a swelling of any type, such as an inflammation, but modern usage generally denotes a neoplasm or cancer (Bast et al., 2000). The word "tumor" is Latin for swelling. Various types of swelling can be mistakenly identified as neoplasms. According to Sparks (1993), tumors and neoplasia are often considered synonymous terms. A neoplasm is an abnormal mass, or colony, of cells produced by relatively autonomous new growth of tissue. Some non-neoplastic cellular proliferations, such as hyperplasia, metaplasia, and dysplasia, must be distinguished through histopathological examinations from neoplasia. Hyperplasia is an absolute increase in the number of cells per unit of tissue. It is generally initiated and regulated by definable (such as hormonal) stimuli, and may be useful to the host (e.g., physiologic and adaptive hyperplasia). Metaplasia denotes a change of one type of adult cell to another, and is usually an adaptive response to an inflammatory or other abnormal stimulus. Metaplasia is often 
reversible. Dysplasia is an abnormal, atypical cellular proliferation (atypical hyperplasia) and is usually reversible. While dysplasia is not neoplasia, it may possibly be a precursor to neoplasm development (www.edcenter.med.cornell.edu.html). Furthermore, dysplasia is the replacement of a normal type of adult tissue (usually epithelium) with non-normal cells, which are not proliferative or invasive.

Most neoplasms arise from the clonal expansion of a single cell that has undergone neoplastic transformation. The transformation of a normal to a neoplastic cell can be caused by a chemical, physical, or biological agent (or event) that directly and irreversibly alters the cell genome. Neoplastic cells are characterized by the loss of some specialized functions and the acquisition of new biological properties, foremost, the property of relatively autonomous (uncontrolled) population growth (cell division). Neoplastic cells pass on these heritable biological characteristics to daughter cells following mitotic divisions. The ability to distinguish these types of cellular changes is a challenge, with the confounding aspects of well differentiated vs. poorly-differentiated neoplasms, hyperplasia vs. anaplasia, reversible vs. irreversible anomalies, and the problem of making a diagnosis from a "snapshot" sample of tissue (Dr. E. Peters, pers. comm.).

Although abnormal growths have been reported in a number of corals (Peters, 1984b; Peters et al., 1986), a clear malignant state has yet to be determined for any coral tumor (Smith, 1999). In an earlier study, Peters et al. (1986) characterized growth anomalies that affected Acropora palmata in Florida as neoplasms. Coles and Seapy (1998) also described coral "neoplasms" in A. valenciennesi and A. valida in the Gulf of Oman. In both of these reports, the coral growth anomalies were considered the result of 
a proliferation of calicoblasts in the calicodermis, based on histopathological examinations and comparison with samples archived at the Registry of Tumors in Lower Animals in Sterling, VA. In 2000, Yamashiro et al. described coral growth anomalies as abnormal proliferations of tissue, usually associated with abnormal skeletal growth. More recently, the Coral Disease and Health Consortium (a working group organized under the auspices of the U.S. Coral Reef Task Force) agreed to refer to coral "tumors" as a type of "skeletal" or "growth" anomaly (Sutherland et al., 2004).

In a review of coral skeletal anomalies by Sutherland et al. (2004), their general histologic features, based on acroporid anomalies, included: (1) thinning of coral tissue over affected areas; (2) increased skeleton porosity; (3) loss of mucocytes and nematocysts; (4) loss of zooxanthellae; (5) loss, reduction or degeneration of normal polyp structures; and (6) fewer reproductive structures. In 1986, Peters et al. considered the neoplastic changes they observed as a serious threat to corals by "potentially reducing fecundity, growth and their primary defense mechanism, mucus production." Additional studies had suggested or observed that the formation of "tumors" on corals imposed energy burdens that can negatively affect part of or the entire colony (Cheney, 1975; Bak, 1983; Yamashiro et al., 2001; Breitbart et al., 2005), including growth. In GAs of branching Porites in Hawaii, Domart-Coulon et al. (2006) recently detected elevations in levels of protein markers, which had a pattern similar to that observed in association with hyperplasia in other organisms.

Published histological tissue accounts of coral growth anomalies are limited (Cheney, 1975; Bak, 1983; Peters et al., 1986; Coles and Seapy, 1998; Gateño et al., 2003; Work and Rameyer, 2005). Sutherland et al. (2004) characterized skeletal 
anomalies of scleractinian corals by changes in morphological features in comparison to surrounding skeleton and tissue. Gateño et al. (2003) felt the terms "skeletal tumor" or "calicoblastic epithelioma" best described their observations of coral tumors and those of others. The growth anomalies of the pavonids as described by Gateño et al., however, are morphologically quite different than acroporid growth anomalies (pers. obs.).

The application of the term "epithelioma" (which is a neoplasm) by Gateño et al. (2003) may be a case of using a term without foundation, as it is debatable whether the GAs they observed were indeed neoplasms. Their use of the term however, was carefully considered in consultation with Dr. Clyde Dawe of Harvard, an internationally recognized authority on comparative pathology, who also noted it best to be conservative since it was not shown whether metastasis might occur or whether the lesions were malignant (causing death) (Dr. Esther Peters, pers. comm.).

Much of what is known histologically of tumors comes from research on human tumors. Routine staining techniques, such as hematoxylin and eosin (H\&E) and the use of special stains for cytoplasmic and secretory products, have been used in the histopathologic evaluation of coral tumors by light microscopy (Peters et al., 1986; Hunter, 1999; this study). Special stains reveal measurable biochemical and cellular changes (biomarkers) caused by contaminants or pathogens, and help identify causal mechanisms underlying observed effects at the population or community levels. Some biochemical markers are molecules that indicate the structural or functional integrity of enzyme pathways or that are induced during exposure to stressors. Possible biomarkers 
(indicative of tumors in other organisms) include acid mucopolysaccharides, which were used in the present study to examine coral disease.

In general, histochemistry, immunohistochemistry, and electron microscopy can be helpful or necessary supplements for diagnosis of tumors. Details of the type and origin of the tumor, its differentiation, and level of invasion, its architecture, and frequency of mitosis may all be relevant in the pathologic assessment of neoplasia (Bast et al., 2000). The present study made use of the characterizations of human tumors as a starting point from which to understand the nature of coral tumors. Because neoplasms are often not grossly visible, for example in the disseminated neoplasm (leukemias) or germinomas of bivalves (Barber, 2004), histological tissue sections are often used to first investigate most suspected neoplasms of invertebrates (Sparks, 1993). Most crustacean and worm neoplasms are also not visible at a gross level of examination (Dr. E. Peters, pers. comm.).

A thorough knowledge of the normal histology of an animal is necessary before one can determine abnormal changes in cellular architecture (Sparks, 1993). Much histological work has been done to define normal coral cell types and describe normal coral tissue (Muscatine and Lenhoff, 1974; Bigger and Hildemann, 1982; Hundgen, 1984; Peters, 1984a; Fautin and Mariscal, 1991; Peters and Yevich, 2001). However, many cellular mechanisms are still unknown, such as understanding how scleractinian corals acquire $\mathrm{Ca}^{++}$and $\mathrm{HCO}_{3}$, and precipitate them together as calcium carbonate. Overall, in cnidarians, epithelial tissues predominate. Anatomically, the tissues of Cnidaria (the phylum to which corals belong) are relatively simple. However, some individual cells may be complex (e.g., cnidocytes) and some tissues appear to have 
complex functions. For example, the eyes of cubozoans (a distant relative of coral) and the calicodermis of stony corals have complex functions. The cells of the calicodermis of coral are indeed specialized in that they play a role in skeletogenesis (Purverel et al., 2005).

For the present study, a number of general applied histology texts were consulted to assess coral MPGAs (Pearse, 1968; Kaiser, 1981; Hundgen, 1984; Kiernan, 1990; Galloway et al., 2006). These were supplemented with the results of histological studies of diseased and stressed corals, which, although limited, were informative for the interpretation of observed alterations associated with MPGAs. For example, VargasAngel et al. (2007) recently described histological responses of coral to sediment and heat stress, which may generate general stress responses. A number of the observed responses in the studies they discussed were similar to that seen in MPGAs, including an accumulation of amoebocytes associated with injuries. Likewise, in a study on growth anomalies in Hawaiian branching Porites, Domart-Coulon et al. (2006) observed clustering of chromophore cells (a granular amoebocyte unique to Porites) in the calicodermis of GA lesions. Similar observations to that seen in the present study were also made by Palmer et al. (2008) in their study of non-normally pigmented massive Porites. Palmer et al. demonstrated the presence of the phenoloxidase (PO) activating melanin pathway in healthy massive Porites from Australia. These investigators concluded that melanin was present in the chromophore cells of Porites, and that an increase in melanin production in pigmented Porites tissues suggested the presence of a generalized defense response to local stress. Melanin is known to have cytotoxic and antibacterial properties (Burkhart and Burkhart, 2005; Nappi and Christensen, 2005). 
Chapter two describes a field study that is the first to quantitatively examine correlations between the prevalence of the diseases MPGAs and UWS and environmental factors. The parameters measured included of colony density, and organic carbon, nitrogen, and phosphorous concentrations in both the water column and surface sediments. These assessments were made using an environmental gradient approach, which is a spatially strong environmental method used in many other communities but underrepresented in studies of coral populations. Principal component analysis was used to determine which orthogonal parameters most strongly correlated the study sites.

Chapter three examines histopathological alterations associated with MPGAs using light microscopy, standard histological stains, and a variety of special stains. It is the most comprehensive quantitative histological assessment of coral growth anomalies to date and includes quantitative assessments of numerous histological features as well as qualitative assessments. Quantitative studies included comparisons of zooxanthellae densities, chromophore cell densities, width of basal gastrovascular canals, thickness of coral tissues, the surface epidermal layer, the basal body wall, and the basal skeleton. Different physiological processes are carried out during the day than at night and, with histological techniques, these processes can be detected and important in the understanding of the pathology of disease (Dr. E. Peters, pers. comm.). Thus, samples from the same colony were collected and fixed for histopathological analyses both at 12 $\mathrm{pm}$ and $12 \mathrm{am}$. In addition, an analysis of the correlation between zooxanthellae density and chromophore cell density was conducted.

Chapter four presents the results of using transmission electron microscopy (TEM) to assess cytological alterations associated with MPGAs at an ultrastructure level. 
Since two distinct types of MPGAs were observed affecting corals, both were compared to healthy coral and to each other. I was the first to use TEM to quantitatively examine cytological alterations associated with coral growth anomalies. As part of the study's goals, it was also the first to search for viruses associated with MPGAs. Assignment of cellular alterations associated with types 1 and 2 MPGAs was made based on comparison of samples of MPGA lesions to tissue samples from colonies with no lesions (i.e., healthy colonies). To this end, cell types from MPGAs with measurable characteristics were compared to cells from healthy coral. For example, the contents of chromophore cell granules and status of mucocytes were examined in detail. Characterization of MPGAs included the health status of zooxanthellae populations and the quantity of their storage vesicles (starch) and membrane break-down product (lipids). These characteristics were statistically tested for significant differences. The implications of significant differences are discussed in this chapter.

The environmental field study was carried out along a known disease prevalence gradient (Kaczmarsky, 2006) off the southeast coast of Negros Island in the central Philippines. Water and sediment samples were analyzed at Florida International University (FIU). Samples for examination by light and electron microscopy were collected from the fringing reef system offshore of the Silliman University Marine Laboratory (SUML) and processed at SUML. Staining and light microscopy were conducted at FIU and electron microscopy at the University of Miami Center for Advanced Microscopy.

In summary, the purpose of this study was to shed light on which environmental variables (including those influenced by human activity) and histopathological 
mechanisms are driving the disease process in the two most common coral diseases of the Philippines, MPGAs and UWS, in order to better understand and manage these diseases. 


\section{REFERENCES}

Antonius, A. 1985. Coral diseases in the Indo-Pacific: a first record. PSZN I: Mar. Ecol. 6, 197-218.

Bak, R.P.M. 1983. Neoplasia, regeneration and growth in the reef-building coral Acropora palmata. Mar Biol 77, 221-227.

Barber, B.J. 2004. Neoplastic diseases of commercially important marine bivalves. Aquat. Living Resour. 17, 449-466.

Bast, R.C., Kufe, D.W., Pollock, R.E., Weichselbaum, R.R., Holland, J.F., Frei, E., 2000. Cancer Medicine 5th edn. Williams and Wilkins, Baltimore.

Bigger, C.H., Hildemann, W.H., 1982. Cellular defense systems of the coelenterata. In: Cohen and Sigel, (Eds.), The Reticuloendothelial System: A Comprehensive Treatise Volume 3: Phylogeny and Ontogeny. pp. 59-87.

Breitbart, M., Bhagooli, R., Griffin, S., Johnston, I., Rohwer, F., 2005. Microbial communities associated with skeletal tumors on Porites compressa. FEMS Microbiology Letters 243, 431-436.

Bruckner, A.W., 2002. Priorities for EVective Management of Coral Diseases. NOAA Tech. Memo NMFS-OPR-22. Washington, DC.

Burkhart, C.G, Burkhart, C.N., 2005. The mole theory: primary function of melanocytes and melanin may be antimicrobial defense and immunomodulation (not solar protection). International journal of dermatology 44, 340-342.

Calumpong, H.P., Estacion, J.S., Lepiten, M.V., Acedo, C.E., 1997. Status of the Coastal Resources of the Negros Learning Site (Manjuyod to Dauin). Silliman University Marine Laboratory, Dumaguete City, Philippines COE-CRM Document No. 1/97, $196 \mathrm{pp}$.

Carpenter, K.E., Springer, V.G., 2005. The center of marine shore fish biodiversity: the Philippine Islands. Environ. Biol. Fish 72, 467-480.

Chapman, G., 1974. The skeletal system in Muscatine L., Lenhoff H.M. (Eds.), Coelenterate Biology: Reviews and New Perspectives. Academic Press, New York.

Cheney, D.P. 1975. Hard tissue tumors in scleractinian corals. Adv. Exp. Med. Biol. 64, 77-87. 
Coles, S.L., Seapy, D.G., 1998. Ultra-violet absorbing compounds and tumorous growths on acroporid corals from Bandar Khayran, Gulf of Oman, Indian Ocean. Coral Reefs 7, 195-198.

Domart-Coulon I.J., Traylor-Knowles, N., Peters, E., Elbert, D., Downs, C.A., Price, K., Stubbs, J., McLaughlin, S., Cox, E., Aeby, G., Brown, P.R., Ostrander, G.K., 2006. Comprehensive characterization of skeletal tissue growth anomalies of the finger coral Porites compressa. Coral Reefs 25, 531-543.

Fautin, D.G., Mariscal, R.N., 1991. Cnidaria: Anthozoa. In: Harrison, F.W., Westfall, J.A. (Eds.), Microscopic Anatomy of Invertebrates, Vol. 2. Placozoa, Porifera, Cnidaria, and Ctenophora. Wiley, N.Y.

Galloway, S.B., Work, T.M., Bochsler, V.S., Harley, R.A., Kramarsky-Winters, E., McLaughlin. S,M., Meteyer, C.U., Morado, J.F., Nicholson, J.H., Parnell, P.G., Peters, E.C., Reynolds, T.L., Rotstein, D.S., Sileo, L., Woodley, C.M., 2007.

Coral Disease and Health Workshop: Coral Histopathology II. NOAA Technical Memorandum NOS NCCOS 56 and NOAA Technical Memorandum CRCP 4. National Oceanic and Atmospheric Administration, Silver Spring, MD.

Gateño, D., Leon, A., Barki, Y., Cortes, J., Rinkevich, B. 2003. Skeletal tumor formations in the massive coral Pavona clavus. Mar. Ecol. Prog. Ser. 258, 97-108.

Harvell, C.D., Kim, K., Burkholder, J.M., Colwell, R.R., Epstein, P.R., Grimes, D.J., Hofmann, E.E., Lipp, E.K., Osterhaus, A.D.M.E., Overstreet, R.M., Porter, J.W., Smith, G.W., Vasta, G.R., 1999. Emerging marine diseases-climate links and anthropogenic factors. Science 285, 1505-1510.

Hughes, T.P., Baird, A.H., Bellwood, D.R., Card, M., Connolly, S.R., Folke, C., Grosberg, R., Hoegh-Guldberg, O., Jackson, J.B.C., Kleypas, J., Lough, J., Marshall, P., Nystrom, M., Palumbi, S.R., Pandolfi, J.M., Rosen, B., Roughgarden, J., 2003. Climate change, human impacts, and the resilience of coral reefs. Science 301, 929-933.

Hundgen, M. 1984. Cnidaria: Cell Types In: Bereiter-Hahn J, Matoltsy AG, Richards KS (Eds.), Biology of the Integument Vol. I. Springer-Verlag, New York.

Hunter, C.L., 1999. First records of coral disease and tumors on Hawaiian reefs. In: Maragos, J.E., Grober-Dunsmore, R. (Eds.), Proc. Hawaii Coral Reef Mon. Workshop, June 9-11, 1998, Hawaii. East-West Center, Honolulu, pp. 73-97.

Kaczmarsky, L., 2004. Dynamics of Coral Diseases and Syndromes in the Central Philippines: Prevalence, Distribution, Progression Rates, Host Ranges, Anthropogenic Links, and Experimental Evidence of Pathogen Involvement in 
Coral Neoplasia. Proc. 10th Int. Coral Reef Symp., Abstract volume, Oral 1-4-B, 170.

Kaczmarsky, L., 2006. Coral disease dynamics in the Central Philippines. Dis. Aquat. Org. 69, 9-21.

Kaczmarsky, L., Richardson, L.L., 2007. Transmission of growth anomalies between Indo-Pacific Porites corals. J. Invertebr. Pathol. 94, 218-221.

Kaiser, H. (Ed.) 1981. Neoplasms - Comparative Pathology of Growth in Animals, Plants and Man. Williams and Wilkins, Baltimore.

Kiernan, J.A. 1990. Histological \& Histochemical Methods Theory \& Practice, $2^{\text {nd }}$ edn Pergamon Press, New York. 502 pp

Loya, Y., Bull, G., Pichon, M., 1984. Tumor formation in scleractinian corals. Helgol. Meeresunters. 37, 99-112.

McClanahan, T.R., Weil, E., Maina, J., 2009. Strong relationship between coral bleaching and growth anomalies in massive Porites. Global Change Biology [doi: 10.1111/j.1365-2486.2008.01799.x]

Nappi, A. J., Christensen, B.M., 2005. Melanogenesis and associated cytotoxic reactions: applications to insect innate immunity. Insect Biochem. Mol. Biol. 35, 443-459.

Palmer, C.V., Mydlarz, L.D., Willis, B.L., 2008. Evidence of an inflammatory-like response in non-normally pigmented tissues of two scleractinian corals. Proc. R. Soc. B 275, 2687-2693.

Pandolfi, J.M., Bradbury, R.H., Sala, E., Hughes, T.P., Bjorndal, K.A., Cooke, R.G., McArdle, D., McClenachan, L., Newman, M.J.H., Paredes, G., Warner, R.R., Jackson, J.B.C., 2003. Global trajectories of the long-term decline of coral reef ecosystems. Science 301, 955-958.

Pearse, A.G.E. 1968. Histochemistry, Theoretical and Applied. $3^{\text {rd }}$ ed. Little, Brown, and Co, Boston. 759 pp

Peters, E.C. 1984a. A survey of the normal and pathological histology of scleractinian corals with an emphasis on the effects of sedimentation stress, chap 1. Doctoral Dissertation, Graduate School of Oceanography, University of Rhode Island, Kingston, RI, pp 1-145

Peters, E.C., 1984b. A survey of cellular reactions to environmental stress and disease in Caribbean scleractinian corals. Helgol. Meersunters 37, 113-137. 
Peters, E.C., Halas, J.C., McCarty, H.B., 1986. Calicoblastic neoplasms in Acropora palmata, with a review of reports on anomalies of growth and form in corals. $\mathrm{J}$. Natl. Cancer Inst. 76, 895-912.

Peters, E.C., Yevich, P.P., 2001. Comparative histology of selected tropical and temperate Atlantic scleractinian corals, an Atlas. In: Coral tissue slide reading workshop. Tropical Research Laboratory, Mote Marine Laboratory. Summerland Key, Florida 137 pp.

Raymundo, L.J., Harvell, C.D., Reynolds, T.L., 2003. Porites ulcerative white spot disease: description, prevalence, and host range of a new coral disease affecting Indo-Pacific reefs. Dis. Aquat. Org. 56, 95-104.

Raymundo, L.J., Reboton, C.T., Rosell, K.B., Kaczmarsky, L., 2005. Coral diseases on Philippine reefs: genus Porites is a dominant host. Dis. Aquat. Org. 64, 181-191.

Rosenberg, E., Loya, Y., (Eds.), 2004. Coral health and disease. Springer-Verlag, Berlin.

Smith, A.C. 1999. Comparative Pathology: Human disease counterparts in marine animals. Arch. Path. Lab. Med. 124, 348-352.

Sparks, A.K. 1993. Invertebrate diseases-an overview In: Couch, J.A., Fournie, J.W. (Eds.), Pathobiology of Marine and Estuarine Organisms. CRC Press, Boca Raton, Florida.

Sutherland, K.P., Porter, J.W., Torres, C., 2004. Disease and immunity in Caribbean and Indo-Pacific zooxanthellate corals. Mar. Ecol. Prog. Ser. 266, 273-302.

Uwins, P.J.R., Jones, M.K., Webb, R.I., Yago, A.E., Miller, G.L., Grinan, R., Bell, P.R.F., 1996. Determination of the origin and pathology of coral tumors. The Marine Environment Conference, University of Queensland (abstract). p. 123.

Vargas-Ángel, B., Peters, E.C., Kramarsky-Winter, E., Gilliam, D.S., Dodge, R.E., 2007. Cellular reactions to sedimentation and temperature stress in the Caribbean coral Montastraea cavernosa. J. Invertebr. Pathol. 95, 140-145.

Veron, J.E.N. 1995. Corals in space and time. Cornell University Press, Ithaca, NY 321 $\mathrm{pp}$

Veron, J.E.N., 2000. Corals of the World. AIMS, Townsville, Australia.

Yamashiro, H., Yamamoto, M., van Woesik, R., 2000. Tumor formation on the coral Montipora informis. Dis. Aquat. Org. 41, 211-217. 
Yamashiro, H., Hirosuke, O., Onaga, K., Iwasaki, H., Takara, K., 2001. Coral tumors store reduced levels of lipids. J. Exp. Mar. Biol. Ecol. 265, 171-179.

Wilkinson, C.R., 2004. Status of coral reefs of the world 2004. Australian Institute of Marine Science, Townsville, Australia.

Work, T.M., Rameyer, R.A., 2005. Characterizing lesions in corals from American Samoa. Coral Reefs 24, 384-390.

Work, T.M., Aeby, G.S., Coles, S.L., 2008. Distribution and morphology of growth anomalies in Acropora from the Indo-Pacific. Dis. Aquat. Org. 78, 255-264. 
CHAPTER 2

CORRELATION OF CORAL DISEASE PREVALENCE ON REEFS OF THE PHILIPPINES WITH HIGH COLONY DENSITY AND ELEVATED NUTRIENTS AND ORGANIC CARBON 


\section{INTRODUCTION}

Coral diseases have negatively affected populations of dominant reef-building corals of the wider Caribbean over the last few decades (Green and Bruckner, 2000; Aronson and Precht, 2001; Sutherland, 2004) and much research has been directed towards this issue. One cause of recent coral decline, in the Caribbean as well as worldwide, has been disease, and disease prevalence is now considered an important indicator of coral community health (Harvell et al., 1999).

Philippine coral reefs are considered to be some of the most negatively affected in the world, with $98 \%$ at medium to high risk of degradation from anthropogenic activities that include eutrophication (Burke et al., 2002). By 1994, 75\% of Philippine reefs were considered to be in "fair" or "poor" condition, largely as a result of human activities (Gomez et al., 1994). According to the Coastal Resource Management Project (1999), the incidence of pollution-related problems in the Philippines increased dramatically over the previous 20 years. Top sources of pollution near coastal cities are fertilizer, pesticides, and sediments from poor agricultural practices, erosion, and aquaculture, as well as untreated domestic sewage.

Human disturbances that reduce environmental quality have been qualitatively linked to an increase in coral disease incidence or severity (Taylor, 1983; Antonius, 1988; Peters, 1993; Bruckner et al., 1997; Goreau et al., 1998; Kim and Harvell, 2002). Green and Bruckner (2000) determined that 97\% of Caribbean areas affected by coral diseases corresponded to areas where human activities have medium to high impacts. Elevated levels of nutrients (Bruno et al., 2003; Voss and Richardson, 2006), organic matter (Kline et al., 2006; Baker et al., 2007), sewage effluent (Walker and Ormond, 1982; 
Kaczmarsky et al., 2005; Sekar et al., 2008), terrestrial run-off (Klaus et al., 2005; Guppy and Bythell, 2006), as well as high coral density (Bruno et al., 2007) are some of the factors that have been implicated in an increase in coral disease incidence and severity. Sewage and high nutrient levels in particular are thought to play important roles in increasing the incidence and severity of disease (Kuta and Richardson, 2002; Bruno et al., 2003; Kaczmarsky et al., 2005; Kuntz et al., 2005; Voss and Richardson, 2006).

In the area of the present study, southeast Negros Island, Philippines, all sewage is untreated and widely discharged at the shoreline. A well-developed fringing coral reef that forms along much of the coast is typically only a few meters from sewage discharge points. Dozens of sewage drain-pipes, each located at the end of most city streets and fronting the reefs, simply pour raw sewage onto the beach at low tide (or into the reef waters at high tide). These are simple, gravity fed pipes that collect sewage from open trenches that line the city streets into which waste from residential structures collects. Flushing of the open trenches depends upon rainfall.

The first coral epizootics in the Philippines were reported off the southeast coast of Negros Island in 1996 and 2002 (Raymundo et al., 2003; Kaczmarsky, 2006). They involved the two most common (and recently discovered) lethal diseases of Philippine corals, ulcerative white spot disease (UWS) and massive Porites growth anomalies (MPGA) (Raymundo et al., 2005; Kaczmarsky, 2006). The disease UWS affects both massive and branching species of Porites and MPGAs affect only massive Porites species. Despite these reports of disease outbreaks, comparatively little effort has been made to gain understanding about the Philippine coral diseases. 
Ulcerative White Spot disease, affecting massive and branching species, was observed for the first time in 1996 on transplanted fragments in Bais Bay, SE Negros Island, an area heavily impacted by fish farms and agriculture (Raymundo et al., 2003). The disease UWS was originally termed "Porites" ulcerative white spot (PUWS) because it was first observed only on Porites (Raymundo et al., 2003), but since then it has been observed to affect many other taxa (Kaczmarsky, 2006). UWS is characterized by discrete, bleached, round foci, 3 to $5 \mathrm{~mm}$ in diameter, that commonly result in ulcerations that coalesce and cause tissue loss and colony mortality (Raymundo et al., 2003).

Massive Porites Growth Anomalies in the Philippines were observed for the first time in 2002 (Kaczmarsky, 2006) near Dumaguete City, SE Negros Island. The MPGAs were observed to specifically affect colonies of different species of massive Porites, including Porites lutea, a species that is the dominant shallow-water reef-building species on these reefs. It should be noted that "massive" is a specific coral term used to describe a coral's shape, not its size (e.g., "branching", "laminar", "encrusting", etc; Veron, 2000). In 2003, both diseases (UWS and MPGAs) were widespread and highly prevalent, with visual estimates suggesting that tens of thousands of colonies were affected (Kaczmarsky, 2006).

The MPGAs were previously termed "coral tumors" (Kaczmarsky, 2006) but, based on the lack of evidence of uncontrolled cellular proliferation, are best referred to as growth anomalies (Dr. E. Peters, pers. comm.). The MPGAs are pale areas of deformed tissue and skeleton with an inconsistent morphology ranging from round, raised areas of enlarged corallites with distinct demarcation lines between unaffected and diseased tissue 
to very irregularly shaped depressed areas of white and pink tissue and no distinct lines of separation.

Field work targeting UWS and MPGAs revealed that the prevalence of both diseases is positively correlated with human population density (Kaczmarsky, 2006). Experimental evidence showed that both UWS (Raymundo et al., 2003) and MPGAs (Kaczmarsky and Richardson, 2007) were transmissible between colonies, suggesting pathogen involvement. Prior to surveys conducted from 2002 to 2003 (Kaczmarsky, 2006) no studies detected correlations between the two diseases and environmental factors (Gateño et al., 2003; Breitbart et al., 2005; Raymundo et al., 2005).

Although degraded water quality is often suggested as contributing to coral diseases, to date very few studies have quantitatively demonstrated positive correlations between coral disease and elevated water column nutrient levels (Kim and Harvell, 2002; Kuta and Richardson, 2002; Bruno et al., 2003; Voss and Richardson, 2006; Baker et al., 2007). In response to experimental nutrient additions, increased rates of tissue loss due to two coral diseases (yellow band and black band diseases) has been reported (Bruno et al., 2003; Voss and Richardson, 2006). Kaczmarsky et al. (2005) showed a significant positive correlation between the prevalence of black band disease and white plague type II with sewage effluent by comparing an impacted site near a sewage outfall with a nearby, ecologically similar control site. These studies have primarily been conducted on reefs of the wider Caribbean.

The present study is the first report of direct measurements of nutrients and organic carbon in association with coral disease prevalence on reefs of the Philippines. Water and sediment samples were collected to determine if there were correlations 
between disease prevalence and nutrient concentrations, organic carbon levels, and colony density.

\section{MATERIAL AND METHODS}

\section{Study area}

Field sites (Figure 1) were centered around Dumaguete City with samples collected from 15 sites along a $40.5 \mathrm{~km}$-long gradient of coastline to each side of the city. Important landscape features along the gradient (designated in Figure 1) are: (1) the city's airport runway jetty that extends seaward $\sim 100 \mathrm{~m}$ and obstructs the predominantly southbound water flow; (2) the city's commercial pier that also extends seaward $\sim 100 \mathrm{~m}$ and obstructs flow; (3) large tidal flats that occur in the Looc and Calongcalong sites; and (4) two distinct bodies of water that meet and form a front at Dumaguete City (i.e., the large Bohol Sea to the south and the more constrained Tañon Straight to the north).

Analyses of coral disease prevalence data collected in a previous study in 2003 (Kaczmarsky, 2006) revealed a positive correlation between coral disease frequency (for both MPGA and UWS) and proximity to Dumaguete City. That relationship prompted the present follow-up investigation of water and sediment quality. In the previous study, 15 reef sites were examined (from March to April 2003) along a 40.5-km environmental gradient of decreasing human population density approximated by distance from a human population center, Dumaguete City, SE Negros Island (Fig. 1; Kaczmarsky, 2006). Prevalence of MPGA and UWS was determined for each site along the gradient. Sites along the gradient were in a line paralleling the coastline north and south of and centered on the Dumaguete City pier $\left(9^{\circ} 18.918^{\prime} \mathrm{N}\right.$ and $\left.123^{\circ} 18.705^{\prime} \mathrm{E}\right)$. The present study was 


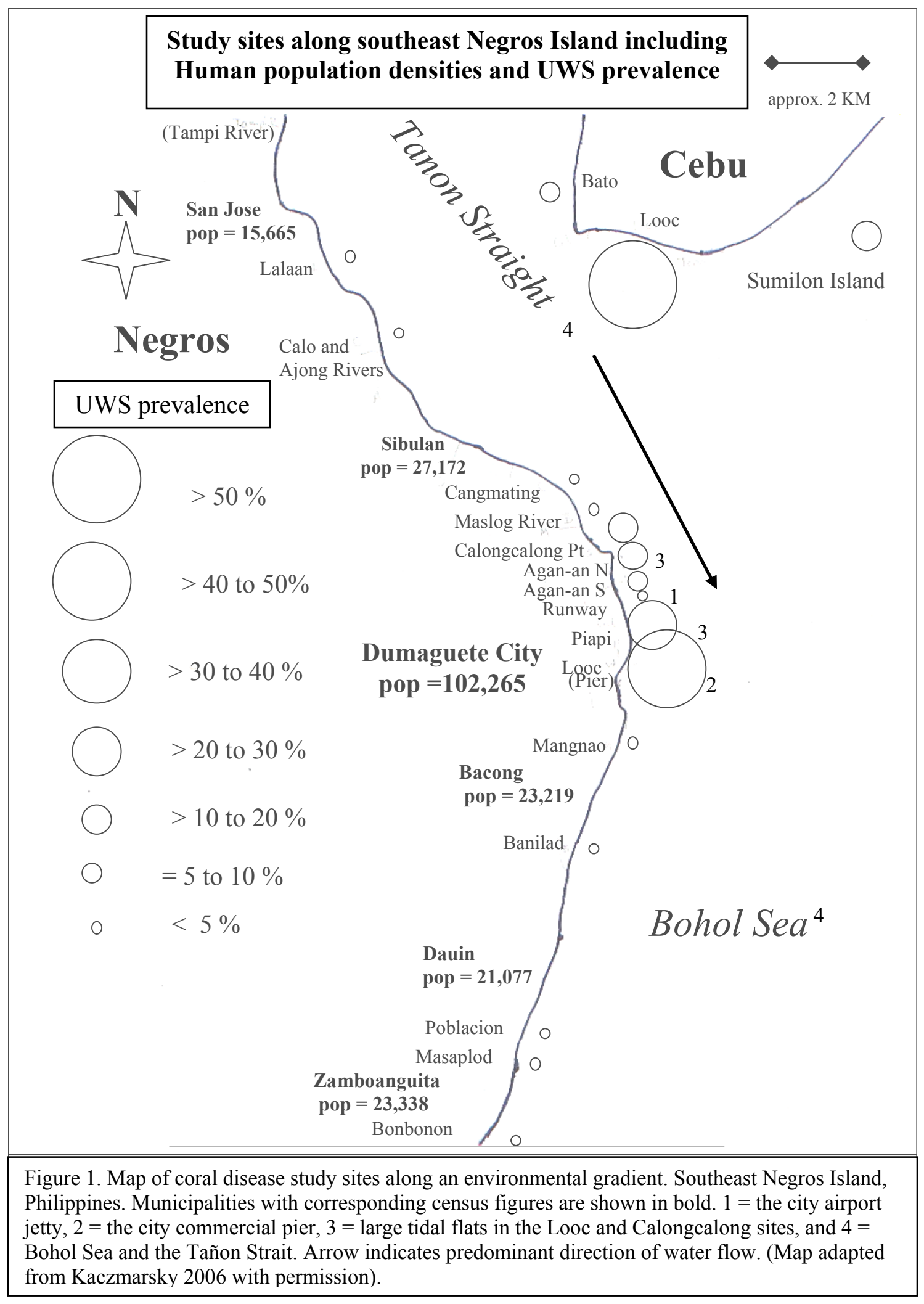


conducted at the same sites in 2005. Interviews with local residents, including local University scientists, in 2005 indicated no changes had occurred in sewage disposal practices or agricultural practices since the 2003 surveys.

\section{Sample Collection}

Unfiltered water samples at each site along the gradient were collected, in duplicate, in $120 \mathrm{ml} \mathrm{HDPE}$ collection bottles that contained $1.5 \mathrm{ml}$ of fixative $\left(50 \% \mathrm{H}_{2} \mathrm{SO}_{4}\right.$, final concentration $0.2 \%$ ), for analysis of nutrients. The measured nutrient concentrations represent the total of dissolved nutrients plus particulate nutrients that were dissolved by the acid preservative (Dr. J. Boyer pers. comm.). Care was taken to collect water samples from areas with no sediment resuspension. Acid-fixed samples were stored refrigerated in sealed containers until analyses.

Sediment samples from the top $2 \mathrm{~cm}$ of reef substratum (which would be most readily resuspended and deposited onto nearby corals) were collected from several locations in each study site in acid-washed, seawater-rinsed bottles. Samples were brought to the lab within $2 \mathrm{~h}$ of collection and oven-dried at $100^{\circ} \mathrm{C}$ until a constant weight (approximately 8 hours) in a gravity-convection drying oven. After drying, the sediment was stored in a desiccator until analysis.

All samples were collected on the same day within 2 hours of low tide when tidal currents were relatively slack. Water was gathered 0.5 meters from the bottom at the same locations where coral disease surveys were conducted in the 2003 study except for Bonbonan, which problematic to visit within the two-hour window on the same day. One 
additional sample was collected from the waterfront of downtown Dumaguete City (where little live coral exists), just south of the city pier.

Analyses of Water and Sediment Nutrients

For water samples, I measured total nitrogen (TN), total organic carbon (TOC), and total phosphorus (TP) and from corresponding sediment samples I analyzed TOC and TP. Water quality parameters were measured using standard techniques (Boyer et al., 1997). I measured TN using an ANTEK $7000 \mathrm{~N}$ Nitrogen Analyzer using $\mathrm{O}_{2}$ as carrier gas (Frankovich and Jones, 1998). I measured TP using a dry ashing, acid hydrolysis technique (Solorzano and Sharp, 1980). I measured TOC by direct injection onto hot platinum catalyst in a Shimadzu TOC-5000 after first acidifying to $\mathrm{pH}<2$ and purging with $\mathrm{CO}_{2}$-free air.

For sediment samples, TOC and TN analyses were carried out by high temperature (flash) combustion using a Carlo Erba EAl 108 elemental analyzer. The sediments were ground with a mortar and pestle, treated for carbonate removal by a modification of the vapor acidification technique of Hedges and Stern (1984), and heated to drive off excess $\mathrm{HCl}$ and water. The carbonate-free sediments were then weighed out in tin combustion boats and analyzed. TP was determined using a dry ashing, acid hydrolysis technique (Solorzano and Sharp, 1980). The resulting orthophosphate ion reacts with ammonium molybdate in acidic solution to form phosphomolybdic acid, which upon reduction with ascorbic acid produces an intensely blue complex, which was analyzed via colorimetry. 


\section{Disease prevalence and coral colony density}

At each site six transects $(10 \times 2 \mathrm{~m})$ were haphazardly chosen and surveyed for prevalence of UWS and MPGA for a total area of $120 \mathrm{~m}^{2}$ per site. Depths ranged from 1 to $3 \mathrm{~m}$. For all sites, every Porites colony $\geq 2 \mathrm{~cm}$ (max. width) was counted within each transect. To calculate prevalence $>100$ colonies per site were examined to minimize potential in-site variability. In each location, prevalence was calculated as number of diseased colonies divided by total number of colonies (diseased and unaffected) and disease prevalence for each site was based upon pooling colonies from the six transects. To determine prevalence of MPGA (which only affected massive Porites) and UWS (which affected both massive and branching Porites) the distinction was made while counting colonies between massive and branching species of Porites. Density was calculated as the number of Porites counted in each site divided by the number of square meters surveyed in that site, again making a distinction between massive and branching species.

\section{Statistical analyses}

For water quality data the results from the two duplicate water samples were averaged. Pearson product-moment correlation analyses (denoted by r) were then used to test nutrient and coral density data against disease prevalence. If data sets failed tests for normality and/or equal variances, the non-parametric Spearman Rank correlation analysis was used (denoted by rs).

Because sites with higher disease prevalence were clustered, post-hoc statistical analyses were performed to determine if there were significant differences in nutrient concentrations and organic carbon levels between the clustered sites that had higher 
disease prevalence and sites with lower prevalence. T-tests were performed for the comparisons. If data sets failed tests for normality and/or equal variances, the nonparametric Mann-Whitney Rank sum test was performed instead. For associations involving MPGA, the sites north of the city and the adjacent "airport" site were treated as one group and compared with a second group, consisting of all other sites to the south. For associations involving UWS, the four sites within city limits were treated as one group and compared with a second group (all other sites). Clustering of sites with higher prevalence was determined to be statistically significant by the following assessment: MPGA prevalence in sites north of the city (including the adjacent "airport" site) that had a median prevalence of $24.2 \%$ was compared to all other sites that had a median MPGA prevalence of $2.2 \%(\mathrm{p}<0.001$, Mann-Whitney Rank sum test). UWS prevalence within the city limits that had a median prevalence of $29.4 \%$ was compared to non-city sites that had a median UWS prevalence of $2.1 \%,(p<0.05$, Mann-Whitney Rank sum test). The threshold of significance used for all tests was $\alpha=0.05$.

Correlations among environmental variables and their overall correlations with site locations were examined with ordination analyses. Principal components analyses (PCA) were used to summarize patterns in the environmental variables. Principal components analyses are usually used when the original variables are correlated. The water and sediment chemical data were normalized, and the results for the samples compared using PCA. The chemical and site data were tested for seriation, i.e., gradual change along the gradient, indicative of a natural gradient. Spearman rank correlation was employed with 999 permutations of the data used to test for the level of significance. The 
analysis of the chemical data was performed by using the Primer5 software package

(Primer-E, Ltd.), using methods described by Clarke and Warwick (2001).

\section{RESULTS}

Water quality along the coastal gradient

Table 1 shows that water column TP and TN and sediment TOC tended to be

highest within or just north of Dumaguete City limits and that the TN:TP ratio was

highest north of the city and lowest within city limits. Water column TOC and sediment

TP tended to be lower north of the city. Water column TP concentrations within city

limits were significantly higher (Fig. 2) than non-city sites $(p<0.05$, Mann-Whitney

Table 1. Water quality along an environmental impact gradient in the Philippines and corresponding environmental parameters that were used in correlation analyses.

\begin{tabular}{|c|c|c|c|c|c|c|c|c|c|c|c|}
\hline $\begin{array}{l}\text { Sites } \\
\text { (north to } \\
\text { south) }\end{array}$ & Km & $\begin{array}{l}\% \\
\text { MPGA }\end{array}$ & \begin{tabular}{|l|}
$\%$ \\
UWS
\end{tabular} & $\begin{array}{l}\text { TN } \\
\text { water } \\
\text { (umol/ } \\
\text { l) }\end{array}$ & $\begin{array}{l}\text { TP } \\
\text { water } \\
(u \mathrm{~mol} / \\
1)\end{array}$ & $\begin{array}{l}\text { TN:TP } \\
\text { ratio }\end{array}$ & $\begin{array}{l}\text { TOC } \\
\text { water } \\
(u \mathrm{~mol} / \\
1) \\
\end{array}$ & $\begin{array}{l}\text { TOC } \\
\text { seds } \\
\%\end{array}$ & $\begin{array}{l}\text { TP seds } \\
\mu \mathrm{g} / \mathrm{g}\end{array}$ & \begin{tabular}{|l|} 
Density \\
colonies/ \\
$\mathrm{m}^{2}$
\end{tabular} & $\begin{array}{l}\text { Colonies } \\
\text { counted/ } \\
\text { site }\end{array}$ \\
\hline Lalaan & 10.5 & 15.3 & 2.4 & 11.3 & 0.14 & 81 & 78.4 & 3.06 & 378. & 3.9 & 466 \\
\hline Calo Rvr. & 7.5 & 12.3 & 2.4 & 8.8 & 0.13 & 68 & 77.4 & 5.66 & 292 & 1.0 & 124 \\
\hline Cangmating & 4.4 & 25.2 & 2.7 & 11.5 & 0.17 & 68 & 78.3 & 2.93 & 367 & 2.8 & 333 \\
\hline Maslog River & 3.8 & 23.1 & 1.2 & 14.7 & 0.26 & 57 & 70.6 & 2.60 & 410 & 2.8 & 335 \\
\hline Calongcalong & 3.0 & 32.8 & 18.5 & 15.0 & 0.21 & 71 & 89.1 & 15.78 & 247 & 3.0 & 363 \\
\hline N. Agan-an & 2.6 & 39.1 & 14.3 & 13.3 & 0.19 & 70 & 76.7 & 10.26 & 299 & 5.8 & 582 \\
\hline S Agan-an & 2.3 & 38.5 & 5.3 & 12.4 & 0.18 & 69 & 76.0 & 7.58 & 324 & 3.3 & 397 \\
\hline $\begin{array}{l}\text { Airport } \\
\text { runway }\end{array}$ & 2.1 & 19.5 & 4.7 & 14.6 & 0.28 & 52 & 83.6 & - & 290 & 2.7 & 322 \\
\hline Piapi & 0.9 & 2.2 & 29.4 & 6.3 & 0.27 & 23 & 89.8 & 0.80 & 848 & 2.1 & 248 \\
\hline Looc & 0.1 & 6.2 & 43.6 & 10.4 & 0.98 & 11 & 90.7 & 1.32 & 377 & 2.9 & 351 \\
\hline $\begin{array}{l}\text { Downtown/ } \\
\text { Pier }\end{array}$ & 0 & & & 11.7 & 0.63 & 19 & 107.0 & 0.65 & 718 & - & l- \\
\hline Mangnao & 2.7 & 0.4 & 0 & 7.1 & 0.53 & 13 & 100.4 & 0.14 & 554 & 2.1 & 252 \\
\hline Banilad & 4.2 & 4.4 & 0.3 & 5.9 & 0.42 & 14 & 88.9 & 7.27 & 587.64 & 5.6 & 670 \\
\hline Poblacion & 14.3 & 9.2 & 1.8 & 6.5 & 0.25 & 26 & 87.8 & 1.51 & 274.7 & 8.0 & 954 \\
\hline Masaplod & 15.3 & 0.9 & 0 & 6.8 & 0.20 & 34 & 116.5 & 0.14 & 417.67 & 3.2 & 190 \\
\hline Bonbonan & 30.0 & 1.8 & 0.4 & & & & & & & 2.1 & 256 \\
\hline
\end{tabular}

Sites in bold indicate those within Dumaguete City limits. $\mathrm{km}=$ the distance from the waterfront in downtown Dumaguete City. MPGA = massive Porites growth anomalies, UWS = ulcerative white spot disease, $\mathrm{TN}=$ total nitrogen, $\mathrm{TP}=$ total phosphorus, $\mathrm{TOC}=$ total organic carbon, seds $=$ in sediments, Density $=$ the density of both branching and massive Porites colonies combined. Blanks are missing data. $120 \mathrm{~m}^{2}$ were surveyed in each site. 
Table 2. Results of correlation analyses.

\begin{tabular}{|l|l|l|l|}
\hline & Distance & \% MPGA & \% UWS \\
\hline TN & - & ++ & \\
\hline TP & - & & + \\
\hline TN:TP & & ++ & \\
\hline TOC & & - & \\
\hline \% C seds & & ++ & \\
\hline TP seds & & - & \\
\hline Density & & + & \\
\hline TOC:TN & & -- & \\
\hline
\end{tabular}

"Distance" refers to distance from Dumaguete City. \% MPGA = prevalence of massive Porites growth anomalies, $\%$ UWS $=$ prevalence of ulcerative white spot disease. For water column nutrients, TN $=$ total nitrogen, $\mathrm{TP}=$ total phosphorus, and, TOC $=$ total organic carbon. "seds" = sediment-associated nutrients Density here is the total of only massive Porites species per meter square. "+" indicates a modest positive correlation ( $\mathrm{r}$ or rs $=0.40$ to 0.69 ), “++" a strong positive correlation ( $\mathrm{r}$ or rs $=0.70$ to 0.89 ), “-“ a modest negative correlation, "- - " a strong negative correlation, and blanks indicate no correlation. $\alpha=0.05$ for all.

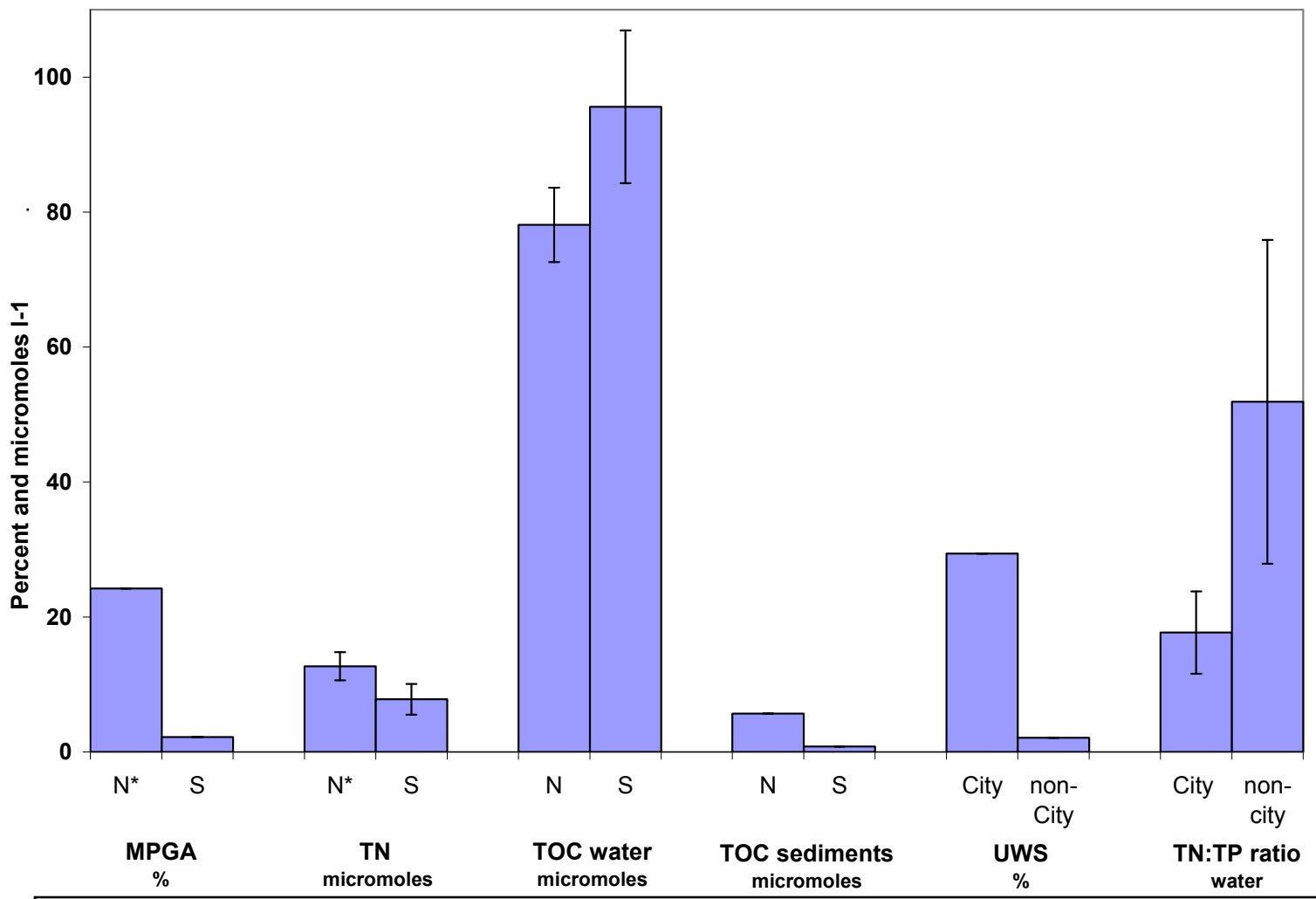

Figure 2. Results of tests comparing (1) sites north of Dumaguete City ("N") with sites within the city limits and south ("S") and (2) sites within city limits with sites outside city limits. All comparisons were significantly different $(\mathrm{p}<0.05)$. Bars that include error bars (SD) show means and passed tests for normality and equal variance; t-tests were performed on these paired data sets. When assumptions were not met, Mann-Whitney Rank sum tests were performed and no error bars are included; bars indicate median values. " $\mathrm{N} *$ " indicates the "airport" site data were included in the calculations for "N" sites. MPGA = massive Porites growth anomalies, $\mathrm{TN}=$ total nitrogen, $\mathrm{TOC}=$ total organic carbon, UWS = ulcerative white spot disease, TN:TP = total nitrogen to total phosphorus ratio. 
Rank sum test). Concentrations of TP in sites north of the city were significantly lower than in sites to the south (including city sites) ( $p<0.05, t$-test). Water column TN concentrations north of the city (including the adjacent "airport" site) were significantly higher than in sites to the south (including city sites) (Fig. 2; $p<0.001, t$-test). The TOC in surface sediments in sites north of the city were significantly higher than in sites to the south (Fig. 2; $p<0.01$, Mann-Whitney Rank sum test). Water column TN:TP ratios in sites within city limits were significantly lower than non-city sites (Fig. $2 ; p<0.05, t$ test). Water column TN:TP ratios in sites north of the city (including the adjacent "airport" site) were significantly higher than sites to the south ( $p<0.001, t$-test). Water column TOC concentrations in sites north of the city were significantly lower than in sites to the south (including city sites) (Fig. 2; $p<0.01$, $t$-test). TP concentrations in surface sediments in sites north of the city had a median value of $324 \mu \mathrm{g} \mathrm{g}^{-1}$, which was lower than the median value in sites to the south $\left(486 \mu \mathrm{g} \mathrm{g}^{-1}\right.$ but these were not significantly different. Colony densities ranged from 1 to 8 colonies $\mathrm{m}^{-2}$ along the gradient and there was no significant pattern in relation to distance to the city. Colony counts along the gradient ranged from 124 to 954 colonies site ${ }^{-1}$.

\section{Relationships between disease prevalence and levels of nutrients and organic carbon}

Prevalence of MPGAs were highest just north of the city airport runway where water column TN, sediment TOC, and colony density of massive Porites tended to be highest (Fig. 3). Prevalence of UWS was highest near the city center and north of the city pier where TP and TOC of the water column and TP in the sediments tended to be highest and the TN:TP ratio was lowest (Table 1 and Fig. 3). The Looc site, within the 
city limits, had the highest prevalence of UWS, the highest water column TP and the lowest TN:TP ratio. Colony density did not have a significant relationship with UWS prevalence.

There were moderate negative correlations between distance from Dumaguete City and both water column TP ( $\mathrm{r} s=-0.61, p<0.05)$ and water column TN $(\mathrm{r} s=-0.64, p$ $<0.01$ ) (Table 2). There were strong correlations between prevalence of MPGA and water column TN $(\mathrm{r}=0.82, p<0.01)$, total carbon content of surface sediments $(\mathrm{r}=0.72$, $p<0.01)$, and the water column TOC:TN ratio $(\mathrm{r}=-0.82, p<0.01)$. There was a moderate correlation between prevalence of MPGA and colony density of massive Porites $(\mathrm{r} s=0.54, p<0.05)$. There was also a moderate correlation between prevalence of UWS and TP $(\mathrm{r}=0.61, p<0.05)$. There was no correlation between prevalence of UWS and the density of all Porites colonies (massive and branching species). Figures $3 \mathrm{c}$ and $3 \mathrm{~d}$ show notable patterns regarding nutrient levels along the gradient. Water column TN concentrations were very high in sites just north of the city and gradually declined up-current, but were sharply lower in sites south of the city. Water column TP concentrations were very high near the city center and gradually declined down-current to the south in sites facing the Bohol Sea but were extremely low north of the city in sites facing the more constricted body of water, the Tañon Strait. These two nutrients ( $\mathrm{N}$ and $\mathrm{P}$ ) occurred at their highest levels within or close to city limits where the diseases were also at their highest prevalence (Table 1; Fig. 3a and 3b).

The highest levels of organic carbon in sediments (Fig. 3e) and water column nitrogen (Fig. 3c) were seen in the area affected by the entrainment of the predominantly south-flowing water in the sites closest to and north of the airport runway jetty. 
Prevalence of MPGA was highest where the highest concentration of water column nitrogen (Fig. 3c), highest levels of organic carbon in surface sediments (Fig. 3e), and highest density of massive colonies (Fig. 3f) occurred. The highest UWS prevalence and water column TP (Fig. 3b and 3d) occurred near the city center (i.e., adjacent to the neighborhood of Looc and just north of the city pier).

Figure 2 reveals that the sites that had a significantly higher prevalence of MPGAs also had significantly higher levels of water column TN and sediment TOC and a significantly lower level of water column TOC. For sites that had a significantly higher prevalence of UWS there was also a significantly lower TN:TP ratio. Where UWS was significantly higher, TP was also significantly higher $(\mathrm{p}<0.05$, Mann-Whitney Rank sum test; not shown in Fig. 2).

The chemical properties of the water and sediment and colony density varied considerably along the gradient. When compared using PCA, 52-54\% of the variation was described in principal component one, which effectively discriminated the sites north of the city from the rest of the sites (Fig. 4). These locations had the highest values for water column TN, TOC in sediments, density of colonies, and prevalence of MPGAs (Table 1 and Fig. 3). Axis 2, accounting for $18-22 \%$ of the variation in physicochemical properties, further discriminated between the sampling locations (Fig. 4). The eigen vectors strongly associated with PC2 were water column TP and TN. This axis strongly discriminates the Looc site (which had the highest prevalence of UWS) based on water column TP. When tested for seriation, the physicochemical properties showed no pattern of natural or gradual change with distance along the gradient $(\mathrm{Rho}=0.096 ; \mathrm{P}=0.202)$. 

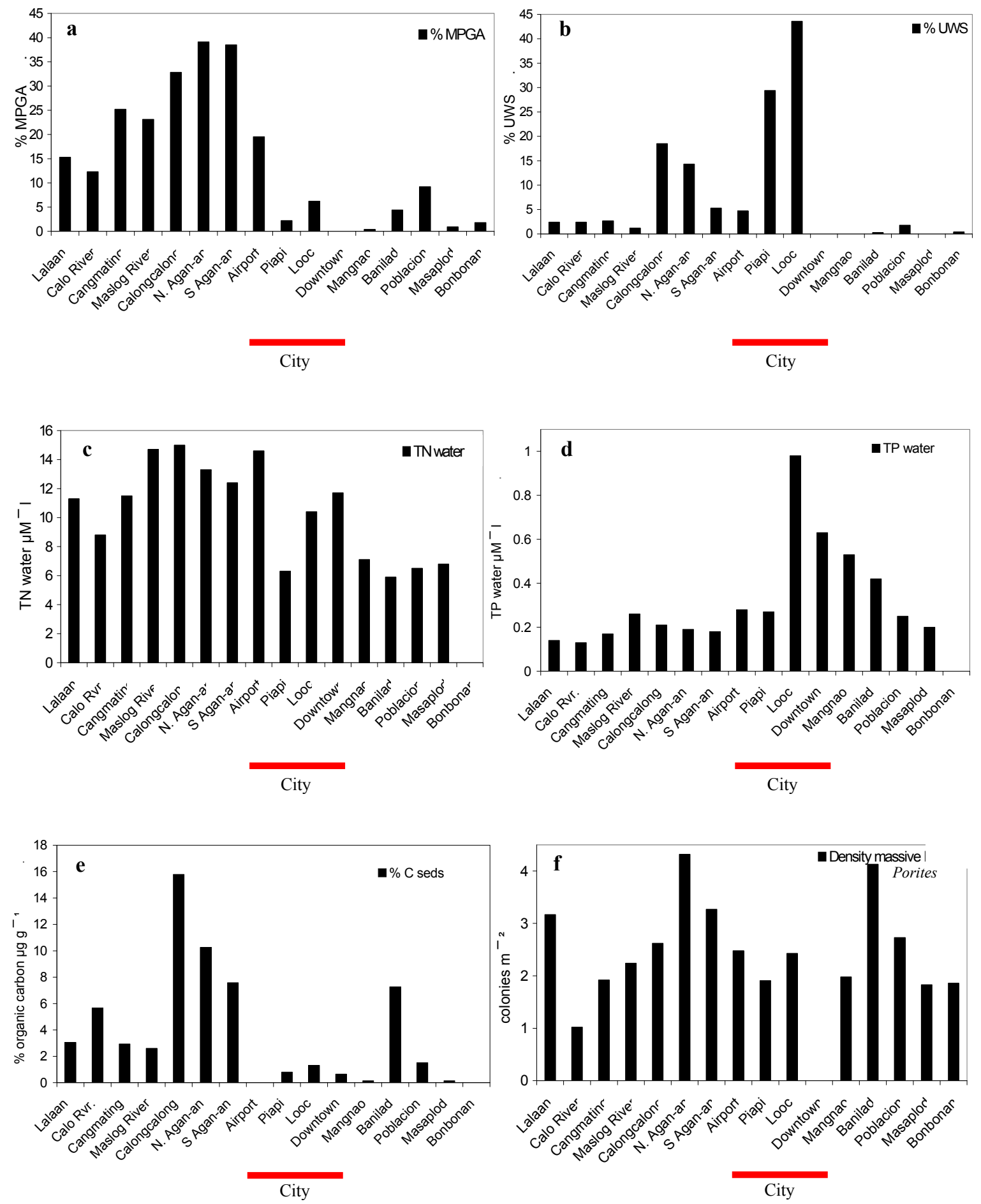

Figure 3. Disease prevalence of MPGA (a) and UWS (b) in relation to sites along the study gradient. Sites are shown from north (left) to south (right). Concentrations of total nitrogen (c) and total phosphorus (d), total organic carbon content of sediments (e) and density of colonies of massive Porites (f). 

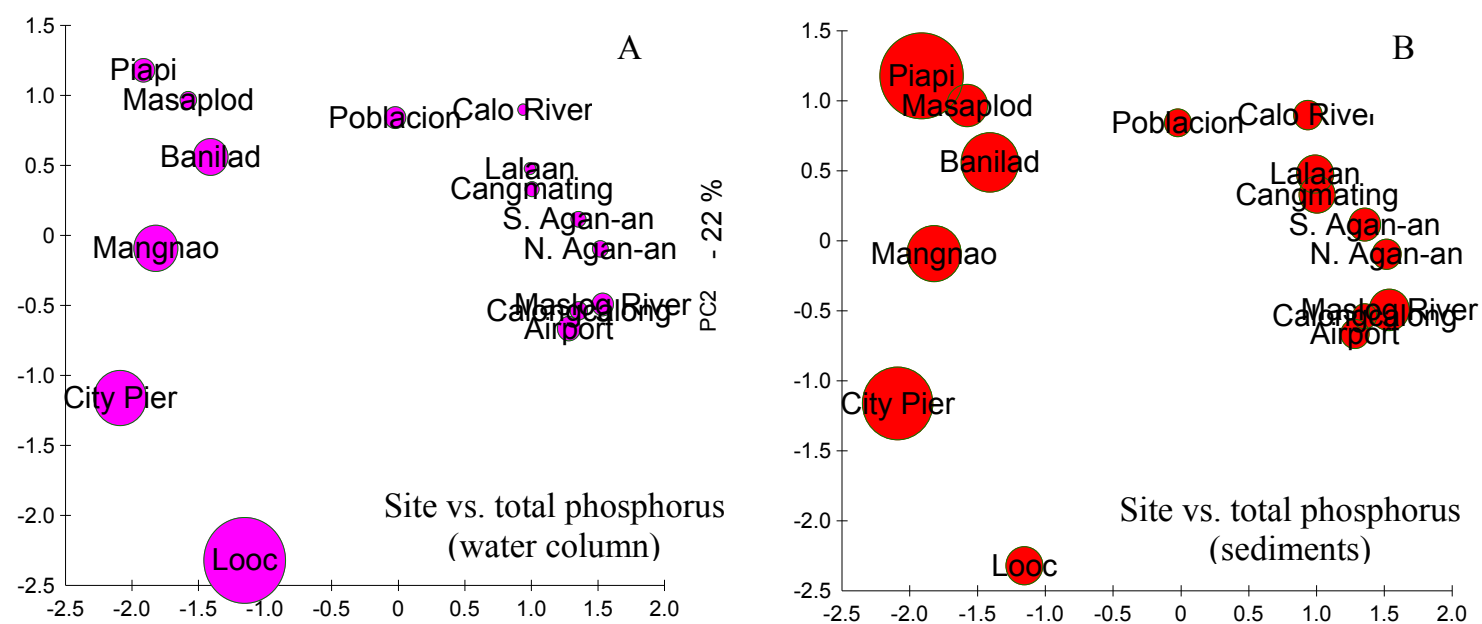

$\mathrm{PC} 1-54 \%$

PC1 - $54 \%$

3)
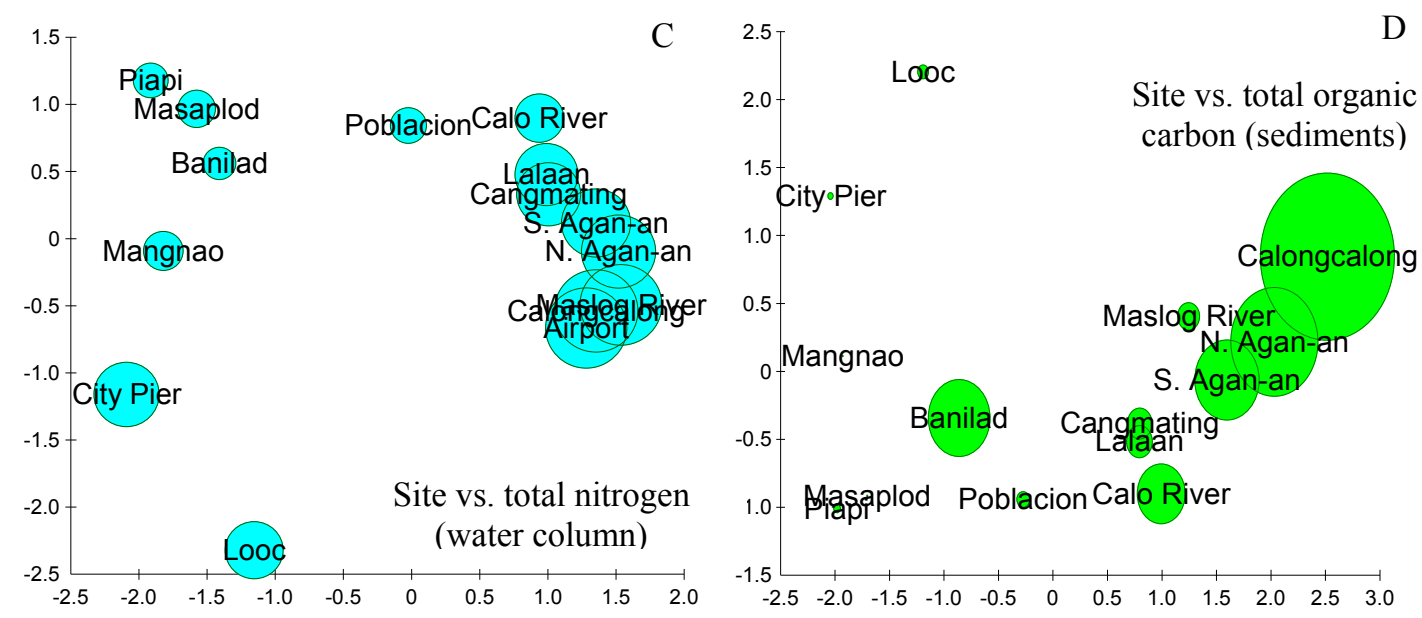

PC $454 \%$

$P C 1-52 \%$

Figure 4. Principal component analysis bubble plots show the correlation between water and sediment quality along reefs in SE Negros Island. A. Site vs. TP (water column). B. Site vs. TP (sediment). C. Site vs. TN (water column). D. Site vs. TN (sediment). 


\section{DISCUSSION}

Correlations of UWS and MPGA prevalence with TP, TN and organic carbon

The prevalence of UWS and MPGAs on the study reefs exhibited different patterns of correlation with TP and TN. In general, the UWS on these reefs was positively correlated with elevated TP. Thus the site with highest UWS prevalence (44\%) was Looc, a coastal neighborhood of Dumaguete City - this site exhibited a sharp spike in water column TP (Table 1 and Fig. 3d)., The two sites with lowest UWS prevalence (both 0\%) exhibited the lowest levels of TP (Fig. 3). This overall pattern can be seen in Fig. 3.

In contrast to UWS, prevalence of MPGA showed a strong positive correlation with $\mathrm{TN}(\mathrm{r}=0.82, \mathrm{p}<0.01$; Table 2$)$. In this case the site with the highest prevalence (39\%), south Agan-an, had approximately twice as much $\mathrm{TN}(13.3 \mu \mathrm{M}$ versus $7.1 \mu \mathrm{M})$ and exhibited two orders of magnitude of the MPGA prevalence when compared to the site with the lowest prevalence $(0.4 \%)$.

Prevalence of MPGAs also had a strong positive correlation with the amount of carbon in surface sediments $(\mathrm{r}=0.72, p<0.01$; Table 2$)$. The very strong tidal currents at the study sites (due to a very high tidal range, up to $2 \mathrm{~m}$ ) generally causes extreme resuspension of surface sediments several times a day, sometimes reducing visibility from $20 \mathrm{~m}$ to $1 \mathrm{~m}$ in just 15 minutes. This resuspension chronically exposes corals to sediment.

While several studies, as discussed previously, have shown correlations between both $\mathrm{N}$ and $\mathrm{P}$ and coral diseases in the wider Caribbean, correlation of disease with organic carbon has been less well defined. The proposal that elevated water column 
organic carbon is a contributor to coral disease and mortality (Kuntz et al., 2005; Kline et al., 2006) was supported by experimental additions of organic carbon which led to increased growth rates among coral microbes. These investigators suggested that coral mucus-associated microbes, including potential pathogens, are carbon-limited. An additional aspect to consider is the biodegradability of organic carbon in marine waters, which has been shown to increase with elevated N and P (Kirchman et al., 1991; Coffin et al., 1993; Pomeroy et al., 1995).

\section{$M P G A, U W S$, and nutrient and carbon ratios}

The TOC:TN ratio was lowest in sites where prevalence of MPGA was highest (north of the airport) even though TOC was highest in sediments north of the airport (Fig. 3). This reflects the high levels of TN in the same sites. MPGA had a strong significant negative correlation with the water column TOC:TN ratio $(r=-0.82, \mathrm{P}<$ 0.01). The TOC:TP ratio was lowest in surface sediments where prevalence of UWS was highest (Looc). Sediment organic matter can be a source of recycled nutrients for water column productivity (including rapid bacterial growth) when it degrades. Thus resuspended sediments can supply a rich source of nutrients to coral-associated bacteria in areas where high rates of decomposition occur. Decomposition of organic matter has been shown to increase as nitrogen and phosphorus contents increase (Enriquez et al., 1992), and as TOC:TN and TOC:TP ratios decrease (Thomann, 1972). Thus, organic matter with low TOC:TN is considered more labile than organic matter with high TOC:TN. Organic matter with a very high TOC:TN releases fewer nutrients when it breaks down, thus supports less bacterial activity. It should be noted that the Looc site and sites north of the airport also appear to have much finer sediments than other sites 
thus the organic matter content may be higher since, in general, there is a positive correlation between TOC (and TN) and \% silt (CSIRO, 2000). Massive Porites growth anomalies and colony density

MPGA prevalence had a positive correlation with colony density of massive Porites ( $\mathrm{r} s=0.54, \mathrm{P}<0.05)$, suggesting the involvement of an infectious agent. Bruno et al. (2007) quantitatively demonstrated that high coral density is linked to higher prevalence of Indo-Pacific white syndrome. Raymundo et al. (2005) also showed a positive correlation between the relative abundance of Porites and disease (although their threshold for significance was less strict; $\mathrm{r}^{2}=43.4, \mathrm{p}=0.076$ ). Similarly, Kuta and Richardson (2002) reported a positive correlation between black band disease and colony density on reefs of the Florida Keys. Although these patterns implicate transmission of disease through the water column, and laboratory experiments demonstrated that MPGAs can be transmitted from infected to healthy Porites colonies in experimental laboratory aquaria (Kaczmarsky and Richardson, 2007), transmission of coral diseases in situ is an area of research in which much remains to be learned.

\section{Patterns of coral disease near Dumaguete City}

Elevated values of water column and sediment nutrient concentrations both within and just north of Dumaguete City limits is likely due to proximity to the high human population density as well as obstructions to the predominant southward water flow by the airport jetty and city pier. The lack of sewage or waste-water treatment, along with runoff from agriculture and aquaculture operations in this dense population center, likely contribute to the high nutrient levels observed on the study reefs. The pattern observed in 
the present study, i.e., correlation of elevated nutrients with higher disease prevalence, supports the findings of Raymundo et al. (2005), who also studied coral disease on Philipine reefs. In this study very little disease was observed in the two best-protected sites (marine reserves) while more disease was observed in two heavily impacted sites. However, this study did not quantify nutrient levels.

While elevated levels of nutrients and organic carbon occur at the Looc site and sites north of the airport, the specific nutrients involved (and combinations of nutrients and carbon) were not the same for the two reef areas. This, in combination with the different relationships of nutrients and organic carbon with the prevalence of the two diseases, suggests different underlying processes associated with the two diseases. Thus different drivers (such as co-limitation) may be responsible for the different distributions of disease on these reefs. While the results of this study are not definitive in terms of the cause of the diseases, the following hypotheses are put forth. First, high incidence of MPGAs may occur in sites where high water column TN is combined with high quantities of organic carbon in sediments, which may release a putative pathogen from $\mathrm{N}$ and C colimitation. Similarly, high incidence of UWS may be related to $\mathrm{P}$ and carbon colimitation. One site investigated did not fit this pattern in that there was relatively high UWS prevalence at the Piapi site despite low TP and C. However, this may be based on the close proximity of the Piapi site to Looc, the site with the highest UWS prevalence. Thus the Looc site may be serving as a reservoir for a putative water-borne pathogen. Similarly, it had been previously proposed that UWS was transmitted via water transport to Sumilon Island and Looc (a different town on Cebu Island) along a front that forms between those two sites and Looc (Negros Island; Kaczmarsky, 2006). 
It is recognized that the relationship between the diseases UWS and MPGA and elevated nutrients may in fact not be directly causative but only correlative. For example, run-off and sewage also may contain and simply deliver large doses of coral pathogens. For example, it has been suggested that the fungal pathogen (Aspergillus sydowii) responsible for the gorgonian coral disease of the Caribbean, aspergillosis, may originate in eroded soils (Kim and Harvell, 2002). In the case of the bacteria, Serratia marscecens, thought to be responsible for the Caribbean coral disease white pox, it is believed it might originate from human fecal waste in sewage (Patterson et al., 2002). Other constituents of sewage that also may increase disease prevalence and severity include toxins, pharmaceuticals, heavy metals, and other microbes (Pastorok and Bilyard, 1985). Furthermore, populations of potential coral pathogens may be regulated by a number of factors besides $\mathrm{N}, \mathrm{P}$, and TOC, including temperature, light levels, $\mathrm{pH}$, viral lysis, zooplankton grazing, and anti-microbial production by both coral and resident beneficial microbes. A case in point, Webster et al. (2001) showed that a pollutant affected the community structure of sponge-associated bacteria and speculated that this shift potentially was the cause of an observed decline in sponge health. Although the relationship between nutrients, microbial communities, and coral health has yet to be examined experimentally, it would not be surprising that elevated nutrients (especially combined with increased seawater temperature) could have similar effects on microbial communities of corals and coral health.

This study presents quantitative evidence linking elevated nutrient and carbon levels to higher coral disease prevalence on reefs of the Philippines. The results suggest several environmental parameters as drivers of coral epizootics in this region. However, 
because the study is limited in a temporal sense, the conclusions must be taken with some degree of caution. This study provides a spatially accurate portrayal of the variability of nutrient levels along a gradient and the nutrient correlation analyses conducted here provide starting points for controlled nutrient experiments with UWS and MPGA. This study also highlights the need for more-detailed, long-term, multi-disciplinary analyses to narrow down potential contributors to UWS and MPGA. 


\section{REFERENCES}

Antonius, A. 1988. Distribution and dynamics of coral diseases in the eastern Red Sea. Proc. 6th Int. Coral Reef Symp. 2, 293-298.

Aronson, R., Precht, W., 2001. White-band disease and the changing face of Caribbean coral reefs. Hydrobiologia 460, 24-38.

Baker, D.M., MacAvoy, S.E., Kim, K., 2007. The relationship between water quality, $\triangle 15 \mathrm{~N}$, and aspergillosis of Caribbean sea fan corals. Mar. Ecol. Prog. Ser. 343, 123-130.

Boyer, J.N., Fourqurean, J.W., Jones, R.D., 1997. Spatial characterization of water quality in Florida Bay and Whitewater Bay by multivariate analyses: zones of similar influence. Estuaries 20, 743-758.

Breitbart, M., Bhagooli, R., Griffin, S., Johnston, I., Rohwer, F., 2005. Microbial communities associated with skeletal tumors on Porites compressa. FEMS Microbiol. Lett. 243, 431-436.

Bruckner, A.W., Bruckner, R.J., Williams, E.H., 1997. Spread of black band disease epizootic through the coral reef ecosystem in St. Ann's Bay, Jamaica. Bull. Mar. Sci. 61, 919-928.

Bruno, J.F., Petes, L.E., Harvell, C.D., Hettinger, A. 2003. Nutrient enrichment can increase the severity of coral diseases. Ecol. Lett. 6, 1056-1061.

Bruno, J.F., Selig, E.R., Casey, K.S., Page, C.A., Willis, B.L., Harvell, C.D., Sweatman, H., Melendy, A.M., 2007. Thermal stress and coral cover as drivers of coral disease outbreaks. PLoS Biol. 5, 1-8.

Burke, L., Selig, E., Spalding, M., 2002. Reefs at Risk in Southeast Asia. World Resources Institute, Washington, DC.

Clarke, K.R., Warwick, R.M., 2001. Change in marine communities: an approach to statistical analysis and interpretation, 2nd ed. Primer-E Ltd., Plymouth, United Kingdom.

Coastal Resource Management Project, 1999. Primer on Coastal Resource Management. CRMP Document No. 06-CRM/1999 Working Document p 122.

Coffin, R.B., Connolly, J.P., Harris, P.S., 1993. Availability of dissolved organic carbon to bacterioplankton examined by oxygen utilization. Mar. Ecol. Prog. Ser. 101, 922. 
CSIRO Huon Estuary Study Team, 2000. Huon Estuary Study: Environmental Research for Integrated Catchment Management and Aquaculture. Project No. 96/284, Final Report to the Fisheries Research and Development Corporation, p 285.

Enriquez, S., Duarte, C.M., Sand-Jensen, K., 1993. Patterns in decomposition rates among photosynthetic organisms: the importance of detritus C:N:P content. Oecologia 94, 457-471.

Frankovich, T.A., Jones, R.D., 1998. A rapid, precise and sensitive method for the determination of total nitrogen in natural waters. Mar. Chem. 60, 227-234.

Gateño, D., Leon, A., Barki, Y., Cortes, J., Rinkevich, B., 2003. Skeletal tumor formations in the massive coral Pavona clavus. Mar. Ecol. Prog. Ser. 258, $97-$ 108.

Gomez, E.D., Aliño, P.M., Yap, H.T., Licuanan, W.Y., 1994. A review of the status of Philippine reefs. Mar. Pollut. Bull. 29, 62-68.

Goreau, T.J., Cervino, J., Goreau, M., Hayes, R., Hayes, M., Richardson, L., Smith, G., DeMeyer, K., Nagelkerken, I., Garzon-Ferrera, J., Gil, D., Garrison, G., Williams, E.H., Bunkley-Williams, L., Quirolo, C., Patterson, K., Porter, J.W., Porter, K., 1998. Rapid spread of diseases in Caribbean coral reefs. Rev. Biol. Trop. 46, 157171.

Green, E.P., Bruckner, A.W., 2000. The significance of coral disease epizootiology for coral reef conservation. Biol. Conserv. 96, 347-361.

Guppy, R., Bythell, J.C., 2006. Environmental effects on bacterial diversity in the surface mucus layer of the reef coral Montastraea faveolata. Mar. Ecol. Prog. Ser. 328, $133-142$.

Harvell, C.D., Kim, K., Burkholder, J.M., Colwell, R.R., Epstein, P.R., Grimes, D.J., Hofmann, E.E., Lipp, E.K., Osterhaus, A.D.M.E., Overstreet, R.M., Porter, J.W., Smith, G.W., Vasta, G.R., 1999. Emerging marine diseases - climate links and anthropogenic factors. Science 285, 1505-1510.

Kaczmarsky, L. 2006. Coral disease dynamics in the central Philippines.

Dis. Aquat. Org. 69, 9-21.

Kaczmarsky, L., Richardson, L.L., 2007. Transmission of growth anomalies between Indo-Pacific Porites corals. J. Invertebr. Pathol. 94, 218-221.

Kaczmarsky, L., Draud, M., Williams, E.H., 2005. Is there a relationship between proximity to sewage effluent and the prevalence of coral disease? Caribb. J. Sci. $41,124-137$. 
Kirchman, D.L., Suzuki, Y., Garside, C., Ducklow, H.W., 1991. High turnover rates of dissolved organic carbon during a spring phytoplankton bloom. Nature 352, 612614.

Klaus, J.S., Frias-Lopez, J., Bonheyo, G.T., Heikoop, J.M., Fouke, B.W., 2005. Bacterial communities inhabiting the healthy tissues of two Caribbean reef corals: interspecific and spatial variation. Coral Reefs 24, 129-137.

Kline, D.I., Kuntz, N.M., Breitbart, M., Knowlton, N., Rohwer, F., 2006. Role of elevated organic carbon levels and microbial activity in coral mortality. Mar. Ecol. Prog. Ser. 314, 119-125.

Kuntz, N.M., Kline, D.I., Sandin, S.A., Rohwer, F., 2005. Pathologies and mortality rates caused by organic carbon and nutrient stressors in three Caribbean coral species. Mar. Ecol. Prog. Ser. 294, 173-180.

Kuta, K.G., Richardson, L.L., 2002. Ecological aspects of black band disease of corals: relationships between disease incidence and environmental factors. Coral Reefs 21, 393-398.

Pastorok, R.A., Bilyard, G.R., 1985. Effects of sewage pollution on coral-reef communities. Mar. Ecol. Prog. Ser. 21, 175-189.

Patterson, K.L., Porter, J.W., Ritchie, K.B., Polson, S.W., Mueller, E., Peters, E.C., Santavy, D.L., Smith, G.W., 2002. The etiology of white pox, a lethal disease of the Caribbean elkhorn coral, Acropora palmata. Proc. Natl. Acad. Sci. USA 99, 8725-8730.

Peters, E.C. 1993. Diseases of other invertebrate phyla: Porifera, Cnidaria, Ctenophora, Annelida, Echinodermata. In: Couch, J.A., Fournie, J.W., (Eds.), Pathobiology of Marine and Estuarine Organisms. CRC Press, Boca Raton, FL pp 393-449.

Pomeroy, L.R., Sheldon, J.E., Sheldon, W.M., Peters, F., 1995. Limits to growth and respiration of bacterioplankton in the Gulf of Mexico. Mar. Ecol. Prog. Ser. 117, 259-268.

Raymundo, L.J., Harvell, C.D., Reynolds, T.L., 2003. Porites ulcerative white spot disease: description, prevalence, and host range of a new coral disease affecting Indo-Pacific reefs. Dis. Aquat. Org. 56, 95-104.

Raymundo, L.J., Reboton, C.T., Rosell, K.B., Kaczmarsky, L., 2005. Coral diseases on Philippine reefs: genus Porites is a dominant host. Dis. Aquat. Org. 64, 181-191. 
Sekar, R., Kaczmarsky, L.T., Richardson, L.L., 2008. Microbial community composition of black band disease on the coral host Siderastrea siderea from three regions of the wider Caribbean. Mar. Ecol. Prog. Ser. 362, 85-98.

Solorzano, L., Sharp, J.H., 1980. Determination of total dissolved phosphorus and particulate phosphorus in natural waters. Limnol. Oceanogr. 25, 754-758.

Sutherland, K.P., Porter, J.W., Torres, C., 2004. Disease and immunity in Caribbean and Indo-Pacific zooxanthellate corals. Mar. Ecol. Prog. Ser. 266, 273-302.

Taylor, D.L. 1983. The black band disease of Atlantic orals. II. Isolation, cultivation, and growth of Phormidium corallyticum. Mar. Ecol. 4, 321-328.

Thomann, R.V. 1972. Systems analysis and water quality measurement. Environmental Research and Application, Inc., New York

Veron, J.E.N. 2000. Corals of the World, Vol. 3. AIMS, Townsville, Australia 490 pp

Voss, J.D., Richardson, L.L., 2006. Nutrient enrichment enhances black band disease progression in corals. Coral Reefs 25, 569-576.

Walker, D.I., Ormond, R.F.G., 1982. Coral death from sewage and phosphate pollution at Aqaba, Red-Sea. Mar. Pollut. Bull. 13, 21-25.

Webster, N.S., Webb, R.I., Ridd, M.J., Hill, R.T., Negri, A.P., 2001. The effects of copper on the microbial community of a coral reef sponge. Environ. Microbiol. 3, $19-31$.

Williams, P.J.B. 2000. Heterotrophic bacteria and the dynamics of dissolved organic material. In: Kirchman, D.L. (Ed.), Microbial ecology of the oceans. Wiley-Liss, New York, pp 153-200. 
CHAPTER 3

HISTOPATHOLOGY OF GROWTH ANOMALIES OF

THE MASSIVE CORAL, PORITES LUTEA, FROM THE PHILIPPINES

PART I: LIGHT MICROSCOPY 


\section{INTRODUCTION}

Coral reefs are in decline throughout the world and coral disease is a significant contributing factor (Wilkinson, 2002; Hughes et al., 2003; Pandolfi et al., 2003;

Rosenberg and Loya, 2004). In the past two decades the numbers of coral diseases, disease events, and host species affected have all increased (Harvell et al., 1999; Sutherland et al., 2004). Yet, the etiologies of many coral diseases are still not well understood.

In 2002 in the Philippines an epizootic of growth anomalies (MPGAs) that affected colonies of the dominant massive reef-building corals of the genus Porites was discovered during a general baseline survey of coral disease prevalence (Kaczmarsky 2004, 2006). Observations suggested that MPGAs were widespread and were estimated to affect $>10,000$ colonies (pers. obs.) along a $41.5 \mathrm{~km}$ long section of fringing reef. The MPGA's affecting colonies of the species Porites lutea, which dominates these reefs, is the focus of the present study.

Despite its location at the heart of the highest coral diversity in the world, very little coral disease research has been conducted in the Philippines. Very little is known about coral diseases of the Philippines or South Asia in general when compared to more intensively studied Caribbean and Australian coral diseases. While the coral diseases often referred to as coral "tumors" (i.e., growth anomalies) have been widely observed (Sutherland et al., 2004), almost nothing is known about their etiologies (Kaczmarsky, 2006). To date, no studies have been able to establish the involvement of an infectious agent associated with these or any other coral growth anomalies. 
There are few reports of coral growth anomaly (GA) epizootics. Recently, GAs were observed to occur at high prevalence among dominant coral species in Australia, Hawaii, Japan, W. Costa Rica, and the Philippines (Uwins et al., 1996; Hunter, 1999; Yamashiro et al., 2000; Gateño et al., 2003; Kaczmarsky, 2004, 2006). Host species in these events include Platygyra pini, P. sinensis (Loya et al., 1984) and Acropora nobilis in Australia (Uwins et al., 1996), Porites lobata in Hawaii (Hunter, 1999), Montipora informis in Japan (Yamashiro et al., 2000) and Pavona clavus in Costa Rica (Gateño et al., 2003). Prevalence values reported in these studies ranged from 19 to $55 \%$. The presence of GAs on massive Porites has been reported by others to cause colony mortality (Hunter, 1999; Yamashiro et al., 2000; Kaczmarsky, 2006; Work et al., 2008). Because gross morphologies of coral GAs associated with these epizootics are quite varied, it is possible that they have different etiologies.

Global databases report growth anomalies (GAs), also referred to as "tumors", "neoplasia", or "hyperplasia" from around the world (Bruckner, 2002). Veron (2000) described GAs (using the term "neoplasms") as found among most coral species and he considered them common. It has been shown that coral GAs have a negative effect on growth of the coral colony (Cheney, 1975; Bak, 1983) and tissue chemistry (Yamashiro et al., 2001). One study detected elevations in levels of protein markers (bio-indicators) in coral GAs, similar to those observed in association with hyperplasia in other organisms (Domart-Coulon et al., 2006). Changes in associated microbial communities (Breitbart et al., 2005) and skeleton chemistry (Gateño et al., 2003) have also been reported for coral GAs. Recently, an experiment demonstrated apparent transmissibility of GAs of massive Porites from diseased to healthy colonies 
(Kaczmarsky and Richardson, 2007). Prevalence of GAs has also been positively correlated with human impacts (Kaczmarsky, 2006).

Growth anomalies in corals have been observed to become progressively larger (Peters et al., 1986; Hunter, 1999; Yamashiro et al., 2000; Kaczmarsky 2006; Work et al., 2008), and several reports of coral growth anomalies have suggested that they are neoplasms (Bak, 1983; Peters, 1984b; Peters et al., 1986; Yamashiro et al., 2000; Gateño et al, 2003). For example, Peters et al. (1986) and Coles and Seapy (1998) described coral GAs as "neoplasms" resulting from a proliferation of calicoblasts in the epithelium. Similarly, Yamashiro et al. (2000) reported that GAs were abnormal proliferations of tissue usually associated with abnormal skeletal growth. However, conclusive evidence of true neoplasia in corals is yet to be widely accepted and Smith (1999) stated that a clear malignant state has yet to be determined for any coral tumor. In a review of coral skeletal anomalies by Sutherland et al. (2004), the general histopathologic features of acroporid anomalies included (1) thinning of coral tissue over affected areas, (2) increased skeleton porosity, (3) loss of mucocytes cells and nematocysts, (4) loss of zooxanthellae, (5) loss, reduction or degeneration of normal polyp structures, and (6) fewer reproductive structures. Several studies had suggested or observed that the formation of "tumors" on corals imposed energy burdens that can negatively affect part of or the entire colony (Cheney, 1975; Bak, 1983; Yamashiro et al., 2001; Breitbart et al., 2005), including growth. According to Peters et al. (1986), the changes they described as neoplasms pose a serious threat to corals by potentially reducing fecundity, growth and their primary defense mechanism, mucus production. 
Diagnosis of a tumor-like growth as true neoplasia is dependent on microscopic studies targeting cellular morphology. Although neoplasia often appears as a mass or growth of tissue, not all such growths are neoplasia (Misdorp, 1990). In corals, examples of non-neoplastic masses include nodules or galls induced by crustacea (Abelson et al., 1991), algae (Morse et al., 1977; Goldberg et al., 1984), and fungi (Le CampionAlsumard et al., 1995).

Massive Porites growth anomalies (MPGAs) on reefs of the Philippines are variably sized lesions that appear anywhere on the colony and are recognized as distinct malformations of the corals tissue and underlying skeleton compared to the surrounding tissue. The affected tissue is paler than the surrounding tissue and tends to have a swollen appearance. Cheney (1975), Peters et al. (1986), Yamashiro et al. (2000), and Work et al. (2008) report that GAs in Acropora also have a swollen appearance. Massive Porites growth anomalies (MPGAs) with two distinct gross morphologies have been observed in the Philippines (Fig. 1). One ("type 1") forms skeletal protuberances, is rounded, and tends to have a well-delineated margin. The other ("type 2") tends to have very diffuse margins and does not form protuberances resulting from greater skeletal extension, although the soft tissue alone does tend to have a swollen appearance and the skeleton, like in type 1 , is deformed. Type 2 MPGAs are paler than type 1 and, unlike type 1 , frequently have sloughing tissues. MPGAs of both types can persist for years but sometimes develop loss of tissues associated with colonization by turf algae and can lead to whole colony death (Kaczmarsky, 2006).

A thorough knowledge of the normal histology of an animal is necessary before one can determine abnormal changes in cellular architecture (Sparks, 1993). Much 

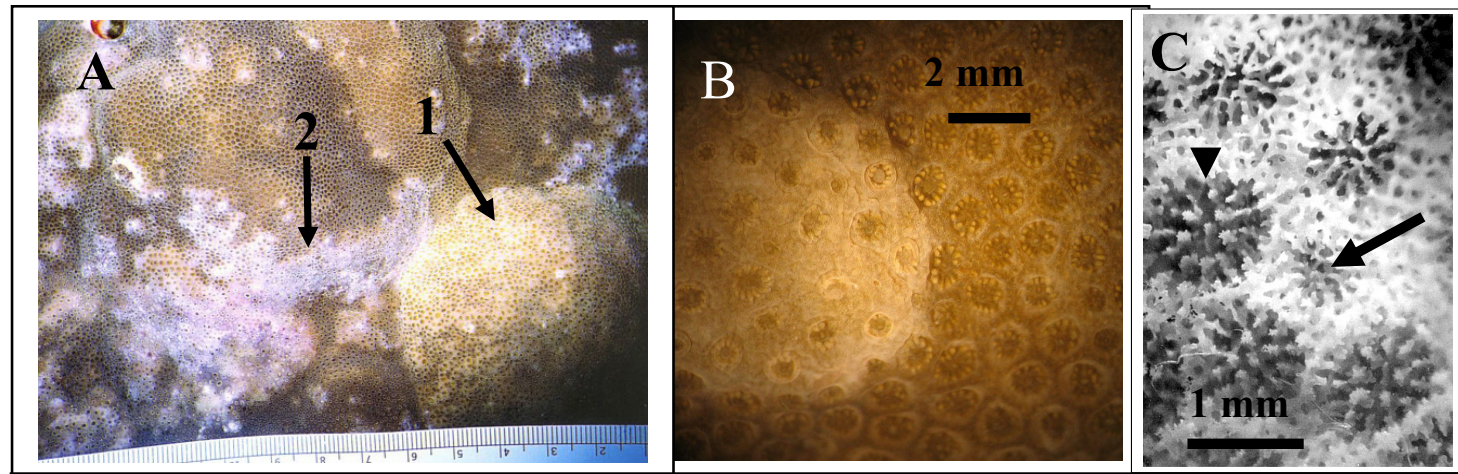

Fig. 1. Gross morphology of massive Porites growth anomalies (MPGAs). (A) MPGA in situ; types 1 and 2. (B) Early stage of a MPGA type 1 on living tissue. (C) Interface between an MPGA and normal tissue that contrasts the underlying MPGA skeleton that has deformed architecture (arrow) and normal skeleton formation (arrowhead).

histological work has been done to define normal cnidarian cell types and to describe normal scleractinian tissue (Muscatine, 1971; Muscatine and Lenhoff, 1974;

Vandermeulen, 1975; Hayes and Goreau, 1977; Isa and Yamazato, 1981; Bigger and Hildemann, 1982; Hundgen, 1984; Peters, 1984a; Fautin and Mariscal, 1991; Peters and Yevich, 2001). The goal of the current research was to characterize the tissues of type I and type II MPGA lesions of $P$. lutea in comparison to tissues of healthy colonies using histopathological methods.

\section{MATERIALS AND METHODS}

Sample site and collection

Sampling was conducted off the southeast coast of the island of Negros in the Philippines. Coral samples were collected at a depth of 1 meter from the fringing reef near the Dumaguete City airport close to the Silliman University Marine Laboratory (SUML). Using snorkel and SCUBA equipment, replicate samples of small whole Porites lutea colonies, approx. $15-20 \mathrm{~cm}$ in diameter, were collected. The samples included colonies with: (1) type 1 MPGAs, (2) type 2 MPGAs, and (3) no MPGAs (i.e., 
healthy reference samples). Colonies were transported in individual plastic bags to SUML within 10 minutes of their removal from the reef waters and placed in 4000-L flow-through shaded holding tanks. Since corals perform different cellular functions at night as opposed to day, comparisons of healthy and diseased tissues fixed both in day and night might better characterize an altered cellular structure than only day-fixed samples (Dr. E. Peters pers. comm.). Sub-samples (fragments) were prepared for histological comparisons as follows: MPGA type 1 (3 fixed at 12pm and 3 at 12am); MPGA type 2 (4 fixed at 12pm and 4 at 12am); non-diseased samples (3 fixed at 12pm and 3 at 12am). Day and night samples were from the same colonies.

\section{Histology preparations}

Small specimens (3-5 cm wide) of diseased and healthy $P$. lutea were fixed in commercially available Bouin's solution for $6 \mathrm{~h}$. Fragments were stored in $70 \%$ ethanol. Before decalcification, samples were trimmed to ca. 1-cm square pieces that included both sides of the disease interface using a disinfected ( $95 \%$ ethanol) table-top jeweler's wet saw with sterile artificial seawater. Decalcification was done in loosely capped labeled glass bottles containing $12.6 \%$ formic acid. Specimens were briefly rinsed in water to remove decalcification solution, dehydrated in graded ethanols, cleared in CitriSolv $^{\mathrm{TM}}$ and embedded in Paraplast. Using a rotary microtome, serial longitudinal sections $5.0 \mu \mathrm{m}$ thick were cut from blocks.

The following stains were utilized: Harris's hematoxylin and eosin (H\&E) for general comparative histology, Gram-Twort for detecting Gram-negative and Grampositive bacteria, Alcian Blue-Periodic Acid Schiff's (AB/PAS)(pH 2.5) for discerning acid and neutral mucopolysaccharides and fungi, and Fontana-Masson (FM) for detecting 
melanin-like substances (Lison, 1954; Pearse, 1968; Kiernan, 1990; Hunter, 1999, Walsh and Jass, 2000; Goldberg 2001; Nyholm et al., 2002; Peters et al., 2005; Peters and Price, 2005; Domart-Coulon et al., 2006; Mydlarz et al., 2008; Palmer et al., 2008). All tissues of the diseased coral (i.e., epidermis, gastrodermis, mesenteries, and calicodermis of the polyps and coenenchyme) were examined for differences with healthy $P$. lutea tissue.

\section{Quantitative assessments}

Average full tissue thickness was obtained by measuring the distances from the most oral to the most aboral extremes with measurements taken at the thinnest and thickest areas of each section. Average minima and maxima values were calculated using sections from replicate colonies (three healthy $P$. lutea, three with type 1 MPGAs, and four with type 2 MPGAs). These averages were statistically analyzed.

All estimates were based on measurements from all replicate colonies (approx. equally represented). Measurements of surface epidermis thickness were taken every 20 linear $\mu \mathrm{m}$, following the natural contour of the tissue (described in Domart-Coulon et al. 2006). For healthy tissue, 199 measurements were made from 50 haphazardly chosen sections covering 3,980 linear $\mu \mathrm{m}$. For type 1 lesions 355 measurements from 62 sections were made covering 7,100 linear $\mu \mathrm{m}$, and for type 2 lesions 308 measurements from 54 sections covering 6,160 linear $\mu \mathrm{m}$. Estimates of the basal body wall thickness, skeletal thickness (i.e., skeletal space left after decalcification), and basal gastrovascular canal diameters were based on taking measurements every 50 linear $\mu \mathrm{m}$ (measured following the natural contour of the tissue). For these parameters 332 measurements from 39 haphazardly chosen sections of healthy tissue covering 16,600 linear $\mu \mathrm{m}$ were made along with 245 measurements from 33 sections of type 1 lesions covering 12,250 linear 
$\mu \mathrm{m}$, and 342 measurements from 31 sections of type 2 lesions covering 17,100 linear $\mu \mathrm{m}$. In the most basal epithelia overlying the skeleton, thickness measurements of the basal body wall were taken every $50 \mu \mathrm{m}$.

Diameter of gastrovascular canals was measured in the tissue immediately adjacent to the most basal body wall and analyzed. Thickness of the most basal body wall and adjacent skeleton were measured and analyzed. Observations of cytological differences between healthy P. lutea and MPGAs tissues were described and recorded.

To detect changes in cell populations of zooxanthellae and chromophore cells, comparisons of cell densities were conducted by first counting cells in haphazardly chosen fields per tissue type at 400X magnification then statistically testing for significant differences using a one-way analysis of variance. Differences between diseased and healthy histological sections were described, classified, and interpreted according to the criteria within histopathology references (Kinne 1980, Kaiser 1981, Hundgen 1984, Peters 1984a and 1984b, Wilkerson et al. 1988, Fautin and Mariscal 1991, Couch and Fournie 1993, Peters 2001; Galloway et al., 2007). The microscope used for this project was a Leica Leitz DMRB (optical). See glossary and figure 2 for terminology and coral anatomy.

Density estimates of zooxanthellae and chromophore cells in the surface epithelia were determined using methods described in Domart-Coulon et al. (2006). Zooxanthella and chromophore cell densities were estimated by counting the number of cells in the surface epithelia along the oral and coenenchyme regions, following the natural contour of the surface tissue. Density estimates were based on cell counts from 65 haphazardly 


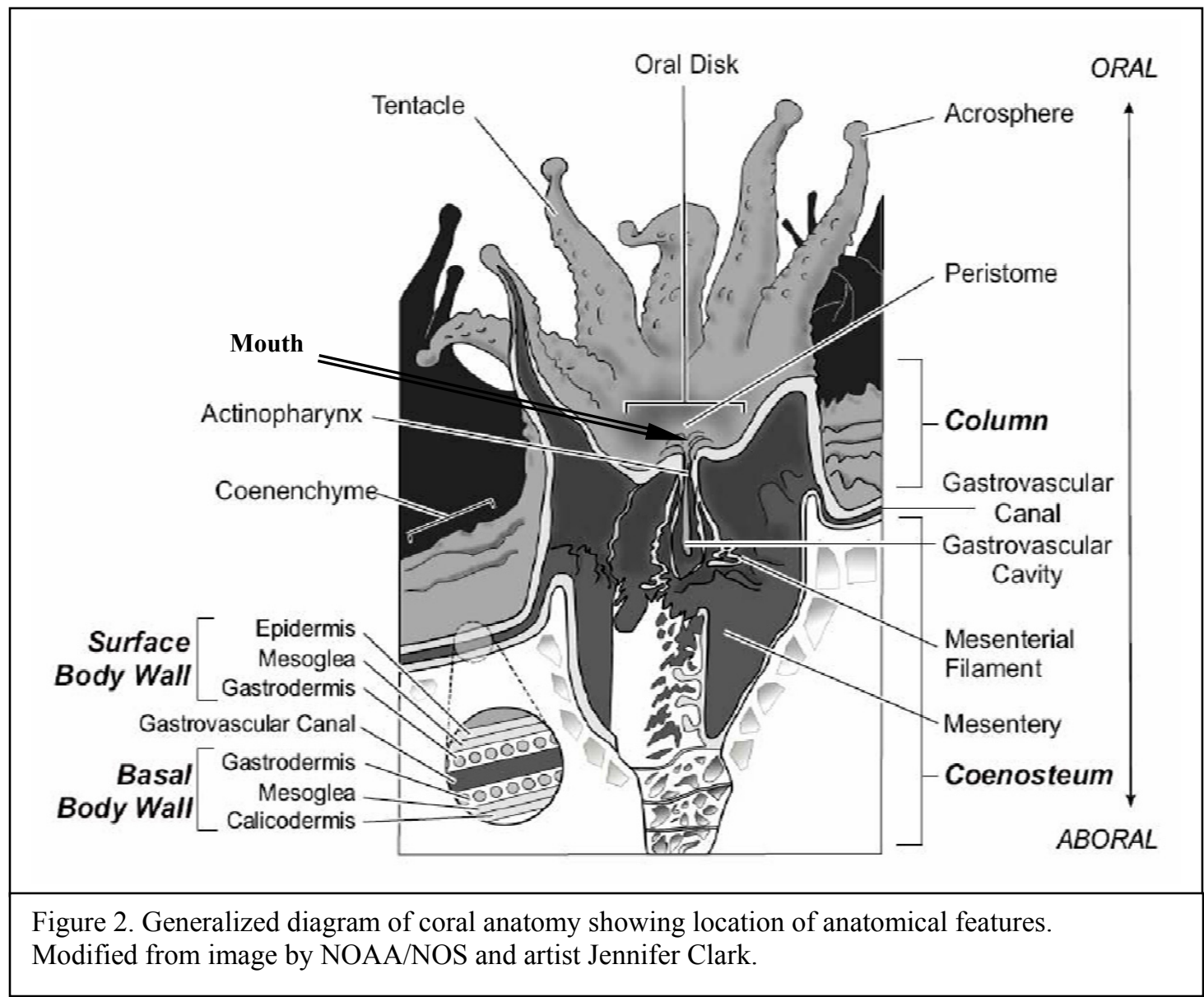

chosen sections of healthy tissue covering 18,147 linear $\mu \mathrm{m}$ (within the cut sections), 64 sections of type 1 lesions covering 16,904 linear $\mu \mathrm{m}$, and 60 sections of type 2 lesions covering 19,710 linear $\mu \mathrm{m}$. Estimates of density of chromophore cells in the most basal body wall were based on cell counts from 36 sections of healthy tissue covering 15,315 linear $\mu \mathrm{m}, 28$ sections of type 1 lesions covering 9,154 linear $\mu \mathrm{m}$, and 25 sections of type 2 lesions covering 14,069 linear $\mu \mathrm{m}$. Since microscopic examination of the chromophore cells suggested a potential association with zooxanthellae, paired data sets were gathered from each section examined to quantitatively assess this proposed propensity. 


\section{Statistical analyses}

For each tissue section both the density of zooxanthellae and chromophore cells were determined, plotted, and statistically tested using Pearson's product moment correlation (SigmaStat ver. 3.5). The coefficient of determination was then calculated for the strength of the relationship if significant correlations were detected.

When multiple data sets were tested and were normally distributed with homogeneous variances a one-way analysis of variance (ANOVA) was used. When the data did not pass tests for normality or did not have homogeneity of variances for a one-way ANOVA, a non-parametric Kruskal-Wallis one-way analysis of variance on ranks was used. When significant differences were detected among treatment means, the difference between each of the groups was tested using the Dunn's post hoc test. Data are reported as means \pm standard deviation. When not normally distributed they are reported as median values. When comparing paired sets of data t-tests were used, and if data were not normally distributed and/or did not have homogeneous variances and could not be successfully transformed, the non-parametric Mann-Whitney U-test was employed.

\section{RESULTS}

Alterations in overall thickness of Porites lutea affected by MPGAs

The thickness of $P$. lutea within type 1 lesions was on average $39 \%$ thicker than healthy tissue $(3.8 \pm 0.57 \mathrm{~mm}$ vs. $2.7 \pm 0.41 \mathrm{~mm} ; \mathrm{P}<0.05$, t-test) (Table 1, Fig. $3 \mathrm{~A}$ and 3C). There was no significant difference between the maximum thickness of type 2 lesions and healthy $P$. lutea $(2.8 \pm 0.62 \mathrm{~mm}$ vs. $2.7 \pm 0.41 \mathrm{~mm} ; \mathrm{P}>0.05$, t-test $)$. Based on 
measures of minimum thickness the areas in type 1 lesions immediately surrounding the lesion were $30 \%$ thinner than healthy tissue $(1.9 \mathrm{~mm}$ vs. $2.7 \mathrm{~mm}$; $\mathrm{P}<0.02$, t-test. Note: to avoid a type 2 error, non-normal data in this case were successfully transformed using

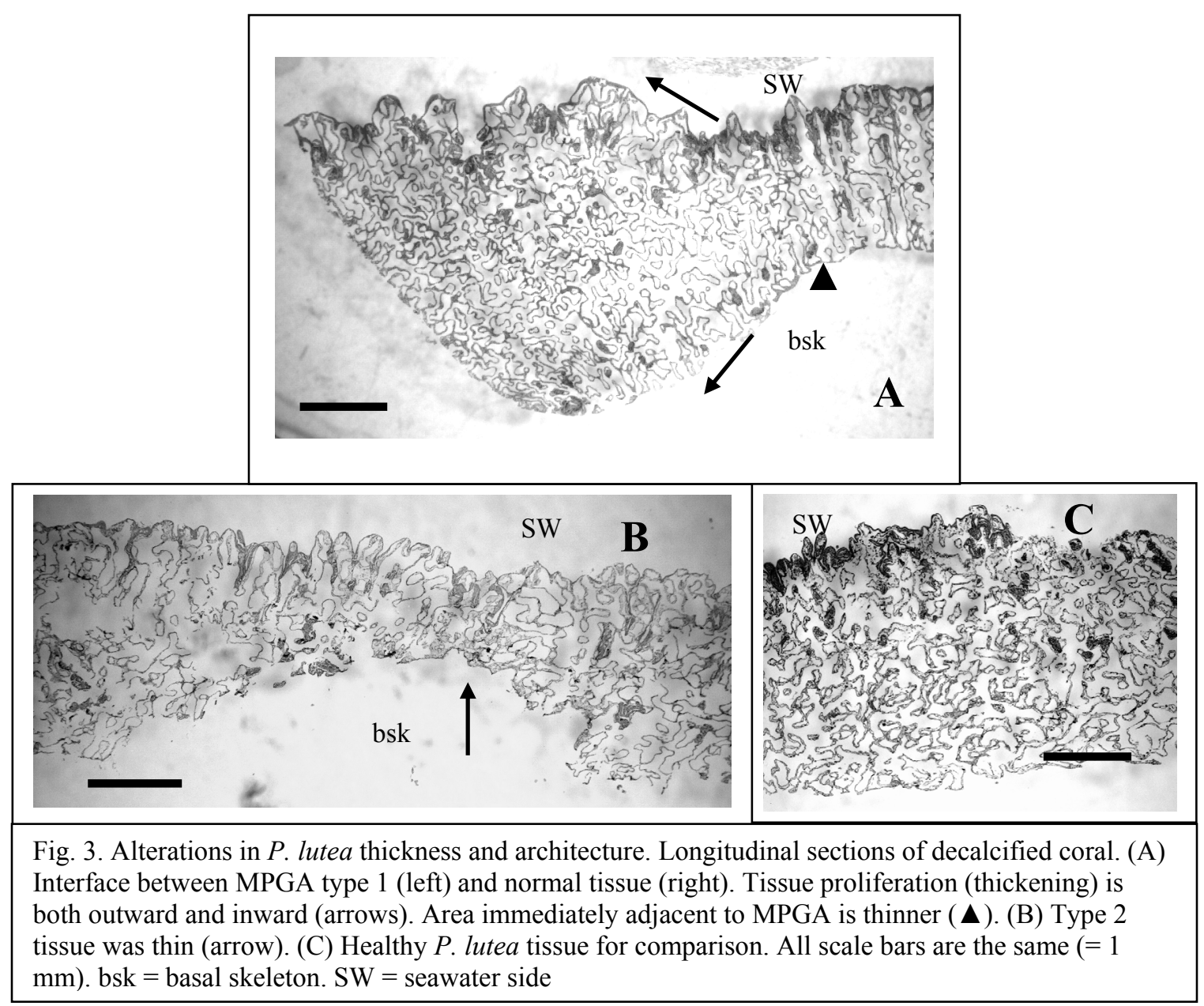

natural $\log$ ). Minimum thickness measures within type 2 MPGA lesions were $68 \%$ thinner than healthy tissue $(0.9 \pm 0.46$ vs. $2.7 \pm 0.41 \mathrm{~mm} ; \mathrm{P}<0.005$, t-test $)$.

Tissues with type 1 lesions were almost always seen as proliferative (thickening) in both outward and inward directions (Fig. 3A). Proliferation in type 1 lesions included an increase in gastrovascular canals and skeleton, with pronounced variability in widths of gastrovascular canals and skeletal spaces (presumed to correspond with skeletal 
structures) compared to the healthy $P$. lutea. These observations resemble descriptions of cellular proliferation in GAs of other coral species (e.g., Peters et al., 1986). In contrast to type 1 lesions, tissues of type 2 lesions were much thinner than healthy P. lutea (Fig. 3B and 3C). As in type 1 lesions, dimensions of gastrovascular canals and skeletal spaces in type 2 lesions within the MPGA lesions were more varied than in healthy P. lutea. Healthy P. lutea had more uniform tissue and skeletal dimensions (Fig. 3C) than the MPGAs. When compared to healthy $P$. lutea, tissues of type 1 MPGAs were significantly thicker, with the area immediately surrounding the MPGA significantly thinner. On average the tissues of type 2 MPGAs were significantly thinner than those of healthy $P$. lutea.

Alterations in the thickness of the surface epidermis associated with MPGAs

The epidermis of type 1 lesions was $73 \%$ thicker than in healthy P. lutea (19.0 vs. $11.0 \mu \mathrm{m}$; median values, $\mathrm{P} \leq 0.001$, Mann-Whitney U-test). Type 2 was $36 \%$ thicker than healthy P. lutea (19.0 vs. $15.0 \mu \mathrm{m} ; \mathrm{P} \leq 0.001 ;$ Mann-Whitney U-test). There was no significant difference between the thickness of the epidermis of types 1 and $2(\mathrm{P}>0.05)$. However, in type 2 MPGAs there were more areas of epidermis greater than $40 \mu \mathrm{m}$ thick and more areas that were completely absent than in type 1 MPGAs.

Typical alterations in the thickness of epidermis associated with MPGAs involved hypertrophied mucocytes in the layers of gastrodermis (Fig. 4C) that very commonly swelled inwardly, appearing to constrict flow through the gastrovascular canals. In addition, hypertrophied mucocytes pushed outwardly, against underlying skeleton, distending and distorting the surface epidermis above. This appeared to be responsible for the thinning of the overlying epidermis of type I lesions as well as the swollen gross 
appearance and lysis of epidermis. Figure 4 shows a significantly thicker epidermis and

gastrodermis in type 1 lesions as compared to healthy $P$. lutea.

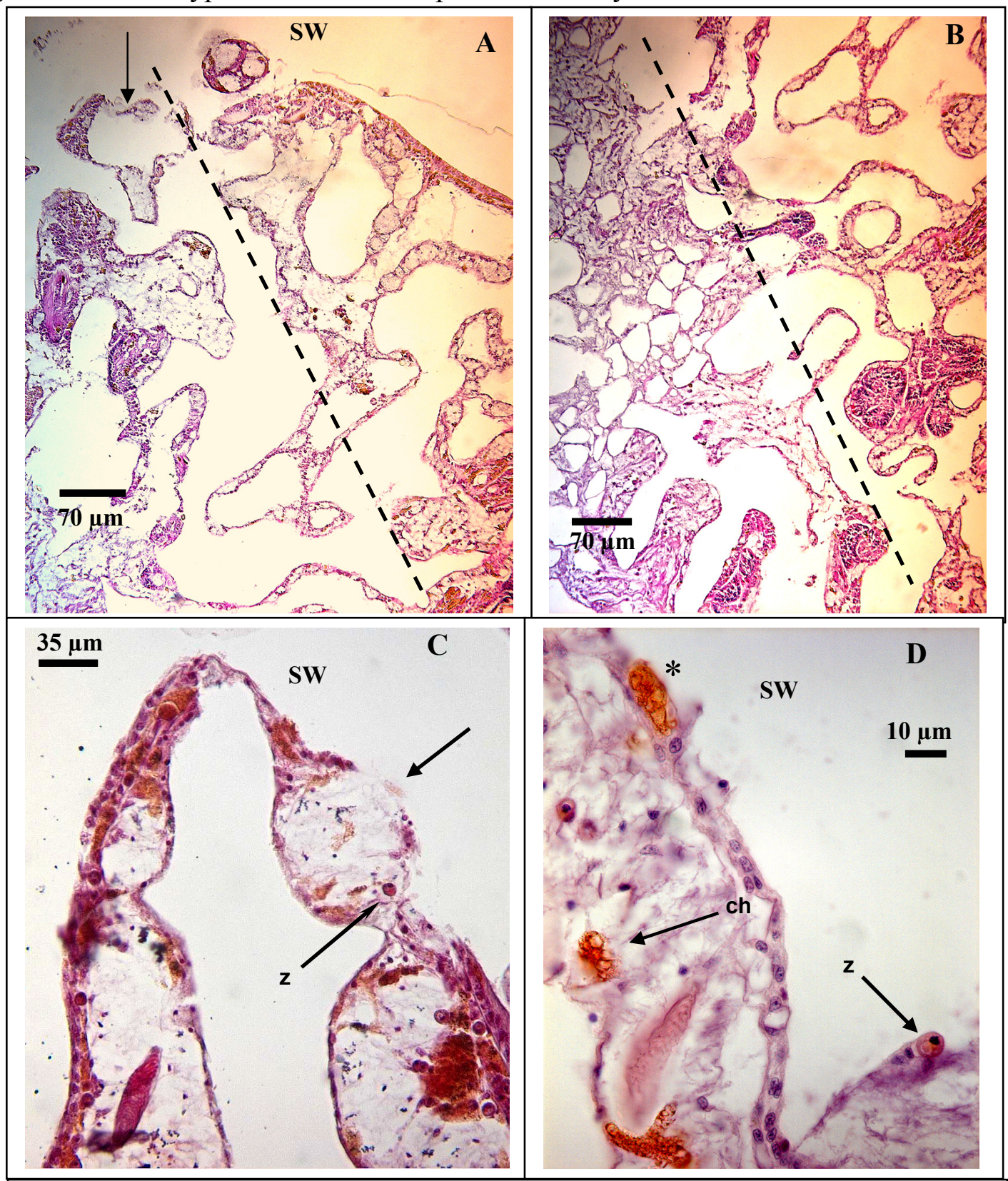

Fig. 4. (A and B) Major tissue alterations at the interface between MPGAs and apparently normal P. lutea. (A) Interface near the surface epithelia between type 1 MPGA (left of dashed line) and apparently normal tissue (to the right). Degraded surface epithelia (arrow) (B) Type 1 MPGA with necrosis (left of dashed line). (C and D) Alterations in zooxanthella (z) densities and thickness of epidermis (arrow) associated with MPGAs. (C) Type 1 MPGA with hypertrophied mucocytes in the gastrodermis. (D) In type 2 MPGAs, surface epidermis was attenuated or absent and few zooxanthellae (arrow) were present. Chromophore cells (ch) contained numerous transparent granules (i.e., granules contained little or no melanin-like substance) but still appeared to form wound-healing plugs $\left({ }^{*}\right)$. 
Alterations in the thickness of the most basal body wall associated with MPGAs

The thickness of the most basal body wall (or epithelia) of healthy, type 1, and type 2 tissues were not significantly different $(17.0 \mu \mathrm{m}$ vs. 18.0 vs. 17.0 , respectively; median values, $\mathrm{P}>0.05$ ). The most basal body wall thickness was slightly more variable in both types than in healthy $P$. lutea.

Very attenuated $(<2 \mu \mathrm{m}$ thick) and hypertrophied ( $>14 \mu \mathrm{m}$ thick) calicodermal cells were observed in close proximity to one another in type 2 lesions (Fig. 5). This pattern was not seen in healthy P. lutea or type 1 MPGAs.

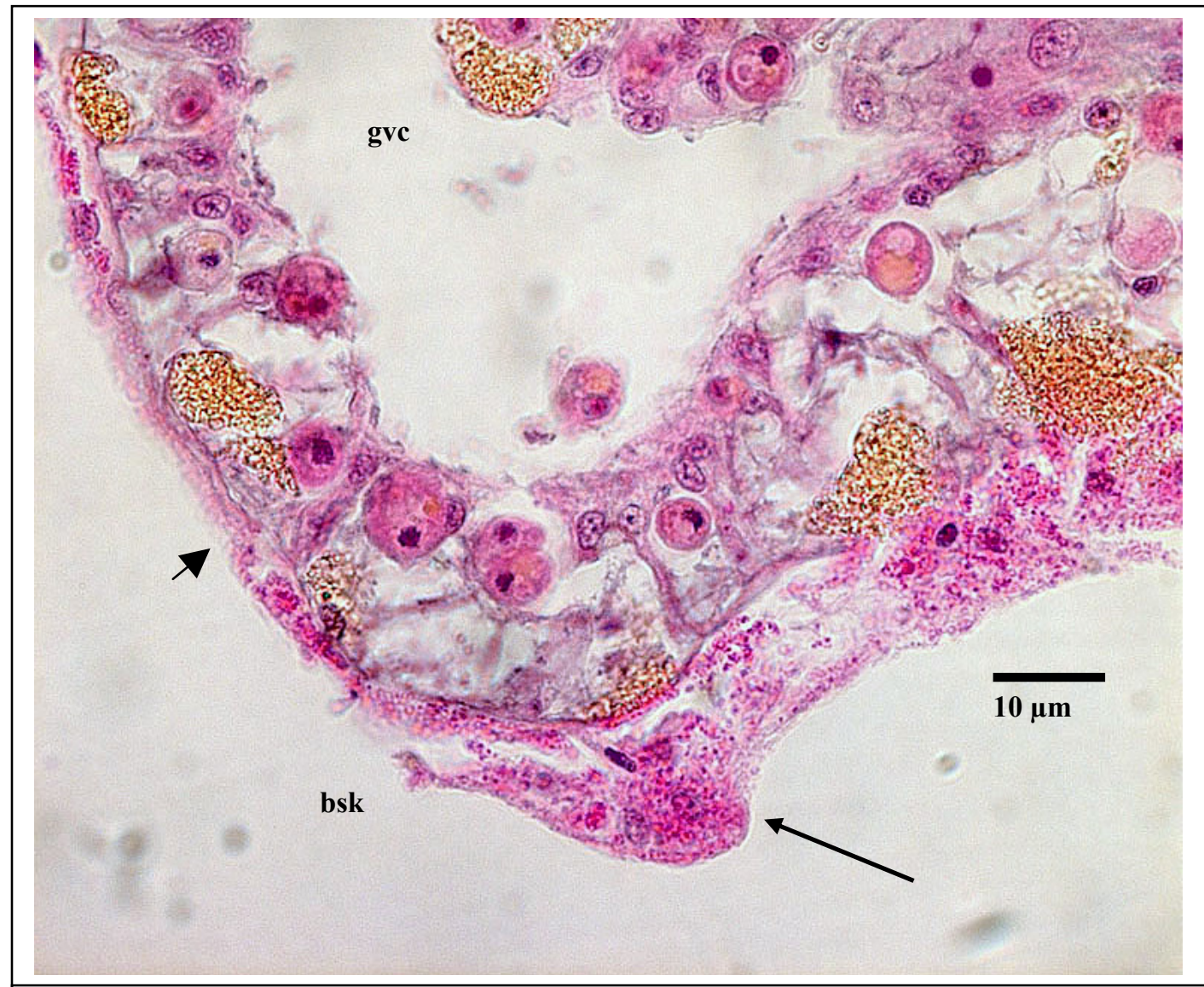

Fig. 5. Type 2 lesion with both attenuated ( $2 \mu \mathrm{m}$ thick, $\nabla)$ and hypertrophied (14 $\mu \mathrm{m}$ thick, arrow) calicodermal cells. H \& E, 1000X. gvc = gastrovascular cavity. bsk = basal skeleton. 
In healthy P. lutea (Fig. 6A), the most basal body wall and adjacent gastrovascular canals and skeleton were fairly uniform in thickness with few chromophore cells. In contrast, in type 1 lesions (Fig. 6B) these dimensions were highly variable, which included areas devoid of epithelia layers (as was seen in type 2 lesions).

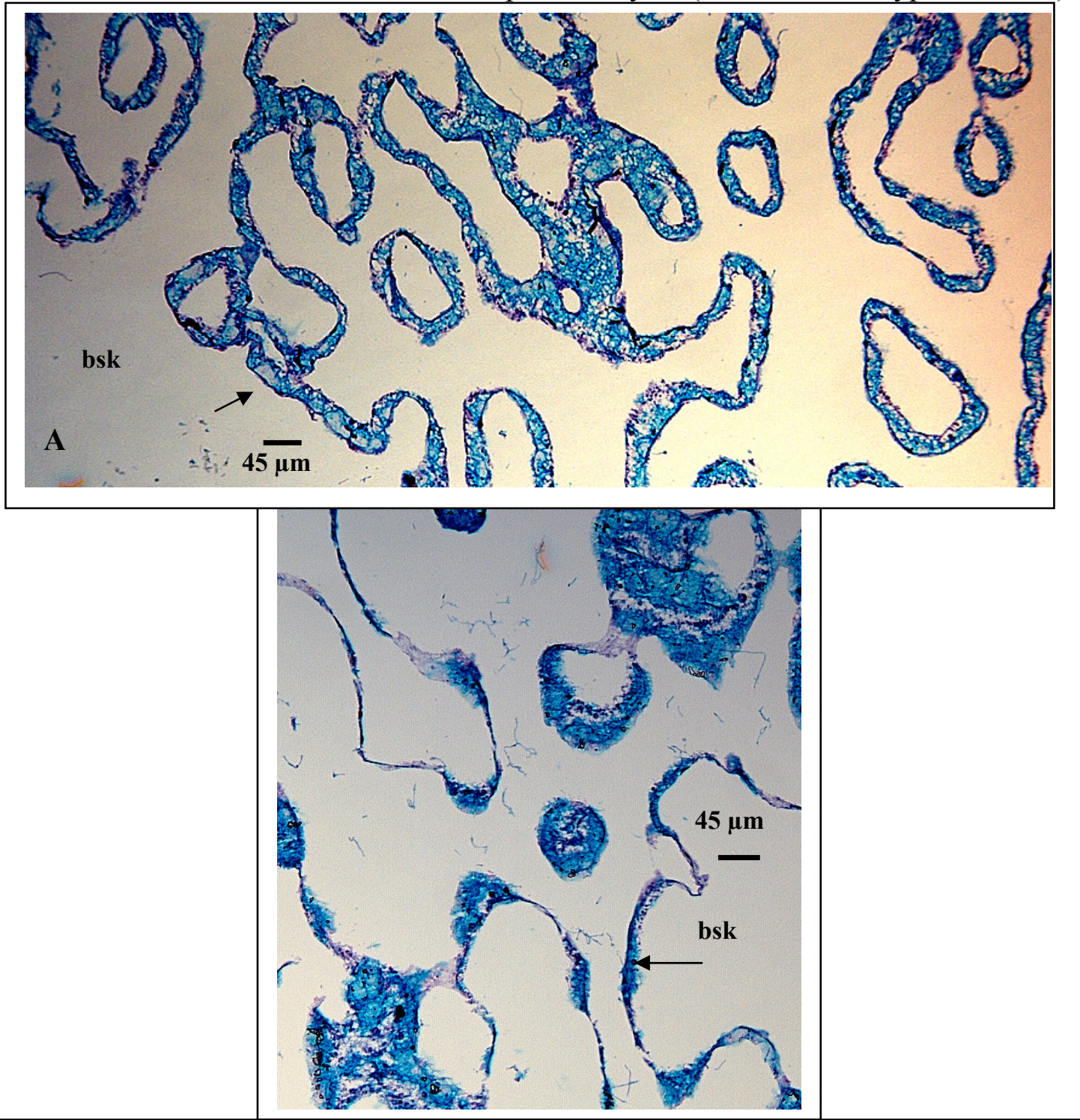

Fig. 6. Alterations in the basal tissue regions in association with MPGAs. In healthy P. lutea (A) the basal epithelia (arrow) and adjacent gastrovascular canals and skeleton were fairly uniform in thickness. In type 1 MPGAs (B) as well as type 2 the epithelia dimensions (arrow) were more variable than in healthy $P$. lutea. Gastrovascular canals and skeletal spaces were also more variable than in healthy tissue. $\mathrm{AB} / \mathrm{PAS} \mathrm{pH} 2.5$. 
Alterations in zooxanthella densities of the surface epithelia associated with MPGAs

There were significantly lower overall densities of zooxanthellae in MPGAs. In type 1 lesions zooxanthella density in the oral region was $43 \%$ lower than in healthy P. lutea ( 4.0 vs. 7.0 cells $/ 100 \mu \mathrm{m})$ and in the coenenchyme $64 \%$ lower ( 2.0 vs. 5.5 cells $/ 100 \mu \mathrm{m}$ ) (both $\mathrm{P} \leq 0.001$, Mann-Whitney U-test). In type 2 lesions density in the oral region was $29 \%$ lower than in healthy tissue ( 5.0 vs. 7.0 cells $/ 100 \mu \mathrm{m} ; \mathrm{P}<0.05$, MW U-test) and in the coenenchyme was also $64 \%$ lower than in healthy tissue (2.0 vs 5.5 cells/100 $\mu \mathrm{m} ; \mathrm{P} \leq 0.001$ cells/100 $\mu \mathrm{m}, \mathrm{M}-\mathrm{W}$ U-test).

In healthy $P$. lutea the density of zooxanthellae in the oral region of the surface epithelium was not significantly different than in the healthy coenenchyme (7.0 vs. 5.5 cells $/ 100 \mu \mathrm{m})$. However, in type 1 lesions density was significantly higher (2-fold) in the oral region than in the coenenchyme ( 4.0 vs. 2.0 cells $/ 100 \mu \mathrm{m}, \mathrm{P}<0.05 ; \mathrm{M}-\mathrm{W}$ U-test). In type 2 lesions density in the oral region was also significantly higher (2.5 times) than the coenenchyme (5.0 vs. 2.0 cells $/ 100 \mu \mathrm{m}, \mathrm{P} \leq 0.001 ; \mathrm{M}$-W U-test). There were no significant differences in zooxanthella densities between types 1 and 2 lesions.

Beginning at the lesions edges (Fig. 4A and B) a breakdown in normal tissue architecture was consistently associated with a decrease in zooxanthellae densities. Figure 7A and B show the surface epithelia of healthy P. lutea in the (A) oral and (B) coenenchyme regions, which had significantly more zooxanthellae than both types of MPGA lesions (Fig. 7C, D, and E) as well as significantly more chromophore cells than type 1 lesions and, in contrast, a uniform thickness of the epidermis. 

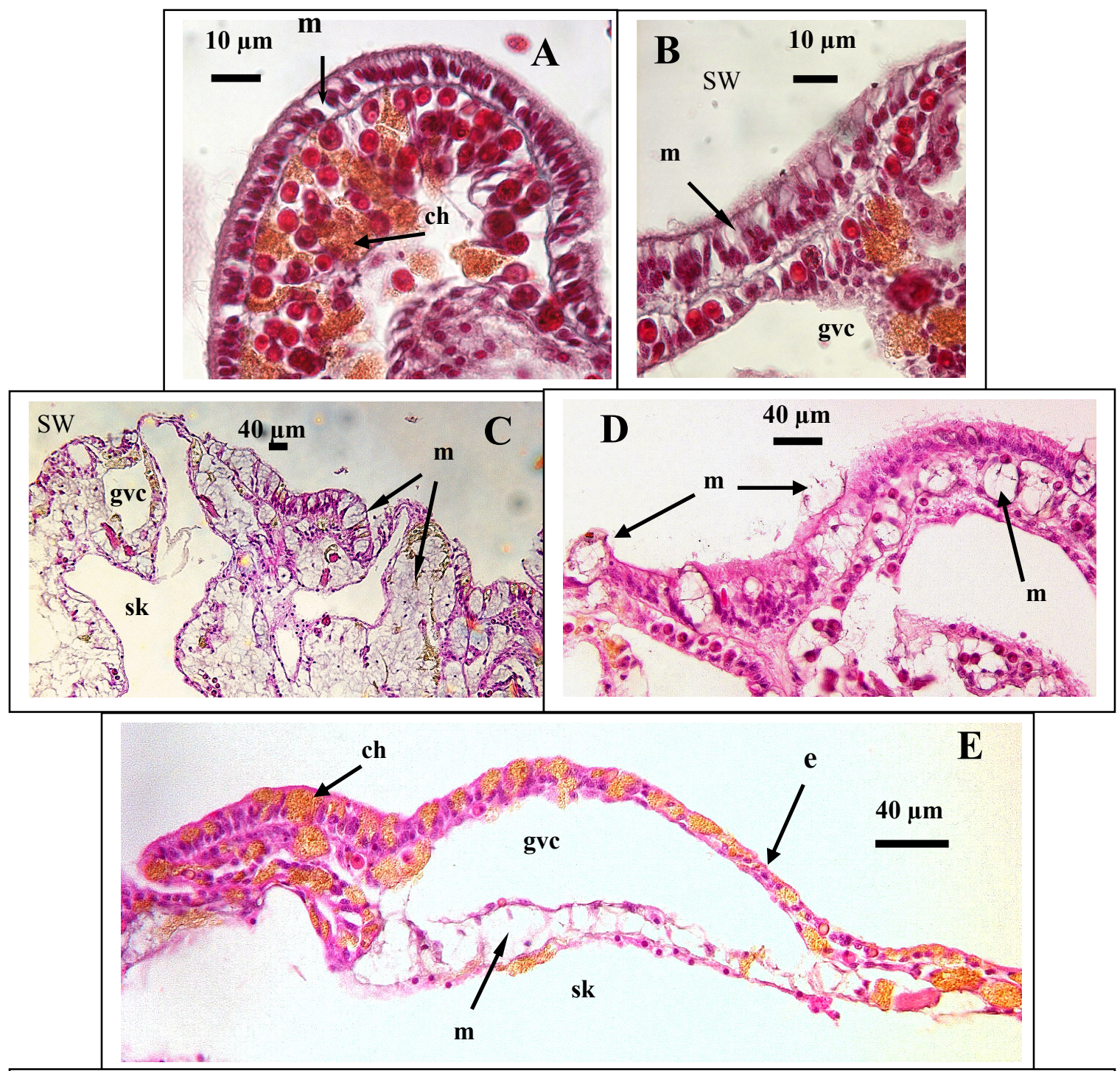

Fig. 7. Alterations in the surface epithelia associated with MPGAs. (A) Typical oral and (B) coenenchyme regions of healthy $P$. lutea had a more uniform thickness of the epidermal (e) tissue layer, and many more zooxanthellae and chromophore cells (ch) than type 1 lesions. (C) Type 1 MPGA lesions had abnormally and irregularly thickened epidermis and gastrodermis that contained many hypertophied mucocytes $(\mathrm{m})$ and fewer zooxanthellae or chromophore cells compared to healthy $P$. lutea. (D) Detail of type 1 lesion showing hypertrophied and lysed mucocytes (arrows). (E) In type 2 lesions the surface epidermis and gastrodermis were more frequently attenuated (arrow) or absent than in type 1 . Also in contrast with type 1, chromophore cells (ch) were often abundant, especially at night. $\mathrm{gvc}=$ gastrovascular canal. $\mathrm{sk}=$ skeletal space. $\mathrm{SW}=$ seawater.

Figure 4C shows the surface epithelia of a typical type 1 lesion with few zooxanthellae or chromophore cells. Figure 4D shows the surface epithelia of a typical type 2 lesion also with few zooxanthellae. In the oral regions of type 1 lesions (Fig. 7D) there was a 
lower density of zooxanthellae and many hypertrophied and lysed mucocytes in contrast to that seen in healthy tissue.

Alterations in the diameters of the basal gastrovascular canals associated with MPGAs

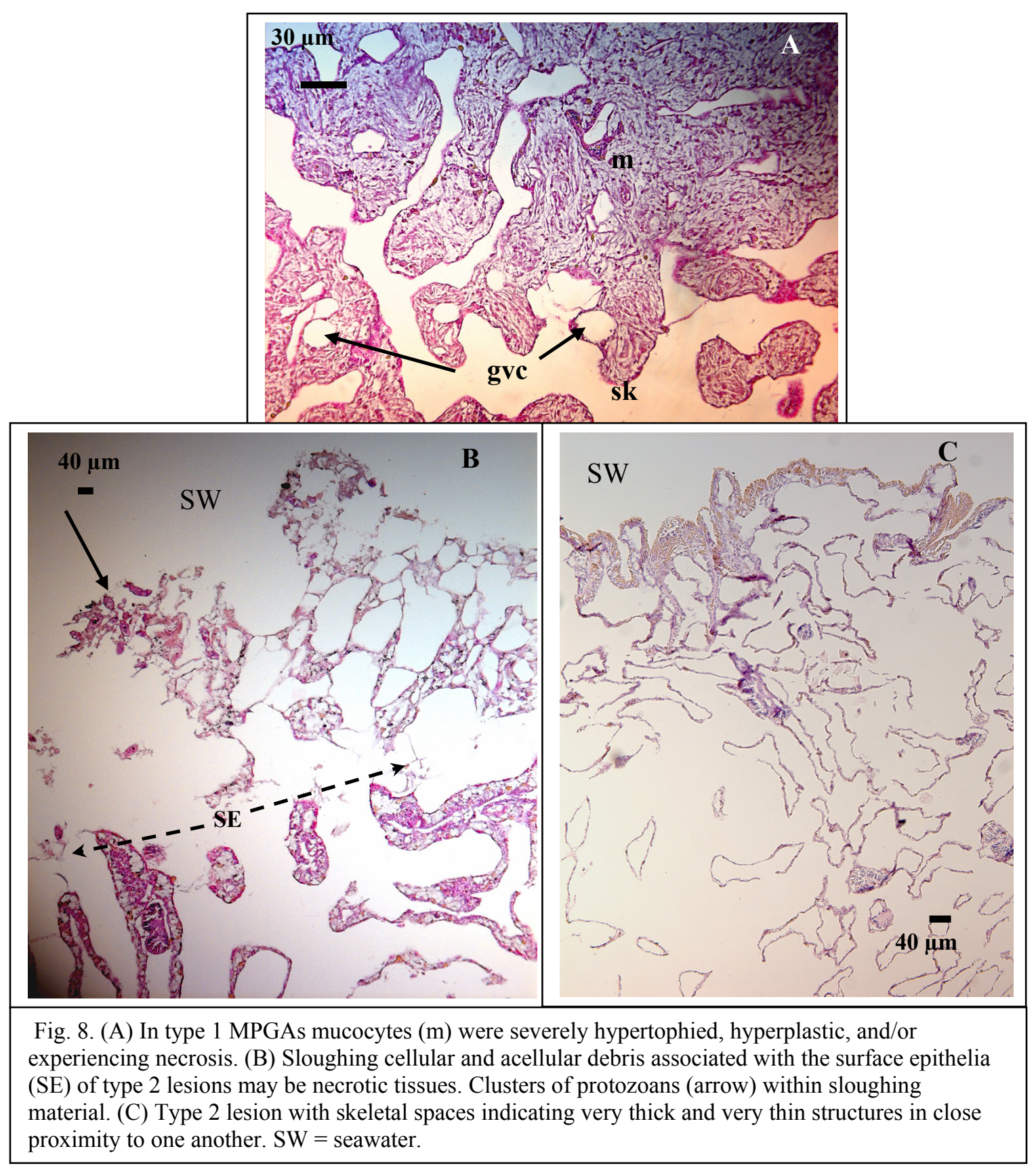


The diameters of the most basal gastrovascular canals in type 2 lesions were $29 \%$ wider than in healthy tissue $(45.0 \mu \mathrm{m}$ vs. $35.0 \mu \mathrm{m}$; median values, $\mathrm{P} \leq 0.001$, KruskalWallis ANOVA \& Dunn's test). There was no significant difference between type 1 lesions and healthy P. lutea. The most basal gastrovascular canals in MPGA lesions had a greater variability in the widths than healthy $P$. lutea and there were many more canals with very large diameters in type 2 lesions.

Large areas of abnormally swollen mucocytes in the gastrodermis, necrotic tissue, and cell debris were observed frequently within MPGA lesions (Fig. 4, 7C, and 8A) and appeared to reduce the size of adjacent gastrovascular canals (GVCs), which exhibited extreme variation in size (Fig. 4, 7C, and 8). In these areas GVCs tended to be reduced in diameter in upper (more oral) regions of lesions and were usually adjacent to abnormally shaped skeletal spaces (Fig. 8C). The width and shape of GVCs and skeletal spaces were much more variable in MPGAs than in healthy tissue (Fig. 6 and 8).

Alterations in the thickness of the skeletal space surrounding the most basal tissue layers associated with MPGAs

The thickness of skeletal space surrounding the most basal tissue layers in type 1 lesions was $29 \%$ thicker than in healthy tissue and in type 2 was $41 \%$ thicker $(55.0 \mu \mathrm{m}$ and $60.0 \mu \mathrm{m}$ vs. $42.5 \mu \mathrm{m}$ respectively; median values, both $\mathrm{P} \leq 0.001$, Kruskal-Wallis ANOVA \& Dunn's). The thickness of the skeletal space surrounding the most basal tissue layers was greater in MPGA lesions compared to healthy $P$. lutea. Alterations in chromophore cell densities and distribution in the surface epithelia associated with MPGAs - day versus night patterns

Figure 9 compares chromophore cell distribution patterns of tissues in healthy $P$. 


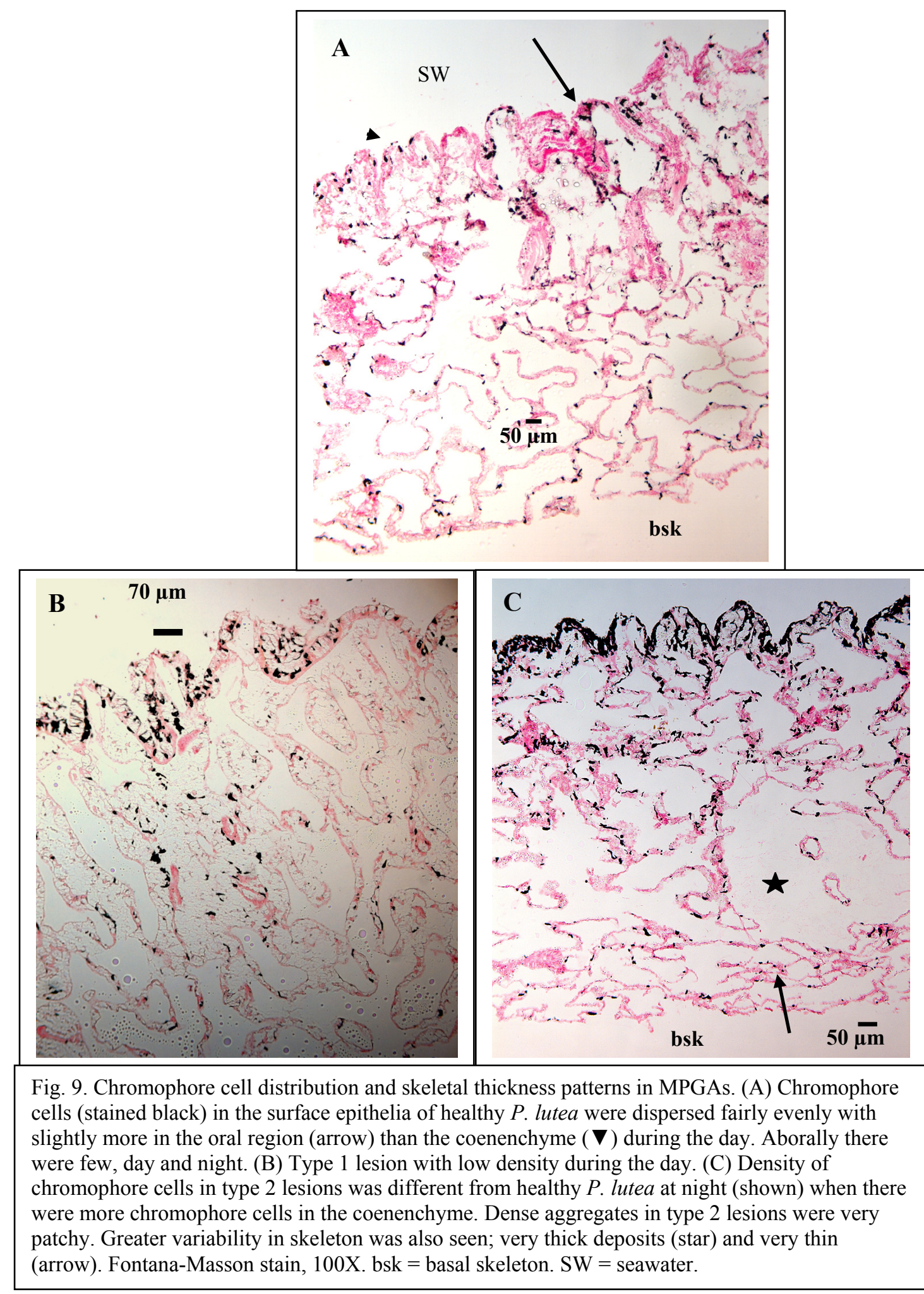


lutea (Fig. 9A), type 1 (Fig. 9B), and type 2 (Fig. 9C). Using pooled data (i.e., samples from oral and coenochyme regions and day and night), type 2 lesions had three times more chromophore cells than type 1 lesions ( 3.9 vs. 1.3 cells/100 $\mu \mathrm{m} ; \mathrm{P}<0.05$, KruskalWallis ANOVA \& Dunn's). Chromophore cell density data, without separating night and day data or coenenchyme and oral data (i.e., pooled simply to determine general differences between healthy $P$. lutea and MPGAs) revealed that type 1 lesions had 53\% fewer chromophore cells in the surface epithelia than healthy P. lutea (1.3 vs. 2.8 cells $/ 100 \mu \mathrm{m} ; \mathrm{P}<0.05$, Kruskal-Wallis ANOVA \& Dunn's test). There was no significant difference in pooled data between chromophore cell density in type 2 lesions and healthy tissue. Figure 9 also contrasts the more uniform skeletal formation in healthy P. lutea (Fig. 9A) with the variability in skeletal thickness seen in type 2 lesions (Fig. 9C).

With pooled day and night data, comparing samples from the oral tissue with the coenenchyme, type 1 lesions had 50\% fewer chromophore cells in the oral region than healthy P. lutea ( 2.0 vs. 4.0 cells $/ 100 \mu \mathrm{m} ; \mathrm{P} \leq 0.005$; Mann-Whitney U-test;). Type 2 lesions had twice as many chromophore cells in the coenenchyme than healthy $P$. lutea (4.0 vs. 2.0 cells $/ 100 \mu \mathrm{m} ; \mathrm{P} \leq 0.01$; Mann-Whitney U-test). There were no significant differences between densities in the type 1 coenenchyme and healthy $P$. lutea or between the type 2 oral region and healthy tissue.

Assessing and comparing chromophore cell densities from different tissue areas based on when the samples were collected and fixed (12 pm or $12 \mathrm{am}$ ) revealed more distinctive patterns of alterations associated with MPGAs. With pooled oral and coenenchyme data to show day vs. night differences, type 1 lesions had $72 \%$ fewer 
chromophore cells in the surface epithelia during the day than healthy P. lutea ( 0.7 vs. 2.5 cells $/ 100 \mu \mathrm{m} ; \mathrm{P} \leq 0.001 ;$ Mann-Whitney U-test).

Type 2 lesions had 1.5 times more chromophore cells in the surface epithelia during the night than healthy tissue ( 4.5 vs. 3.0 cells $/ 100 \mu \mathrm{m} ; \mathrm{P} \leq 0.005$; Mann-Whitney U-test; Fig. 10). There were no significant differences between the chromophore cell densities in type 1 lesions during the night and healthy $P$. lutea nor type 2 lesions during the day and healthy tissue.

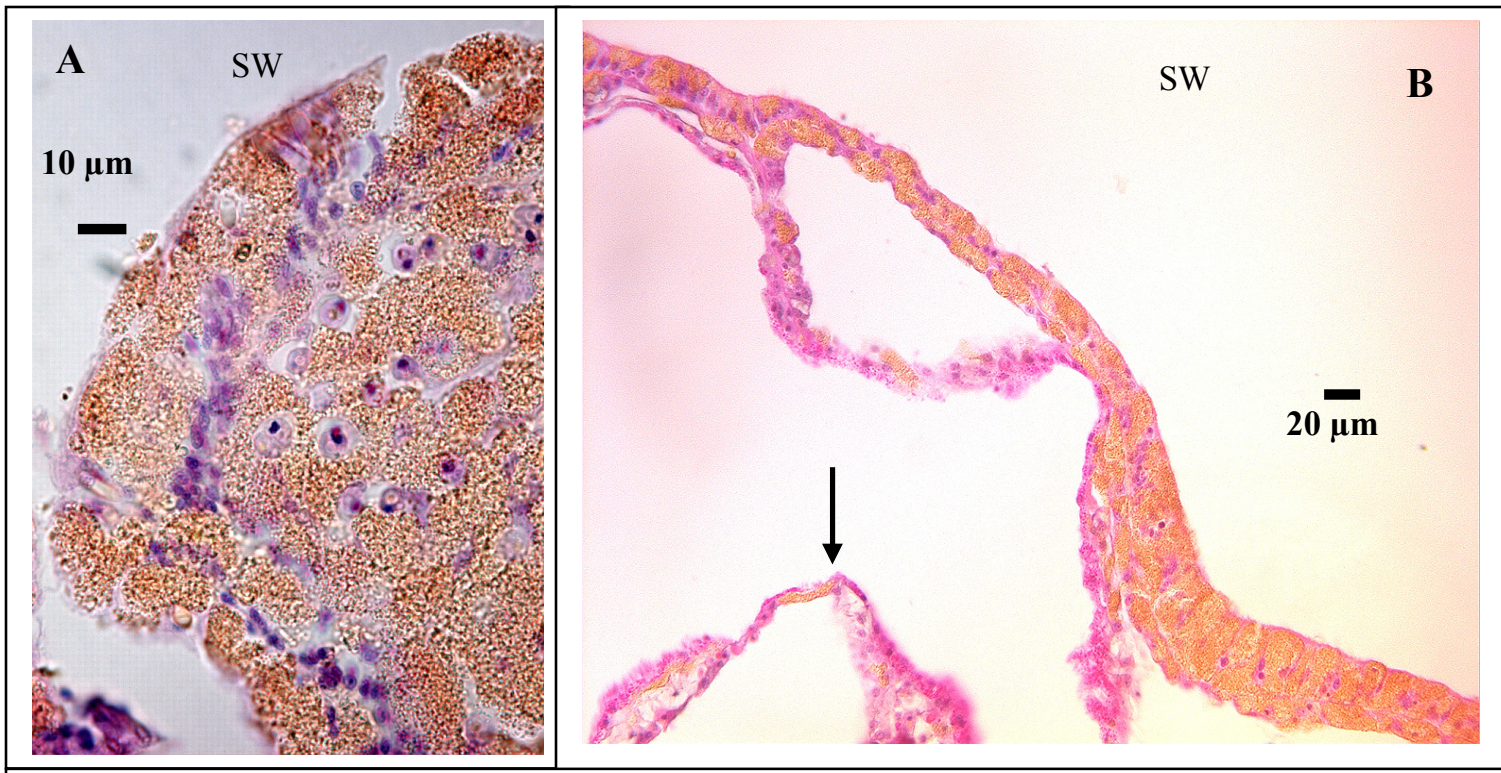

Fig. 10 (A) Type 2 MPGA lesion at night. Oral disk area contained massive aggregation of chromophore cells in epidermis and gastrodermis. (B) Type 2 MPGA at night. The outer epithelia is badly eroded (gastrodermis is almost non-existent) and chromophore cells appeared to infiltrate en masse in closely packed aggregations. (B) also shows chromophore cells playing a role in woundhealing in calicodermis as evidenced by the "plugging" of breaches in the tissue-skeleton barrier (arrow). $\mathrm{H} \& \mathrm{E}$ stain, $1000 \mathrm{X}$. SW = seawater. gvc = gastrovascular cavity. bsk = basal skeleton.

In healthy $P$. lutea surface tissues, chromophore cells often formed dense aggregates in the gastrodermis (Fig. 11A). Only rarely did they do so in the surface epidermis and only where there was apparent damage, as can be seen in Fig. 11A. In the gastrodermis chromophore cells were often observed surrounding zooxanthellae. In contrast, chromophore cells in the type 2 lesions (Fig. 11B) appeared to infiltrate the 


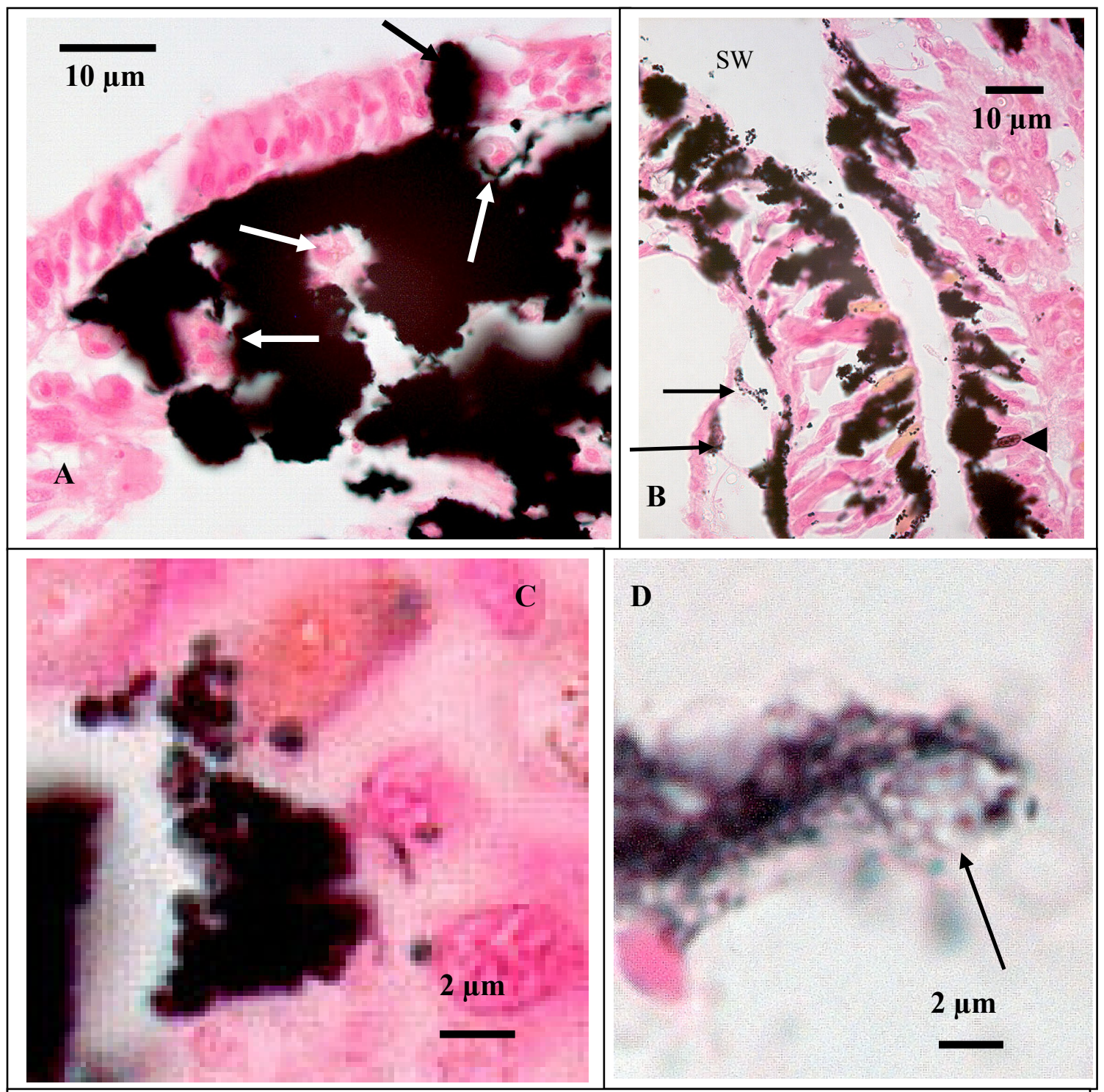

Fig. 11. Representative images showing alterations in chromophore cells in association with MPGAs. Granules densely packed within chromophore cells contained a melanin-like substance (black). (A) Chromophore cells in healthy $P$. lutea formed dense aggregates in the gastrodermis; only rarely in the surface epidermis (black arrow), where there was damage. In the gastrodermis they were seen surrounding zooxanthellae (white arrows). (B) In contrast, chromophore cells in the type 2 lesions appeared to regularly infiltrate the surface epidermis, especially at night and into vacuolated, degraded tissues, or where tissue was absent. De-granulating chromophore cells with the granules coating cell debris and cnidocytes (arrows). Epidermal nucleus coated with melanin-like substance ( $)$. (C) In healthy P. lutea chromophore cell granules stained very darkly suggesting that the granules were rich in melanin-like substance. Chromophore cell granules in type 2 lesions (D) were often weakly stained suggesting their contents were depleted. Fontana-Mason stain, 1000X. SW = seawater. 


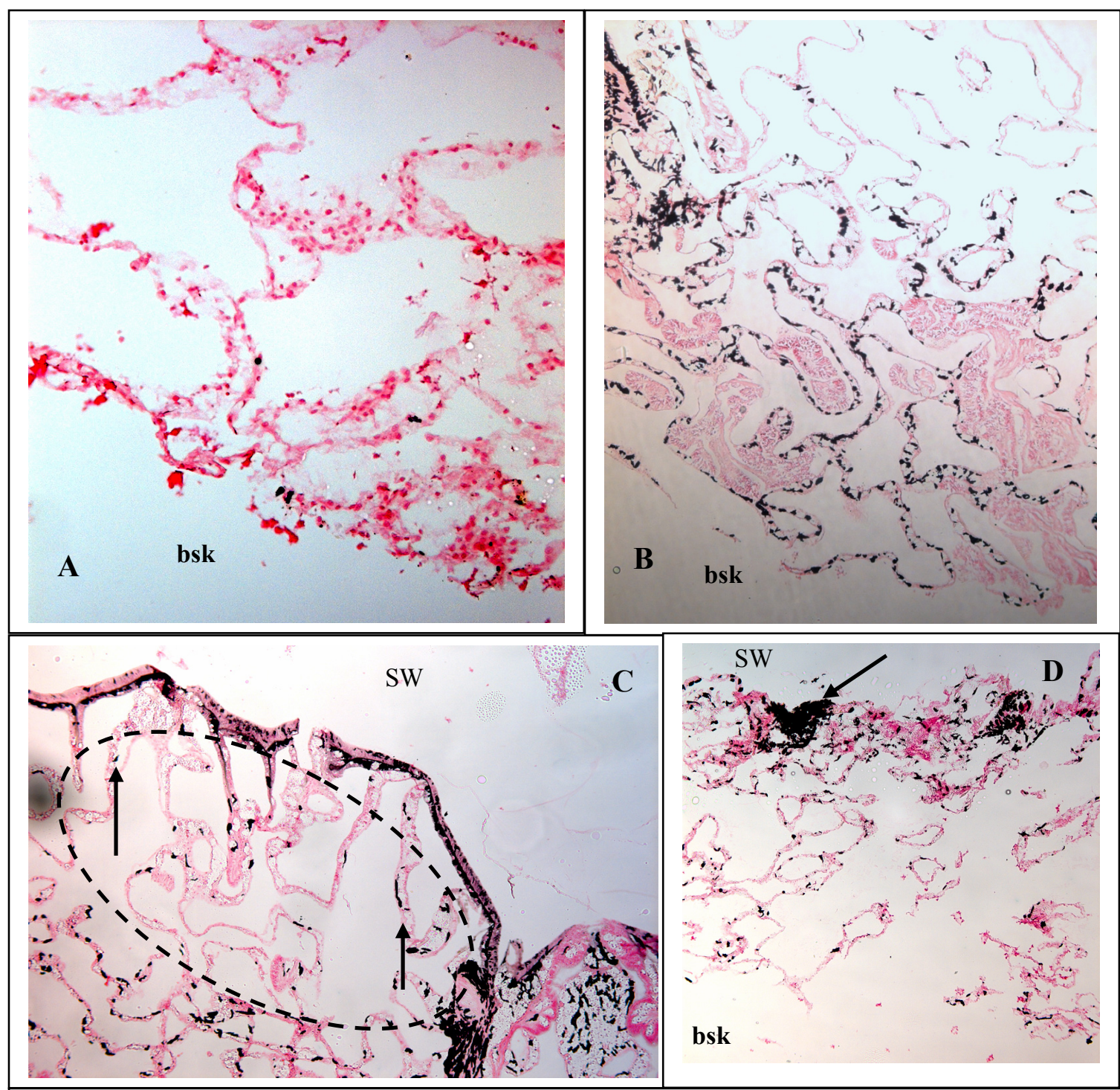

Fig. 12. Alterations in chromophore cell behavior in association with type 1 MPGA. (A) Type 1 lesion during the day with few chromophore cells (black) in the calicodermis. (B) Type 1 lesion at night with higher chromophore cell density in the calicodermis. (C) Type 1 lesion at night. Chromophore cells appeared to migrate (arrow) into the surface epithelia at night from adjacent areas, indicated by low density or absence in adjacent areas (area within dashed line). (D) Type 2 lesion at night. Chromophore cells were densely aggregated (arrow) in the surface epidermis. F-M stain. SW = seawater. 200X.

surface epidermis, especially at night, and were observed in vacuolated, degrading tissues or where tissue was absent.

Fig. 12C shows a type 1 lesion at night where chromophore cells appeared to have migrated into the surface epithelia from adjacent areas as indicated by their low density 
or absence in adjacent areas (circled with dashed line). This pattern was not observed in the daytime samples or in healthy tissues.

Alterations in chromophore cell densities and distribution in the basal body wall associated with MPGAs

In healthy $P$. lutea at night, chromophore cells were generally dispersed more evenly within the interior. At night in type 1 and type 2 lesions chromophore cells were frequently densely aggregated in the surface epidermis but only slightly more in the basal calicodermis (Fig. 12B).

Type 1 lesions (Fig. 12A) had few chromophore cells (stained black) in the calicodermis during the day (significantly fewer than type 2 lesions and healthy P. lutea). At night however chromophore cell densities increased significantly in the basal calicodermis of type 1 (Fig. 12B) as well as in type 2 lesions and healthy $P$. lutea. There were no significant differences among healthy and MPGA tissues at night.

Nocturnal activity and dispersal of chromophore cells, their free granules, and secretions of melanin-like substance associated with MPGAs

Special staining (Fontana-Masson) revealed that granules densely packed within chromophore cells contained a melanin-like substance (black = melanin-like substance). Fig. 13 and 14 show the melanin-like secretion and dispersal patterns associated with MPGAs. 


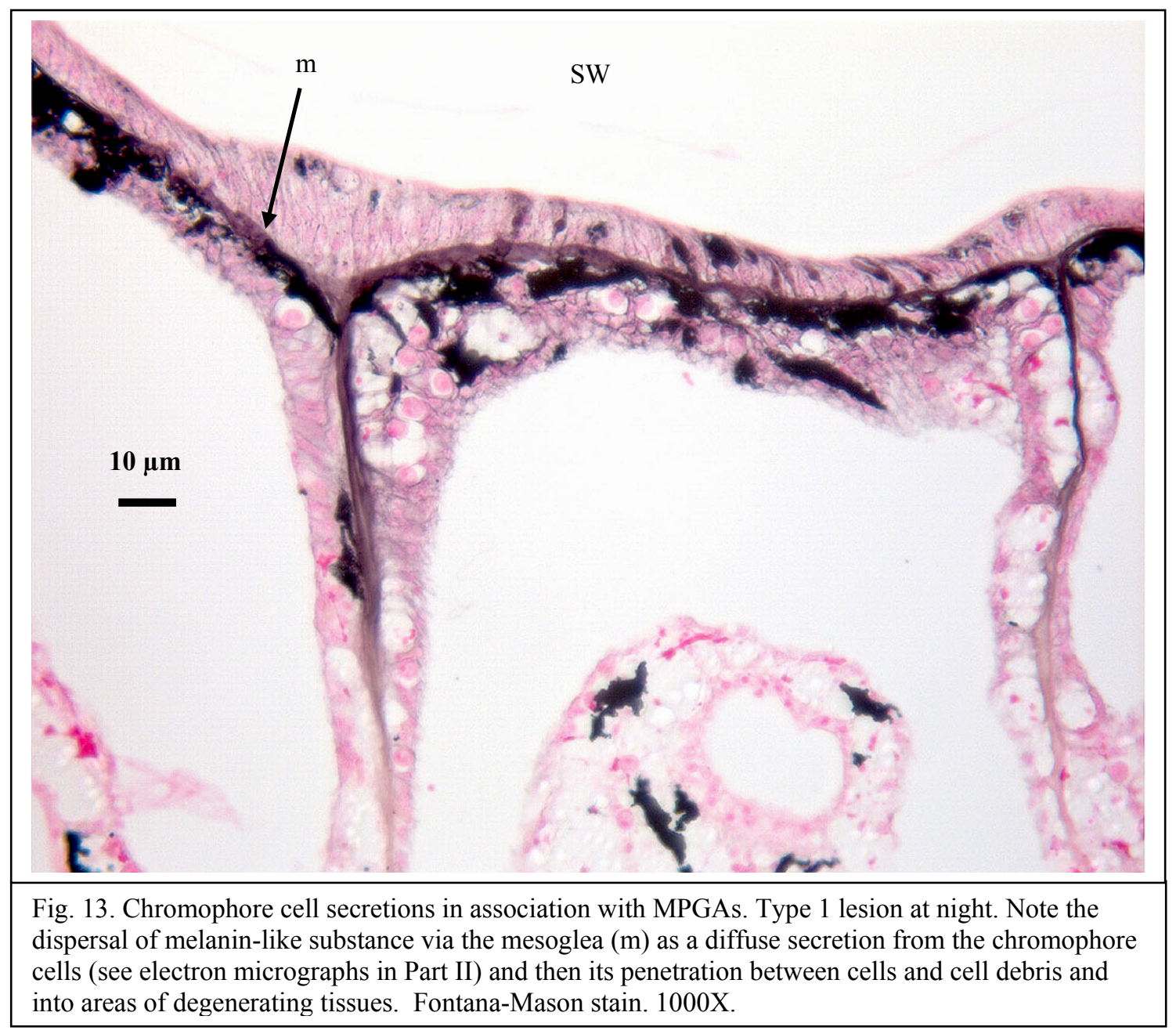




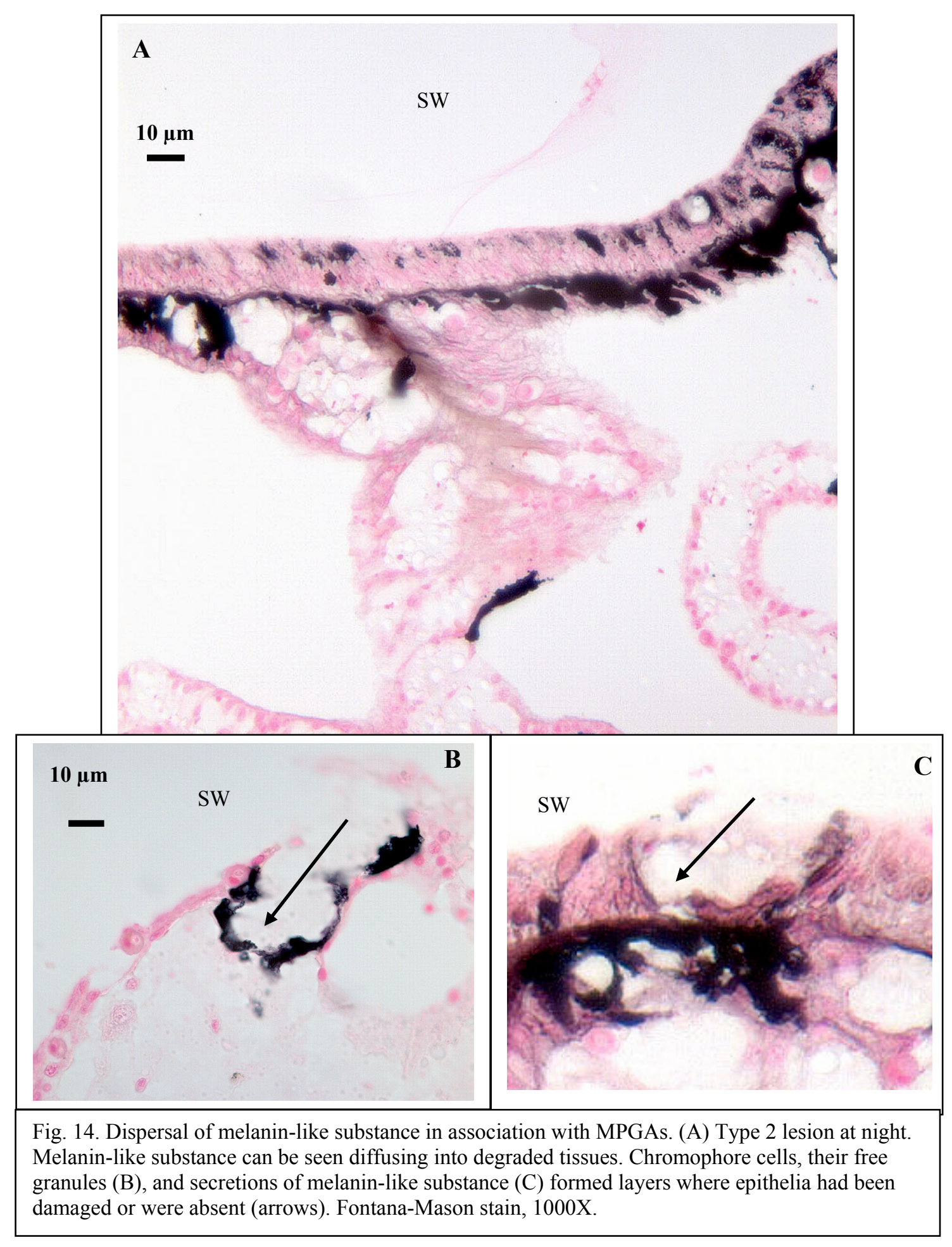


Correlation between zooxanthella density and chromophore cell density - day vs. night

It was determined that in healthy $P$. lutea during the day there was a moderate but significant positive correlation between zooxanthellae density and chromophore cell density $(\mathrm{R}=0.61 ; \mathrm{P}<0.01)$. However, there was no significant correlation at night. In MPGAs there were very weak or no correlations.

Alterations in mucus acidity and mucocytes associated with MPGAs

The mucus in intact mucocytes of type 2 lesions (Fig. 15) was mostly acidic (acid $=$ blue, pink $=$ neutral $)$ whereas much mucus in degraded mucocytes was at a neutral $\mathrm{pH}$. The surface mucus was less acidic in areas affected by MPGAs and mucocytes were often hypertrophied in the associated epidermis. 

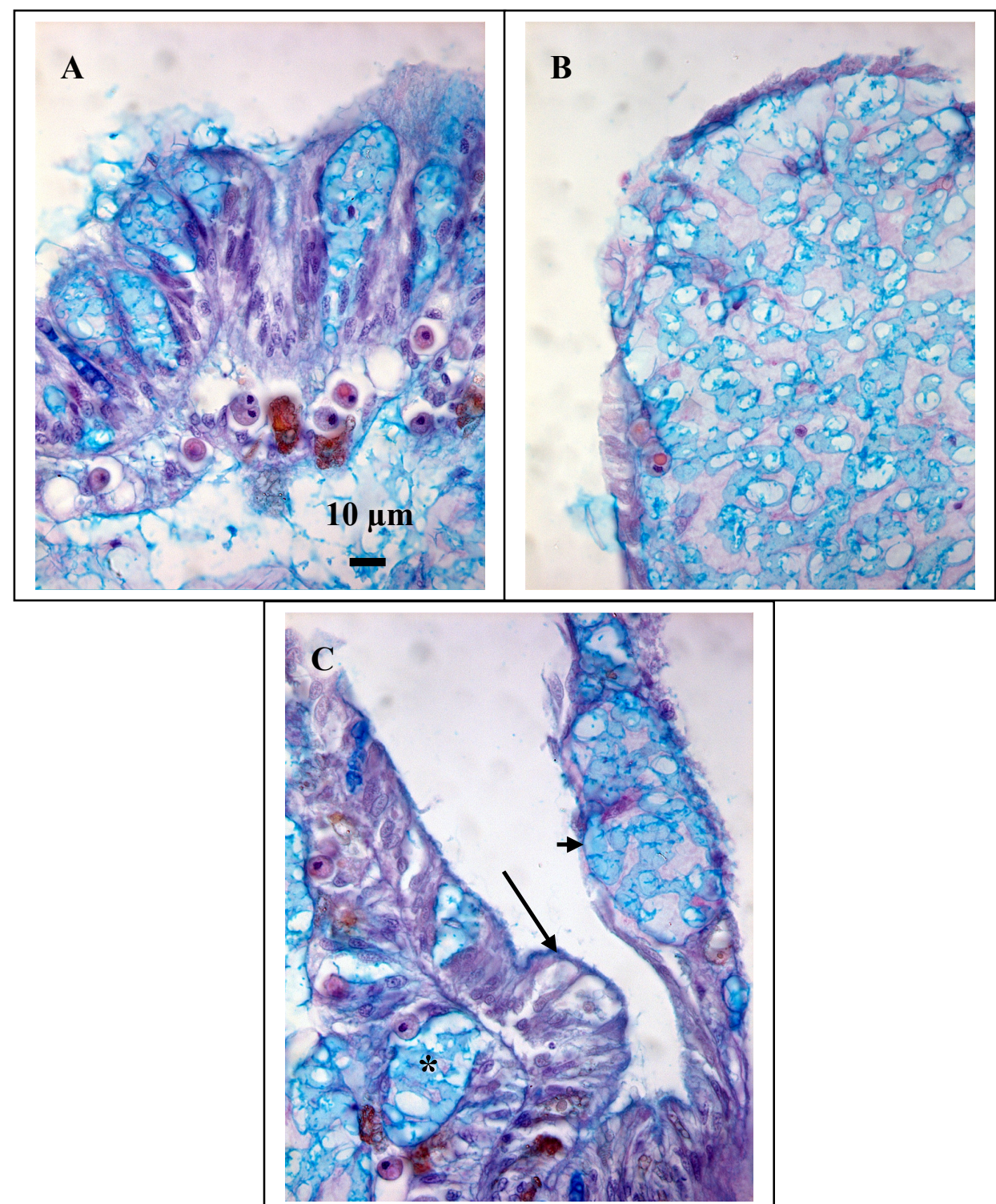

Fig. 15. Alterations in mucocytes in association with type 2 MPGAs. (A) Mucus in intact mucocytes of type 2 lesions was mostly acidic (acid = blue, pink = neutral). (B) Type 2 lesion with severely degraded epidermis and gastrodermis. The underlying gastrodermal cells and mucocytes were lysed. Mucus that filled the areas where gastrovascular canals once were stained pink suggesting breaches in the epithelia and an influx of the more neutral, buffering seawater. In less eroded and thicker epidermis the mucus was less pink. In type 2 lesions (C), intact surface epidermis (arrow) was usually coated with a more acidic (blue) mucus as often seen in healthy $P$. lutea, but more affected epidermis $(\boldsymbol{\nabla})$ that was distended by nearby hypertrophied mucocytes did not have this acidic mucus coating. Mucocytes of MPGA lesions (*) also had many clear zones (= mucus-depleted) using the AB/PAS pH 2.5 stain. 1000X. 


\section{Observations of necrosis, hyperplasia, and possible neoplasia in association with}
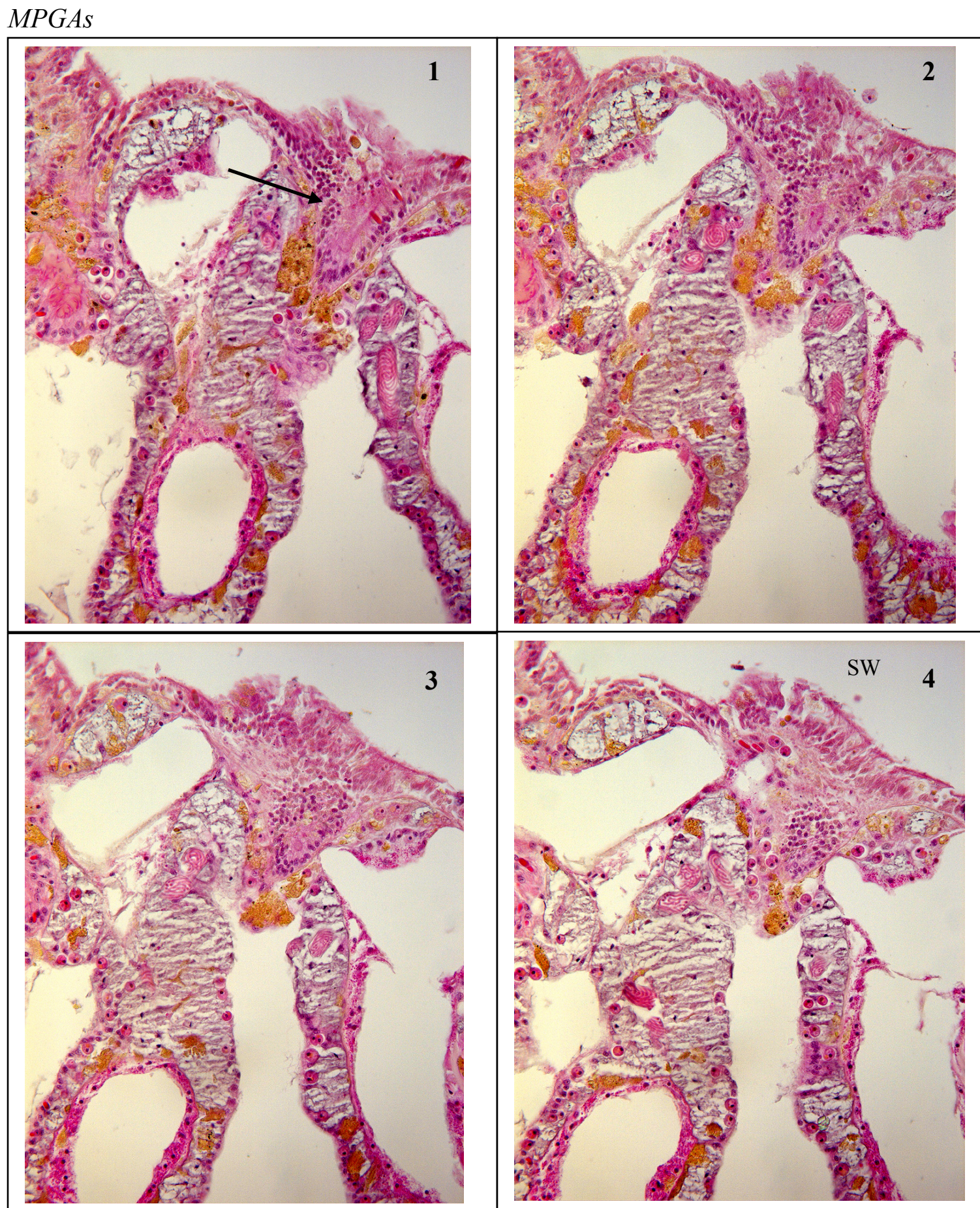

Fig. 16. A sequential series of cut sections shows an apparent inward growing abnormal mass (arrow) associated with a type 2 lesion. The portion exposed to seawater appears fragile that may account in part for the gross appearance of sloughing tissue. The interior of the abnormal growth appears to contain a cluster of acellular or mesogleal material. H\&E. 200X. 


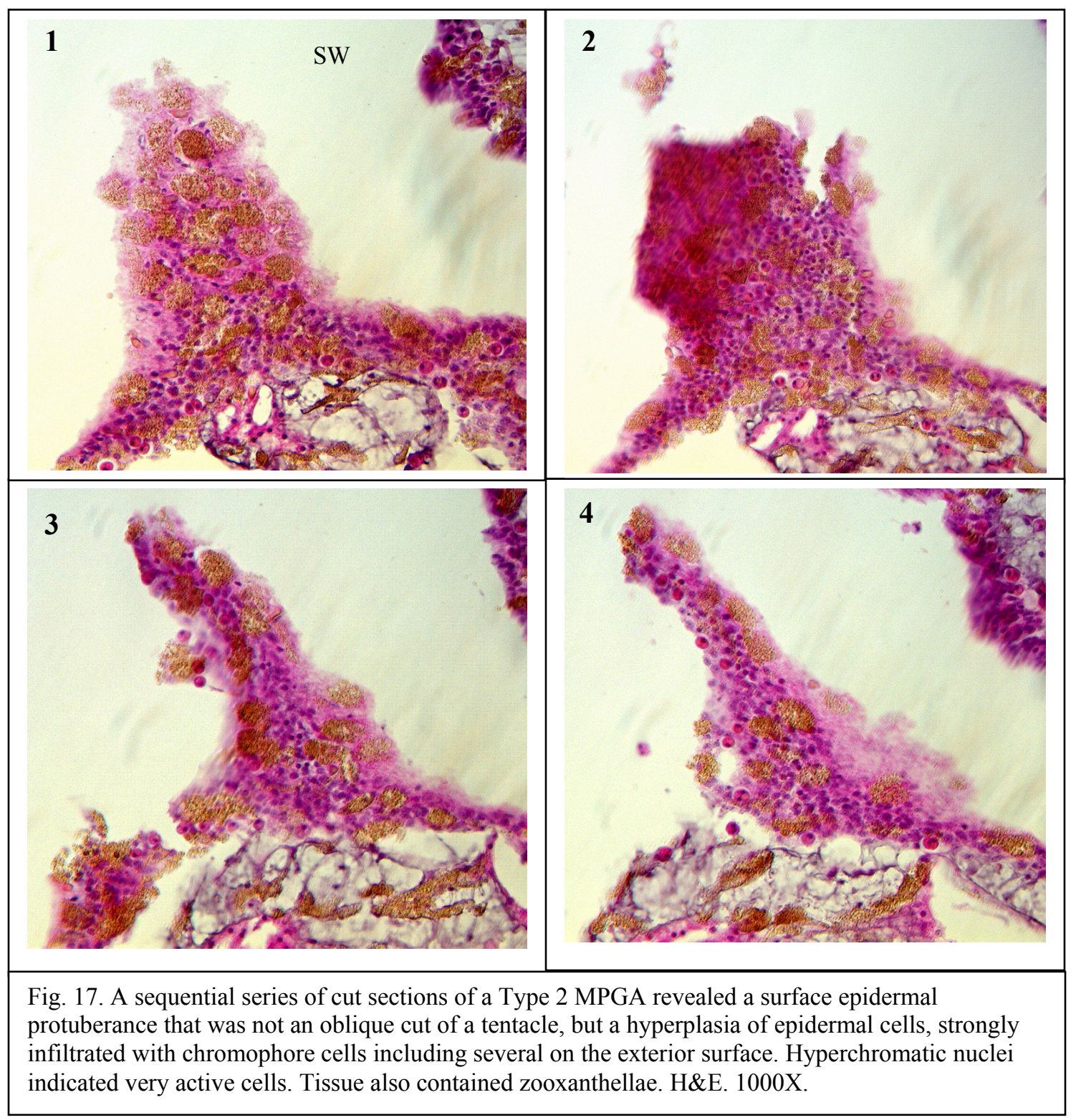

Necrosis was a common feature of MPGAs. As seen in Fig. 8A and B severe necrosis was present at the interface between MPGAs and apparently normal tissue and sloughing necrotic tissue was regularly observed. In MPGAs mucocytes that were severely hypertophied and hyperplastic, and/or experiencing necrosis were commonly observed (Fig. 8A). 


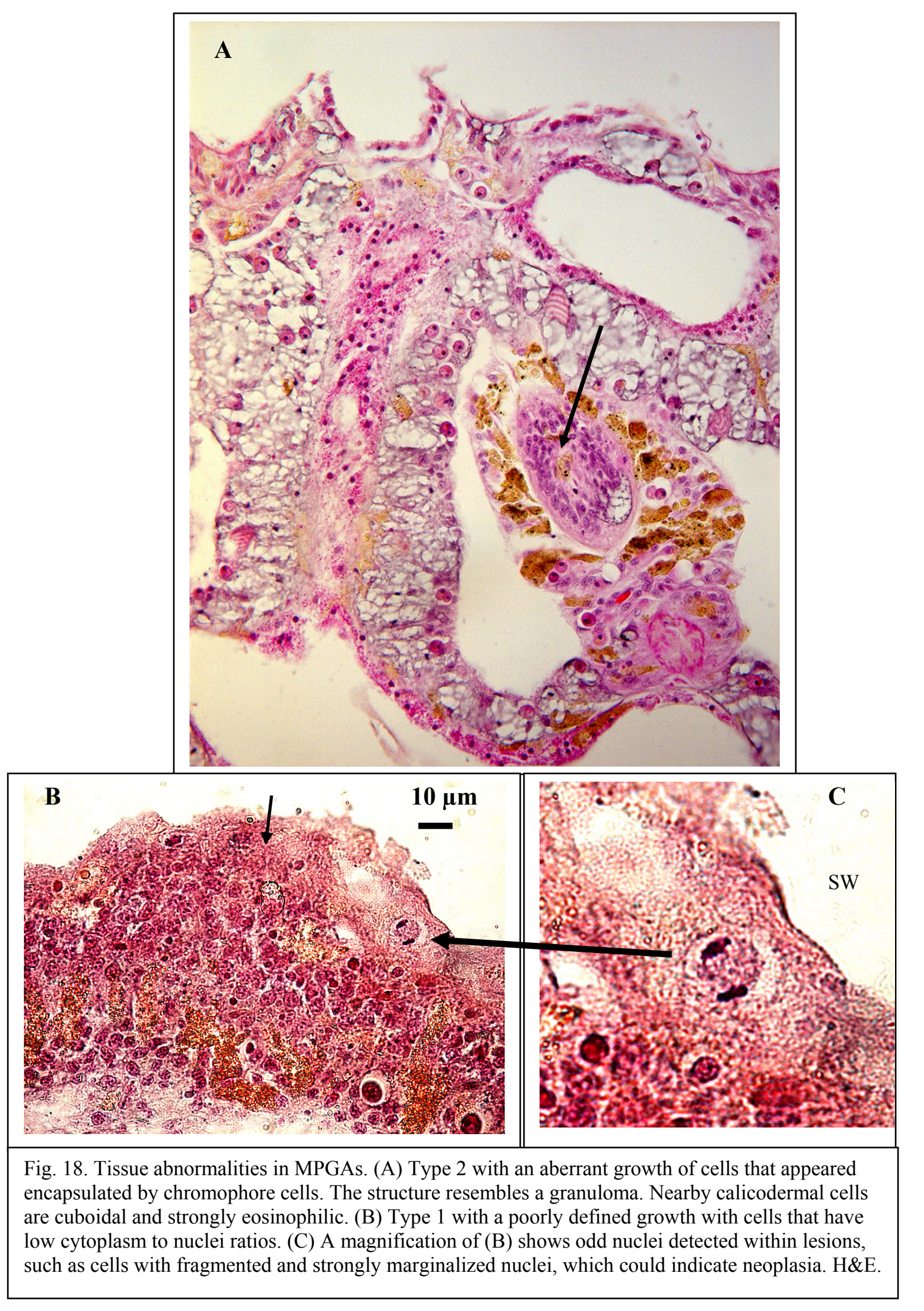


In addition to necrosis, abnormal growths of tissue were observed occasionally in type 2 lesions (Fig. 16). Odd growths exposed to the exterior of the colony (seawater) often appeared fragile, which may account in part for the gross appearance of sloughing tissue in situ in type 2 lesions. Abnormal growths that occurred in the interior tissue appeared to contain clusters of acellular or mesogleal material.

A sequential series of sections revealed that surface epidermal protuberances were potentially caused by hyperplasia of epidermal cells (Fig. 17). These growths were infiltrated with chromophore cells and contained zooxanthellae. Strongly basophilic nuclei indicated very active cells within these growths. Such growths, although small, appeared frequently on type 2 MPGAs.

Figure 18 presents examples of previously unreported types of aberrant tissue growths that contained abnormal cells. Figure 18A shows a growth of undifferentiated cells that appeared encapsulated by chromophore cells. Calicodermal cells near this growth had cuboidal cell shapes and appeared very active (indicated by strong eosinophilia). Figures $18 \mathrm{~B}$ and 19 show examples of poorly defined growths of tissue in odd locations in MPGAs with apparently undifferentiated cells that have low cytoplasm to nuclei ratios. In such growths, odd nuclei were detected (Fig. 18C), such as those with fragmented and strongly marginalized nuclei. Figure 19 shows an abnormally located cellular proliferation from a type 1 MPGA that might be considered either a hyperplasia or neoplasia. 


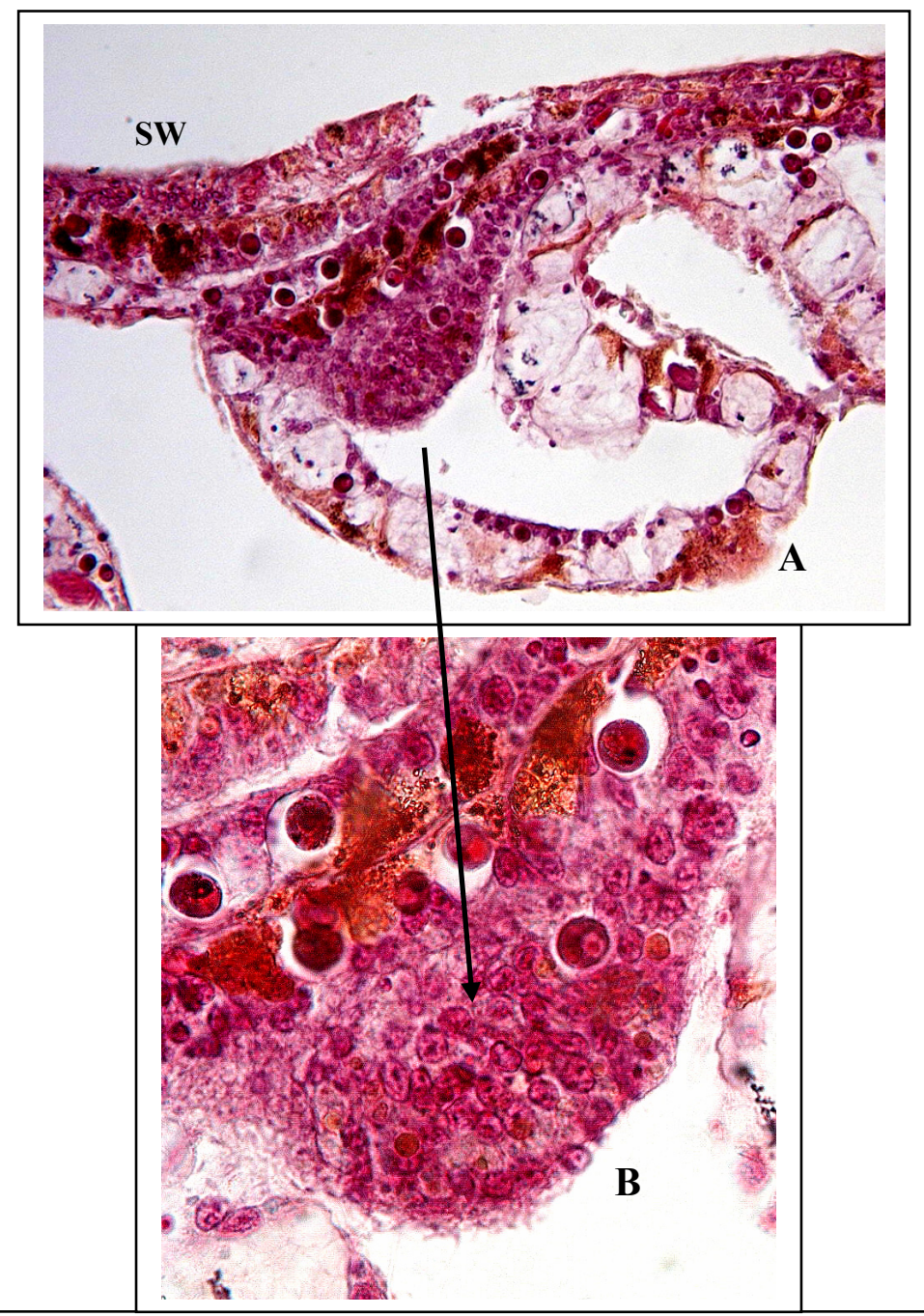

Fig. 19. Type 1 lesion with putative neoplasia. (B) is a magnification of (A).Undifferentiated growth of cells in an odd location that had pleomorphic, hypertrophied nuclei, with prominent nucleoli and very low cytoplasm to nucleus ratios. H \& E. 1000X.

\section{DISCUSSION}

Summary of general histopathological characteristics of MPGAs of Porites lutea

The main characteristics that differentiated type 1 and type 2 MPGAs from healthy $P$. lutea are summarized in Table 1 . The most important differences were changes in tissue and skeletal thickness, GVC width, chromophore cell density, and the presence of necrotic tissues. 


\section{Table 1. Summary of general histopathogical characteristics of massive Porites growth anomalies of $P$. lutea as compared to healthy $P$. lutea}

\begin{tabular}{|l|l|l|}
\hline Characteristic & Type 1 & Type 2 \\
\hline Alteration in Full Tissue Thickness & $+39 \%$ & $-68 \%$ \\
\hline Increase in Number of Gastrovascular Canals? & Yes & No \\
\hline Surface Epidermis, Average Thickness & $+73 \%$ & $+36 \%$ \\
\hline Most Basal Body Wall Thickness & n.s. & n.s. \\
\hline Most Basal Gastrovascular Canals, Average Width & n.s. & $+29 \%$ \\
\hline Most Basal Skeleton, Average Thickness * & $+29 \%$ & $+41 \%$ \\
\hline Surface Zooxanthellae Density, Oral Region & $-43 \%$ & $-29 \%$ \\
\hline Surface Zooxanthellae Density, Coenenchyme Region & $-64 \%$ & $-64 \%$ \\
\hline Surface Chromophore Cell Density, Overall Average & $-53 \%$ & n.s. \\
\hline Surface Chromophore Cell Density, Daytime Average & $-87 \%$ & n.s. \\
\hline Surface Chromophore Cell Density, Nighttime Average & n.s. & n.s. \\
\hline P. All perag & & \\
\hline
\end{tabular}

Note: All percentages shown indicate a significant difference from healthy P. lutea.

n.s. = not significantly different from healthy; * estimated based on the space left after decalcification.

Additionally, mucocytes of both types of MPGAs in the surface epidermis and gastrodermis were hypertrophied and some were lysed. Endolithic fungus-like filaments were more abundant in MPGAs than in healthy $P$. lutea. There were fewer zooxanthellae in both types of MPGAs. There was no or very little correlation between densities of zooxanthellae and chromophore cells in types 1 and 2 MPGAs but in healthy P. lutea there was a moderate positive correlation during the day. In both types of MPGAs melanin-like secretions from chromophore cells concentrated within and were apparently 
being transported via the mesoglea and was being dispersed within degrading and necrotic tissues. Acidity of surface mucus appeared greatly reduced in degraded surface epithelia of types 1 and 2 MPGAs compared to healthy P. lutea. Types 1 and 2 had more strongly eosinophilic tissues than healthy P. lutea. Types 1 and 2 MPGAs had more rounded-up chromophore cells than healthy $P$. lutea.

Comparison with other described coral growth anomalies.

There has only been one other, in-depth histological study of GAs in coral and that was of P. compressa of Hawaii (Domart-Coulon et al., 2006). Differences between the findings of this study and the results of the $P$. compress $a$ study are summarized in Table 2.

Like the P. compressa GAs of Hawaii, coral tissue of type 1 MPGAs was thicker compared to healthy $P$. lutea (Table 2 ; Fig. 3). That tissues immediately surrounding type 1 lesions, in the supposed unaffected areas of $P$. lutea, were significantly thinner (attenuated) than healthy tissue (Fig. 3) supports the hypothesis proposed by others (Cheney 1975, Bak 1983, Yamashiro et al. 2001, Breitbart et al. 2005) that nutrients are being translocated into the GA lesion from surrounding tissue thus starving those adjacent areas to some extent (Yamashiro et al., 2001; Gateño et al., 2003; Breitbart et al., 2005).

The significant increase in thickness in type 1 lesions was a result of proliferation of gastrovascular canals and associated cells in the interior of the coral tissue (e.g., gastrodermis, calicodermis, and mucocytes). This is similar to findings by others looking at GAs in different coral species (e.g., acroporid GAs; Peters et al., 1986; Work and 
Raymeyer, 2005; Work et al., 2008). Type 2 lesions generally did not follow this pattern

although there were some small patchy areas within these lesions that were thickened.

\begin{tabular}{|c|c|c|c|c|c|}
\hline & $\begin{array}{l}\text { Philippines } \\
\text { Healthy }\end{array}$ & MPGA 1 & MPGA 2 & $\begin{array}{l}\text { Hawaii } \\
\text { Healthy }\end{array}$ & $\begin{array}{l}\text { Hawaii } \\
\text { GA }^{2}\end{array}$ \\
\hline $\begin{array}{l}\text { Coral thickness }(\mathrm{mm}) \\
\text { (polyp length) }\end{array}$ & $2.7 \pm 0.4$ & $\begin{array}{l}3.8 \pm 0.6^{3} \\
(39 \%)\end{array}$ & $\begin{array}{l}2.8 \pm 0.6^{3} \\
\mathrm{n} / \mathrm{c}\end{array}$ & $2.9 \pm 0.3$ & $\begin{array}{l}6.3 \pm 2.3 \\
(117 \%)\end{array}$ \\
\hline $\begin{array}{l}\text { Gastrovascular canal }{ }^{4} \\
\text { Diameter }(\mu \mathrm{m})\end{array}$ & $\begin{array}{l}40.1 \\
\pm 23.6\end{array}$ & $\begin{array}{l}44.6 \pm 39.3 \\
\mathrm{n} / \mathrm{c}\end{array}$ & $\begin{array}{l}61.1 \pm 48.0 \\
\mathrm{n} / \mathrm{c}\end{array}$ & $\begin{array}{l}126.1 \\
\pm 21.8\end{array}$ & $\begin{array}{l}160 \pm 9.9 \\
(27 \%)\end{array}$ \\
\hline $\begin{array}{l}\text { Most basal body wall } \\
\text { Thickness }^{4}(\mu \mathrm{m})\end{array}$ & $\begin{array}{l}21.8 \\
\pm 16.1\end{array}$ & $\begin{array}{l}22.6 \pm 18.6 \\
\mathrm{n} / \mathrm{c}\end{array}$ & $\begin{array}{l}21.5 \pm 17.3 \\
\mathrm{n} / \mathrm{c}\end{array}$ & $\begin{array}{l}29.1 \\
\pm 5.7\end{array}$ & $\begin{array}{l}51.4 \pm 7.3 \\
(76 \%)\end{array}$ \\
\hline $\begin{array}{l}\text { Density of zooxanthellae } \\
\text { in oral region per } 1.0 \mathrm{~mm}\end{array}$ & $70^{5}$ & $\begin{array}{l}40 \\
(-43 \%)\end{array}$ & $\begin{array}{l}50^{5} \\
(-29 \%)\end{array}$ & $70^{6}$ & $\begin{array}{l}37^{6} \\
(-48 \%)\end{array}$ \\
\hline $\begin{array}{l}\text { Density of zooxanthellae } \\
\text { in coenenchyme per } 1.0 \mathrm{~mm}\end{array}$ & $55^{5}$ & 20 & 20 & - & - \\
\hline $\begin{array}{l}\text { Density of chromophore cells } \\
\text { in basal tissue per } 1.0 \mathrm{~mm}\end{array}$ & $10.5^{5}$ & $\begin{array}{l}8.0 \\
(-24 \%)\end{array}$ & $\begin{array}{l}31.3 \pm 17.6 \\
(198 \%)\end{array}$ & $12.7^{6}$ & $\begin{array}{l}45.3^{6} \\
(257 \%)\end{array}$ \\
\hline
\end{tabular}

Characteristics significantly different from healthy tissue are indicated by giving the percent change in parentheses. Philippines values are followed by the \pm standard deviation, Hawaiian by \pm standard error unless otherwise indicated. Superscripts (1): from Domart-Coulon et al., 2006; (2) the percent changes from healthy tissue are given in parentheses; (3) values are maximum thickness/tissue type; (4) $P$. compressa measurements from the lower third of the polyp and $P$. lutea from only immediately adjacent to the most basal body wall; (5) median values, as these counts were not normally distributed; (6) value recalculated from Domart-Coulon et al., 2006. " $\mathrm{n} / \mathrm{c}$ " is no significant change compared to healthy coral.

Low densities of zooxanthellae appeared common in GAs of other coral species (e.g., Peters et al., 1986; Gateño et al., 2003; Work et al., 2008) as was the case in the present study. While there was no significant difference between type 1 and type 2, zooxanthella densities in the coenenchyme, in both types of MPGAs, were significantly less than in oral areas, which would explain the much more darkly colored oral areas observed in situ (Fig. 1B) in MPGAs.

\section{Chromophore cell behavior}

Chromophore cells, which are amoeboid, were regularly observed apparently infiltrating into degraded epidermis of type 2 lesions (Fig. 10 and 11) and appeared to perform wound-healing by plugging gaps where tissue was absent. In type 2 lesions chromophore cell density in the surface epithelia during the day was similar to healthy 
tissue, but at night type 2 coenenchyme had significantly more chromophore cells than healthy $P$. lutea, as did type 1 . During the day, type 1 lesions had significantly fewer chromophore cells in the surface epithelia than healthy coral or type 2 lesions. Frequently, in type 1 lesions chromophore cells were absent for long stretches of tissue especially in badly degraded epithelia. At night, chromophore cells also appeared to migrate into the basal tissue of healthy $P$. lutea and types 1 and 2 MPGAs at which time there were significantly more than during the day but there were no significant differences in chromophore cell densities among them.

One of the most notable observations of the present study was observed in type 1 and 2 lesions at night (Fig. 13 and 14), in which a diffuse secretion of a melanin-like substance was seen discharged from the chromophore cells (also seen in electron micrographs; Kaczmarsky, chapter 4) via the mesoglea and then apparently its subsequent penetration between cells and into areas of acellular material and degenerating tissues (Fig. 13 and 14). Evidence that chromophore cells in type 1 and 2 lesions were depleted of their melanin-like substance, possibly from greater activity, was that they were much paler in the outer (more oral) region of the coral Aberrant growths associated with MPGAs

Figures 16 through 19 present examples of previously unreported types of aberrant tissue growths containing abnormal cells. Fig. 18 shows a growth of undifferentiated cells that was being surrounded by chromophore cells. In addition, calicodermal cells nearby this granuloma-like formation had altered cell shapes and were strongly eosinophilic, perhaps contributing to an encapsulation process by laying down more (thicker) skeleton around the putative aberrant growth. If the anomalous growths 
observed in MPGAs are indeed neoplastic, they are not likely to survive for long as coral tissues are not vascularized and need to be in contact with seawater (externally or within the GVC) for adequate removal of wastes and other necessary physiological exchanges (Dr. E. Peters, pers. comm.).

Figures 18 and 19 show examples of poorly defined growths of tissue in odd locations observed in MPGAs with apparently undifferentiated cells that have low cytoplasm to nuclei ratios. In such growths atypical nuclei were detected (Fig. 18), such as cells with fragmented and strongly marginalized nuclei, which in vertebrates have been used as indicators of neoplasia. The cellular proliferation shown in Fig. 19 resembles the growth anomaly observed in the gastrodermis of an acroporid from American Samoa and considered to be hyperplasia by Work and Raymeyer (2005). New observations

A number of observations were made during this investigation that have not been previously reported in the literature. These include: (i) Observations of clusters of chromophore cells that surrounded neoplastic-like growths (Fig. 18A), zooxanthellae (Fig. 11A), bacterial-like aggregates (not shown), and necrotic cells (not shown), suggested encapsulation; (ii) Chromophore cell densities were correlated positively with zooxanthellae densities in the surface epithelia of healthy $P$. lutea during the day but not at night, which was not observed in MPGAs; (iii) Infiltrative wound-healing behavior of chromophore cells, their granules, and secretions into damaged tissues was widespread; (iv) Melanin-like secretions from chromophore cells were concentrated within and apparently transported via the mesoglea in MPGAs and were dispersed into degrading and necrotic tissues. This was not observed in healthy $P$. lutea; (v) Granules containing a 
melanin-like substance appeared to degranulate from chromophore cells and attach to cellular structures; (vi) Melanin-like substance in granules of chromophore cells appeared to be depleted in tissue affected by MPGAs; (vii) Chromophore cells appeared to migrate from adjacent tissues nocturnally into surface and basal epithelia; (ix) MPGA type 2 lesions appeared to be a novel (i.e., not previously described) coral GA distinguished by having a thinner full tissue thickness compared to healthy reference coral and a decrease in skeletal extension, whereas in other previously described coral GAs the full tissue thickness was greater and/or skeletal extension was greater compared to reference material; and (x) Hyperplasia and neoplasia-like growths were observed within MPGAs.

\section{Conclusions}

In summary, type 1 and type 2 MPGAs of the coral Porites lutea on reefs of the Philippines appear to be different pathologies when compared to those described in the literature for other corals in different geographical regions. Newly described behaviors of chromophore cells (that are unique to the genus Porites) were also presented here in relation to MPGA pathologies. In addition, new evidence of neoplastic-like growths within MPGAs was reported. 


\section{REFERENCES}

Abelson, A., Galil, B., Loya, Y. 1991. Skeletal modifications in stony corals caused by indwelling crabs: hydrodynamical advantages for crab feeding. Symbiosis 10, 233-248.

Bak, R.P.M. 1983. Neoplasia, regeneration and growth in the reef-building coral Acropora palmata. Mar. Biol. 77, 221-227.

Bigger, C.H., Hildemann, W.H., 1982. Cellular defense systems of the Coelenterata. In: Cohen, N., Sigel, M. (Eds.), The Reticuloendothelial System Vol. 3, Plenum, New York, pp. 59-87.

Breitbart, M., Bhagooli, R., Griffin, S., Johnston, I., Rohwer, F., 2005. Microbial communities associated with skeletal tumors on Porites compressa. FEMS Microbiol. Lett. 243, 431-436.

Bruckner, A.W. 2002. Priorities for the effective management of coral diseases. NOAA technical memorandum. Silver Springs, Maryland.

Burkhart, C.G, Burkhart, C.N., 2005. The mole theory: primary function of melanocytes and melanin may be antimicrobial defense and immunomodulation (not solar protection). Int. J. Dermatology 44, 340-342.

Cheney, D.P. 1975. Hard tissue tumors in scleractinian corals. Adv. Exp. Med. Biol. 64, 77- 87.

Coles, S.L., Seapy, D.G., 1998. Ultra-violet absorbing compounds and tumorous growths On acroporid corals from Bandar Khayran, Gulf of Oman, Indian Ocean. Coral Reefs 17, 195-198.

Couch, J.A., Fournie, J.W. (Eds.), 1993. Pathobiology of Marine and Estuarine Organisms. CRC Press, Boca Raton, Florida.

Domart-Coulon I.J., Traylor-Knowles, N., Peters, E., Elbert, D., Downs, C.A., Price, K., Stubbs, J., McLaughlin, S., Cox, E., Aeby, G., Brown, P.R., Ostrander, G.K., 2006. Comprehensive characterization of skeletal tissue growth anomalies of the finger coral Porites compressa. Coral Reefs 25, 531-543.

Fautin, D.G., Mariscal, R.N., 1991. Cnidaria: Anthozoa. In: Harrison, F.W., Westfall, J.A. (Eds), Microscopic Anatomy of Invertebrates, Vol. 2. Placozoa, Porifera, Cnidaria, and Ctenophora. Wiley, NY.

Galloway, S.B., Work, T.M., Bochsler, V.S., Harley, R.A., Kramarsky-Winters, E., McLaughlin. S,M., Meteyer, C.U., Morado, J.F., Nicholson, J.H., Parnell, P.G., 
Peters, E.C., Reynolds, T.L., Rotstein, D.S., Sileo, L., Woodley, C.M., 2007. Coral Disease and Health Workshop: Coral Histopathology II. NOAA Technical Memorandum NOS NCCOS 56 and NOAA Technical Memorandum CRCP 4. National Oceanic and Atmospheric Administration, Silver Spring, MD.

Gateño, D., Leon, A., Barki, Y., Cortes, J., Rinkevich, B. 2003. Skeletal tumor formations in the massive coral Pavona clavus. Mar. Ecol. Prog. Ser. 258, 97-108.

Goldberg, W.M., Makemson, J.C., Colley, S.B., 1984. Entocladia endozoica sp nov., a pathogenic Chlorophyte: structure, life history, physiology, and effects on its coral host. Biol. Bull. 166, 368-383.

Goldberg, W., 2001. Acid polysaccharides in the skeletal matrix and calicoblastic epithelium of the stony coral Mycetophyllia reesi. Tissue Cell 33, 376-387.

Harvell, C.D., Kim, K., Burkholder, J.M., Colwell, R.R., Epstein, P.R., Grimes, D.J., Hofmann, E.E., Lipp, E.K., Osterhaus, A.D.M.E., Overstreet, R.M., Porter, J.W., Smith, G.W., Vasta, G.R., 1999. Emerging marine diseases - climate links and anthropogenic factors. Science 285, $1505-1510$.

Hughes, T.P., Baird, A.H., Bellwood, D.R., Card, M., Connolly, S.R., Folke, C., Grosberg, R., Hoegh-Guldberg, O., Jackson, J.B.C., Kleypas, J., Lough, J., Marshall, P., Nystrom, M., Palumbi, S.R., Pandolfi, J.M., Rosen, B., Roughgarden, J., 2003. Climate change, human impacts, and the resilience of coral reefs. Science 301, 929-933.

Hundgen, M. 1984. Cnidaria: Cell Types In: Bereiter-Hahn, J., Matoltsy, A.G., Richards, K.S. (Eds.), Biology of the Integument I. Springer-Verlag, New York.

Hunter, C.L. 1999. First records of coral disease and tumors on Hawaiian reefs. In: Maragos, J.E., Grober-Dunsmore, R. (Eds.), Proc. Hawaii Coral Reef Mon. Workshop. pp 73-97.

Kaczmarsky, L., 2004. Dynamics of Coral Diseases and Syndromes in the Central Philippines: Prevalence, Distribution, Progression Rates, Host Ranges, Anthropogenic Links, and Experimental Evidence of Pathogen Involvement in Coral Neoplasia. Proc. 10th Int. Coral Reef Symp., Abstract volume, Oral 1-4-B, 170.

Kaczmarsky, L., 2006. Coral disease dynamics in the Central Philippines. Dis. Aquat. Org. 69, 9-21.

Kaczmarsky, L., Richardson, L.L., 2007. Transmission of growth anomalies between Indo-Pacific Porites corals. J. Invertebr. Pathol. 94, 218-221. 
Kaiser, H. (Ed.), 1981. Neoplasms - Comparative Pathology of Growth in Animals, Plants and Man. Williams and Wilkins, Baltimore.

Kiernan, J.A. 1990. Histological \& Histochemical Methods Theory \& Practice, $2^{\text {nd }}$ edn Pergamon Press, New York. 502 pp.

Kinne, O. 1980. Diseases of Marine Animals. Vol. 1 General Aspects, Protozoa to Gastropoda. John Wiley and Sons 466 pp.

Le Campion-Alsumard, T., Golubic, S., Priess, K., 1995b. Fungi in corals: symbiosis or disease? Interaction between polyps and fungi causes pearl-like skeleton biomineralization. Mar. Ecol. Prog. Ser. 117, 137-147.

Lison, L. 1954. Alcian blue $8 \mathrm{G}$ with chlorantine fast red 5B. A technic for selective staining of mucopolysaccharides. Stain Technol 29, 131-138.

Loya, Y., Bull, G., Pichon, M., 1984. Tumor formation in scleractinian corals. Helgol. Meeresunters 37, 99-112.

Meszaros, A., Bigger, C.H., (1999) Qualitative and quantitative study of wound healing processes in the coelenterate, Plexaurella fusifera: spatial, temporal, and environmental (light attenuation) influences. J. Invert. Pathology 73: 321-331.

Misdorp, W. 1990. General considerations. In: Moulton, J. (Ed.), Tumors in domestic animals. Berkeley: University of California Press. pp. 1-22.

Morse, D., Morse, A., Duncan, H., 1977. Algal "tumors" in the Caribbean sea-fan, Gorgonia ventalina. In Proceedings, Third International Coral Reef Symposium, pp. 623-629. Rosenstiel School of Marine and Atmospheric Science: University of Miami.

Muscatine L., Lenhoff H.M., 1974. Coelenterate Biology: Reviews and New Perspectives. Academic Press, New York.

Mydlarz, L.D., Holthouse, S.F., Peters, E.C., Harvell, C.D., 2008. Cellular responses in sea fan corals: granular amoebocytes react to pathogen and climate stressors. PLoS ONE 3, 1-9. (doi:10.1371/journal.pone. 0001811)

Nyholm, S.V., Deplancke, B., Gaskins, H.R., Apicella, M.A., McFall-Ngai, M.J., 2002. Roles of Vibrio fischeri and nonsymbiotic bacteria in the dynamics of mucus secretion during symbiont colonization of the Euprymna scolopes light organ. A.E.M. 68, 5113-5122. 
Palmer, C.V., Mydlarz, L.D., Willis, B.L., 2008. Evidence of an inflammatory-like response in non-normally pigmented tissues of two scleractinian corals. Proc. R. Soc. B 275, 2687-2693.

Pandolfi, J.M., Bradbury, R.H., Sala, E., Hughes, T.P., Bjorndal, K.A., Cooke, R.G., McArdle, D., McClenachan, L., Newman, M.J.H., Paredes, G., Warner, R.R., Jackson, J.B.C., 2003. Global trajectories of the long-term decline of coral reef ecosystems. Science 301, 955-958.

Pearse, A.G.E. 1968. Histochemistry, Theoretical and Applied. $3^{\text {rd }}$ ed. Little, Brown, and Co, Boston.

Peters, E.C. 1984a. A survey of the normal and pathological histology of scleractinian corals with an emphasis on the effects of sedimentation stress, chap 1. Doctoral Dissertation, Graduate School of Oceanography, University of Rhode Island, Kingston, RI, pp 1-145.

Peters, E.C., 1984b. A survey of cellular reactions to environmental stress and disease in Caribbean scleractinian corals. Helgol. Meersunters 37, 113-137.

Peters, E.C. 2001. Coral tissue slide reading workshop. Tropical Research Laboratory, Mote Marine Laboratory. Summerland Key, Florida 137 pp.

Peters, E.C., Halas, J.C., McCarty, H.B., 1986. Calicoblastic neoplasms in Acropora palmata, with a review of reports on anomalies of growth and form in corals. $\mathrm{J}$. Natl. Cancer Inst. 76, 895-912.

Peters, E.C., Yevich, P.P., 2001. Comparative histology of selected tropical and temperate Atlantic scleractinian corals, an Atlas. In: Coral tissue slide reading workshop. Tropical Research Laboratory, Mote Marine Laboratory. Summerland Key, Florida 137 pp,

Peters, E.C., Price, K.L. 2005. Coral Histotechniques Workshop. International Registry of Coral Pathology. NOAA Cooperative Oxford Laboratory. Oxford, Maryland $88 \mathrm{pp}$.

Peters, E.C., Price, K.L., Borsay-Horowitz, D.J., 2005. Histological preparation of invertebrates for evaluating contaminant effects in Techniques in Aquatic Toxicology Vol 2 (Ostrander GK, ed). CRC Press, Boca Raton, FL 766 pp.

Rosenberg, E., Loya, Y., 2004. Coral health and disease. Springer-Verlag, Berlin.

Rózanowska, M., Sarna, T., Land, E.J., Truscott, T.G., 1999. Free radical scavenging properties of melanin: Interaction of eu- and pheo-melanin models with reducing and oxidising radicals. Free Radical Biology and Medicine 26, 518-525. 
Sparks AK (1993) Invertebrate diseases - an overview In: Couch JA \& Fournie JW (eds) Pathobiology of Marine and Estuarine Organisms. CRC Press, Boca Raton, 245-253

Sutherland, K.P., Porter, J.W., Torres, C., 2004. Disease and immunity in Caribbean and Indo-PaciWc zooxanthellate corals. Mar. Ecol. Prog. Ser. 266, 273-302.

Uwins, P.J.R., Jones, M.K., Webb, R.I., Yago, A.E., Miller, G.L., Grinan, R., Bell, P.R.F., 1996. Determination of the origin and pathology of coral tumors. The Marine Environment Conference, University of Queensland (abstract). p. 123.

Veron, J.E.N., 2000. Corals of the World. AIMS, Townsville, Australia.

Walsh, M.D., Jass, J.R. 2000. Histologically based methods for detection of mucin. In: Corfield, A., (Ed), Methods in Molecular Biology vol. 125. Humana Press, Totowa, New Jersey.

Wilkerson, F.P., Kobayashi, D., Muscatine, L. 1988. Mitotic index and size of symbiotic algae in Caribbean Reef corals. Coral Reefs 7, 29-36.

Wilkinson, C.R., 2004. Status of coral reefs of the world 2004. Australian Institute of Marine Science, Townsville, Australia.

Work, T.M., Rameyer, R.A., 2005. Characterizing lesions in corals from American Samoa. Coral Reefs 24, 384-390.

Work, T.M., Aeby, G.S., Coles, S.L., 2008. Distribution and morphology of growth anomalies in Acropora from the Indo-Pacific. Dis. Aquat. Org. 78, 255-264.

Yamashiro, H., Yamamoto, M., van Woesik, R., 2000. Tumor formation on the coral Montipora informis. Dis. Aquat. Org. 41, 211-217.

Yamashiro H., Hirosuke, O., Onaga, K., Iwasaki, H., Takara, K., 2001. Coral tumors store reduced levels of lipids. J. Exp. Mar. Biol. Ecol. 265, 171-179. 
CHAPTER 4

\section{HISTOPATHOLOGY OF GROWTH ANOMALIES OF THE MASSIVE CORAL, PORITES LUTEA, FROM THE PHILIPPINES. \\ PART II: ULTRASTRUCTURE}




\section{INTRODUCTION}

Massive Porites Growth Anomolies (MPGAs) affecting colonies of the reef building species Porites lutea on reefs of the Philipines have been characterized in terms of light microscopy (chapter 3). To fully assess the ultrastructure of these diseases, specifically types 1 and 2 MPGAs, investigations at the cellular level are needed.

It was recently suggested that a standardized morphologic criteria for coral growth anomalies (GAs) was lacking (Work et al., 2008). Because of that, Work et al. (2008) began to develop a nomenclature for the gross morphology of GAs and for use in characterization of GAs at the cellular level. While Work et al. described growth anomalies (GAs) that had protuberant masses on the coral skeleton as an easily recognizable disease of scleractinian corals, it was recognized that protuberant morphology is not always associated with lesions considered growth anomalies. Work et al. (2008) also described GAs as consisting of a hyperplastic basal body wall with distinct patterns of necrosis.

In the first systematic descriptions of GAs, Peters et al. (1986) found them to involve primarily the basal body wall, i.e. the tissue apposed to skeleton and comprising calicodermis, mesoglea and gastrodermis, and to have attenuated or an absence of polyps, increased cellular density and decreased numbers of zooxanthellae. Other investigators have reported that GAs have a relatively rapid growth rate when compared to normal tissues which ultimately leads to death (Cheney, 1975; Bak, 1983; Peters et al., 1986). In a review of coral diseases Sutherland et al. (2004) defined GAs as tumors, galls, nodules, and other abnormalities of coral tissue and skeleton that involve abnormal tissue proliferation often associated with an abnormal skeletal growth, and described them as 
observed on reefs throughout the world. GAs are reported to affect 16 Caribbean and 24 Indo-Pacific scleractinian species.

While the etiology of GAs is unknown, several studies have been conducted assessing the structure of GA affected coral tissue and skeleton. Growth anomalies have been variably characterized by: (1) thinning of coral tissue (Peters et al., 1986; Coles and Seapy, 1998); (2) loss of zooxanthellae (Bak, 1983; Peters et al., 1986; Coles and Seapy, 1998; Yamashiro et al., 2001); (3) increased porosity of coral skeleton (Peters et al., 1986; Coles and Seapy, 1998; Yamashiro et al., 2001); (4) loss of mucous secretory cells and nematocytes (Peters et al., 1986; Coles and Seapy, 1998); (5) loss, reduction, or degeneration of normal polyp structures (Bak, 1983; Peters et al., 1986; Coles and Seapy, 1998; Yamashiro et al., 2001); and (6) reduced fecundity (Yamashiro et al., 2001).

Few studies have examined coral ultrastructure as a means to understand disease and most have not been extensive (Renegar et al., 2007; Ainsworth et al., 2007a). The use of transmission electron microscopy (TEM) to describe the ultrastructure of healthy coral has only covered a limited number of reef-building or scleractinian coral species (Chapman, 1974; Bigger and Hildemann, 1982; Fautin and Mariscal, 1991; Goldberg 2001a, 2001b, 2002a, 2002b). Transmission electron microscopy is a uniquely informative approach in studies of coral health and diagnoses of coral diseases. For example, virus-like particles (VLPs) were recently detected in healthy corals using TEM (Wilson et al., 2005; Patten et al., 2008). Transmission electron microscopy has also allowed the visualization of how bacterial communities change within the gastrodermis of healthy coral when corals became thermally bleached (Ainsworth and HoeghGuldberg, 2009). 
The only published TEM investigations of coral growth anomalies (GAs) did not detect cell types or subcellular components that might be affected by the disease other than that also seen with light microscopy (Peters et al., 1986; Gateño et al., 2003). Other than detecting reduced numbers of zooxanthellae in GAs of Pavona clavus, Gateño et al. (2003) recorded no cytological changes or infection by parasitic agents associated with GAs.

Some studies of corals with diseases other than GAs that used TEM also did not detect any cellular abnormalities that were not already seen using light microscopy, except for observing that nuclei appeared unaffected (Peters et al., 1986; Patten et al., 2008); but these studies were not quantitative. Using TEM, Patten et al. (2008) were able to determine qualitatively that zooxanthellae in corals affected by "white syndrome" often appeared degraded. Other studies of coral diseases using TEM have provided more extensive information. Glynn et al. (1985) were able to detect bacteria in bleached coral tissue using TEM but not when using light microscopy (LM). Transmission electron microscopy also enabled them to determine that it was host tissue rather than symbiotic zooxanthellae that was most affected during bleaching. With the recent TEM detection of virus-like particles (VLPs) in healthy and bleached corals, researchers have hypothesized about the potential causative role of viruses in thermal coral bleaching (Wilson et al., 2005; Davy et al., 2006; Danovaro et al., 2008) and in yellow band disease (Cervino et al., 2004). Ainsworth et al. (2007b) used TEM to provide the first evidence of programmed cell death as a primary mechanism of cell death in the disease "white syndrome" of Australian acroporids. Transmission electron microscopy allowed visualization of the signs of apoptosis such as strong marginalization of condensed 
chromatin within the nucleus, rounded-up cells, and loss of cell-to-cell contact but no evidence of necrosis.

Transmission electron microscopy has been a useful diagnostic tool in many invertebrate diseases, for example, in diagnosing viral and bacterial diseases of oysters (Perkins, 1996; Elston, 1997; Paillard et al., 2004; Renault and Novoa, 2004; Yee et al., 2005) and shrimp (Johnson, 1984; Lightner 1999; Khanobdee et al., 2002; SánchezMartínez et al., 2007; Walker and Mohan, 2009). In diagnosing disease, TEM has proven helpful in detecting and confirming the presence, location, and identification of viruses, bacteria, and protozoans including what cell types were affected and in what way they were affected. For example, TEM showed that in the gill necrosis disease of oysters hypertrophied globular cells contained cytoplasmic VLPs (Renault and Novoa, 2004). In shrimp infected with yellow head virus, TEM revealed that lymphoid organ tissue displayed features of apoptosis, which included marginated, condensed and fragmented chromatin (Khanobdee et al., 2002). Such studies at the cellular and sub-cellular level have helped determine what mechanisms and processes are involved in a disease and given direction for further studies.

The GA diseases in the present study affect and kill species that have a massive growth form in the genus Porites, thus are referred to as MPGAs. Experiments have shown GAs to be transmissible (Kaczmarsky and Richardson, 2007) and to be positively correlated with density of human coastal communities (Kaczmarsky, 2006), high nutrients, total organic carbon, and colony density (chapter 1). There also appeared to be an increase in prevalence during warmer summer months (Kaczmarsky, 2006). 
Unfortunately, these are some of the most dominant reef-forming corals in the Philippines and the disease is highly prevalent in some locations (Kaczmarsky, 2006).

Two distinct morphological types of MPGAa (see Fig. 1 in Chapter 3), were previously described and documented to be roughly equally prevalent on Philippine reefs (Kaczmarsky, 2006). Compared to surrounding tissue both types are usually paler, include fewer polyps per unit area, and the surface epithelia appear swollen (Fig. 1 in Chapter 3). Like unaffected tissues, the MPGAs of both types generally produce mucus (albeit in reduced quantities) in contrast to GAs of the acroporids (Peters et al., 1986; Kaczmarsky, 2006). Based on experiments and long-term monitoring, onset of both types appears subacute to chronic (Kaczmarsky, 2006). The extent of both lesion types can be mild to severe. In both, the underlying skeletal architecture of corallites and coenosteum are abnormal and malformed and include some areas that appear abnormally thin and porous and others that are abnormally thickened and dense (Kaczmarsky, 2006). Because the details of skeletogenesis are undoubtedly tied to events and processes immediately adjacent to the extracellular environment (Goldberg, 2001b) a close focus on the calicodermal cells was included in the present study.

The gross morphology of type 1 MPGAs resemble previous descriptions of anomalies of massive Porites in other locales in the Indo-Pacific (Peters, et al., 1986; Hunter and Peters, 1993; Domart-Coulon et al., 2006). The Type 1 MPGA appears anywhere on the colony as single or multifocal lesions that can coalesce. They tend to be round to oval areas of variable size, with an elevated (umbonate) protruding relief sometimes rising to more than a $\mathrm{cm}$ above surrounding normal-appearing coral tissue and distinctly delineated from it with smooth linear margins. 
Type 2 MPGAs are somewhat similar to type 1 except their edges are diffuse, their shape is highly irregular, and they are paler. Other gross distinctions are that type 2 lesions often have sloughing tissue, typically do not have an elevated relief, and in some cases have a depressed profile compared to surrounding coral.

Although mortality is uncommon, the tissue of both lesions appears to persist in a diseased state indefinitely. Field observations have shown that neither types of MPGA lesions have been seen to resolve and often became progressively larger. Occasionally the central area of a large MPGA becomes colonized by algae that spread and steadily erode tissue causing partial mortality. Rarely, a MPGA will progress and affect an entire colony that then dies from algal overgrowth. MPGAs are also a target for focused grazing by corallivorous fish, which contributes to partial mortality, potentially spreads putative pathogens, and permits invasion by bioeroders. Lesions of both types spread slowly but sometimes coalesce and involve the entire colony (Kaczmarsky, 2006).

The present study is the first to document the histology and ultrastructure of MPGAs. This was done by comparing diseased tissues of both type 1 and type 2 MPGAs to healthy tissues of the same species, Porites lutea. Results provide understanding about the modes of action on a cellular level of these novel and widespread growth anomalies.

\section{MATERIALS AND METHODS}

\section{Sample site and collection}

Sampling was conducted off the southeast coast of the island of Negros in the Philippines. Coral samples were collected at a depth of 1 meter from the fringing reef near the Dumaguete City airport close to the Silliman University Marine Laboratory (SUML). Using snorkel and SCUBA equipment, replicate samples of small whole 
massive Porites ( $P$. lutea) colonies and large (approximately $10 \mathrm{~cm}$ diameter) $P$. lutea fragments (removed with hammer and chisel) were collected. Samples included those from type 1 GAs, type $2 \mathrm{GAs}$, and healthy coral from healthy colonies (reference samples). During field collection, coral samples (small whole colonies or large fragments) were kept in individual plastic bags that included a large volume of water to minimize stress during the approximately hour-long collection process. Samples were brought to SUML within 10 minutes of their removal from the reef waters and placed in 4000-L flow-through shaded holding tanks. Samples with GAs $(\mathrm{n}=19)$ and healthy samples $(n=4)$ were processed for TEM.

\section{Sample preparation}

Fragments were fixed in 3\% glutaraldehyde and 1\% paraformaldehyde buffered to $\mathrm{pH} 7.8$ in artificial seawater for $2 \mathrm{~h}$ immediately after return to the laboratory. Decalcification was carried out in loosely capped glass bottles containing combined solutions of sodium citrate $(0.3 \mathrm{M})$ and formic acid for a final formic acid concentration of $12.6 \%$. To improve contact with decalcifying solution, fragments were raised off of the bottom by placing them upon standard histology processing cassettes. The solution was changed daily until samples were fully decalcified. Afterwards, samples were rinsed briefly in tap water, then trimmed to approximately $1-1.5 \mathrm{~cm}$ wide with a razor blade. Samples were then placed in individual processing cassettes which were rinsed with running tap water to remove all traces of decalcification solution. After final trimming to $<2 \mathrm{~mm}^{2}$ samples were post-fixed for $1 \mathrm{~h}$ at room temperature in $1 \%$ osmium tetroxide containing $0.1 \mathrm{M}$ cacodylate buffer ( $\mathrm{pH}$ adjusted to 7.8 in artificial seawater), then rinsed three times (each $15 \mathrm{~min}$ ) with buffer (1 part $0.4 \mathrm{M}$ cacodylate with 1 part artificial 
seawater). After post-fixation, samples were dehydrated in a graded ethanol series and then embedded in Spurr resin in a silicon mold following standard procedures (Bythell et al., 2002; Goldberg, 2002b). Resin polymerization took place overnight in a $70{ }^{\circ} \mathrm{C}$ oven. Gold longitudinal sections ( $90 \mathrm{~nm}$ ) of tissue were made by diamond knives on a Sorvall MT-2 ultramicrotome and picked up on nitrocellulose and carbon coated copper grids (200 mesh) (Peters et al., 1986; Wilson et al., 2005). At the University of Miami Center for Advanced Microscopy (UMCAM) facility, sections were stained with Reynold's lead citrate, and examined with (1) a Philips EM 300 TEM at $60 \mathrm{kV}$ from which negatives were scanned and (2) a JEOL 1400 TEM at $80 \mathrm{kV}$ from which digital images from a Gatan digital imaging system were taken.

\section{Ultrastructure observations}

Comparisons of tissue and cell ultrastructure of healthy and diseased corals were conducted using several references as guides. These included Muscatine and Lenoff (1974), Sparks (1985), Fautin and Mariscal (1991), and Couch and Fournie (1993). Cell types, organelles, and storage products (lipids and starch) were also identified by comparison with published transmission electron micrographs (e.g., Crossland et al., 1980; Muller-Parker, 1987; Berner and Izhaki, 1994; Muller-Parker et al., 1996; Salih et al., 1998; Dunn et al., 2004; Franklin et al., 2004; Roff et al., 2008; Yellowlees et al., 2008; Strychar and Sammarco, 2009). VLPs were characterized by comparisons with published work (Johnson, 1984; Miller, 1986; Kurstak 1991; Renault and Novoa, 2004). Quantitative analyses were based on longitudinal sections and not absolute values, meaning that sections were not always necessarily cut through the mid-point of each cell 
type assessed. However, since the three tissue types (healthy and MPGA types 1 and 2) were treated similarly results were deemed to be averages.

Numerous representative photomicrographs were taken of each tissue region (i.e., outer epidermis, gastrodermis, and calicodermis). Differences in various cell-types, organelles, and other ultrastructural features between the three tissue types were determined. For quantitative comparisons cell-types demonstrating measurable characteristics for statistical comparisons were tested. All clearly visible cell images of cell-types targeted for statistical comparisons in all photomicrographs were quantitatively assessed as follows:

(1) Estimation of the percentage of chromophore cells (a type of granular amoebocyte) that fell into the following categories: (i) chromophore cells in which greater than 50 $\%$ of their cytoplasmic granules (that contain a melanin-like substance, see chapter 3 ) appeared electron-opaque or "full" and (ii) chromophore cells in which $100 \%$ of their granules appeared electron-lucent or "empty";

(2) Estimation of the average number of starch granules and lipid globules within zooxanthellae (Symbiodinium spp.);

(3) Estimation of the average thickness of the zooxanthellae pyrenoid starch caps and;

(4) Estimation of the percentage of zooxanthellae that showed (i) major signs of degeneration (severe necrosis) and (ii) vacuolization (early necrosis).

\section{Statistical Analyses}

To statistically compare the relative amounts of various cell-types Chi-square tests were used. To compare the numbers of organelles in a particular cell type z-tests 
were used. The thickness measurements of the starch caps of the pyrenoid body in zooxanthellae were not normally distributed thus Mann-Whitney U-tests were used.

\section{RESULTS}

\section{Cytopathology}

Alterations in chromophore cells associated with MPGAs

Chromophore cells are a pigmented type of granular amoebocyte unique to the coral genus Porites (Galloway et al., 2007) that are tightly packed with cytoplasmic granules. Evidence for the chemical content of chromophore cell granules indicates a melanin-like substance is an abundant component (Mydlarz et al., 2008; Palmer et al., 2008; Kaczmarsky, Chapter 3). These granules are rounded, $<2 \mu \mathrm{m}$ in diameter and pack the cell, leaving little cytoplasm (Fig. 1).

The most notable ultrastructural difference between chromophore cells in healthy P. lutea and those in MPGAs was electron-opacity (Table 1). In contrast to the electronopaque granules seen in chromophore cells from healthy $P$. lutea (Fig. 1A), many granules in MPGA chromophore cells (Fig. 1B, 1C) were electron-lucent, especially those in type 2 lesions. Rounded-up chromophore cells (Fig. 1E) appeared more frequently in MPGAs than in healthy P. lutea (not compared statistically). Necrotic chromophore cells were only observed in type 2 MPGAs (Fig. 1D). Also notable in TEM were chromophore cell distribution pattern and behavior, which included surrounding other cells and necrotic cells (Fig. 1A). Most cells that were surrounded were either zooxanthellae or cells with signs of degeneration. Also regularly observed was 

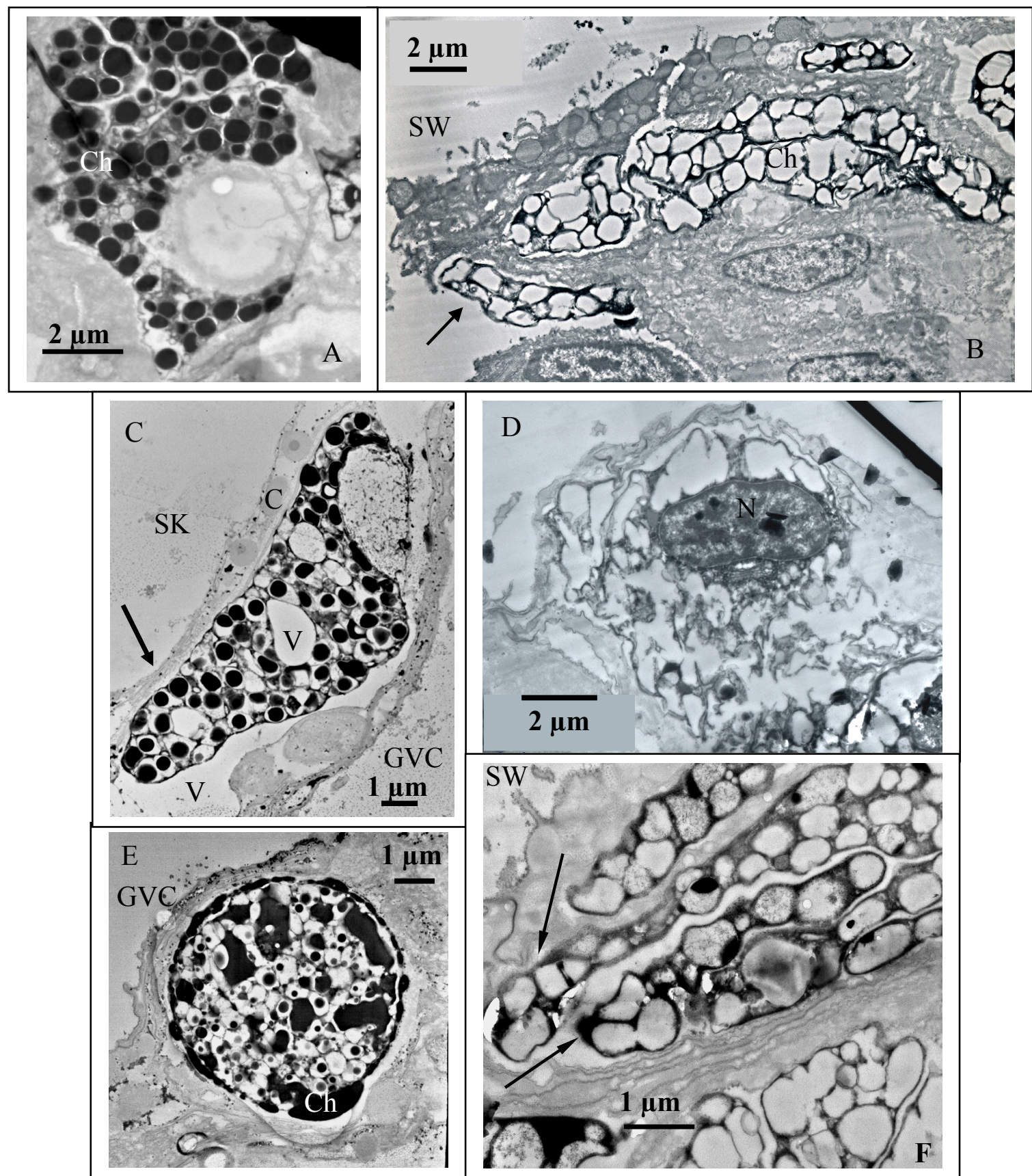

Fig 1. Representative images showing alterations in chromophore cells in MPGAs. (A) Chromophore cells with electron-opaque granules in healthy $P$. lutea. Chromophore cell is surrounding a necrotic cell. (B) Electron lucent chromophore cell in type 2 MPGA. Chromophore cell "plugging" degraded tissues (arrow). (C) Granules in type 1 MPGAs were more electron-opaque than type 2. Attenuated calicodermis (arrow). Large vacuoles (V) were common in MPGAs. (D) Necrotic chromophore cell in type 2; only the nucleus is unruptured. (E) Rounded-up chromophore cell in MPGAs with cellular content condensed and blebbing out from cell surface. (F) Electron-opaque substance (arrows) discharging from chromophore cell vesicles into intercellular spaces. $\mathrm{SW}=$ seawater, $\mathrm{GVC}=$ gastrovascular cavity, $\mathrm{Ch}=$ chromophore, $\mathrm{N}=$ nucleus, $\mathrm{SK}=$ skeletal space, $\mathrm{V}=$ vacuole, $\mathrm{C}=$ calicodermis. 


\begin{tabular}{|l|l|l|l|}
\hline \multicolumn{5}{|l|}{ Table 1. MPGA associated chromophore cell alterations. } \\
\hline Condition & Healthy & MPGA type 1 & MPGA type 2 \\
\hline Alterations & 89 & 32 & 100 \\
\hline Total number of chromophore cells examined & 0 & $43.0^{\mathrm{B}}$ \\
\hline $\begin{array}{l}\text { Percentage of chromophore cells with all } \\
\text { cytoplasmic granules electron-lucent } \\
\text { ("empty") }\end{array}$ & $0^{\mathrm{A}}$ & $0^{\mathrm{A}}$ & $0{ }^{\mathrm{C}}$ \\
\hline $\begin{array}{l}\text { Percentage of chromophore cells with }>50 \% \\
\text { of cytoplasmic granules electron-opaque } \\
\text { ("full") }\end{array}$ & $18.0^{\mathrm{A}}$ & $72.0^{\mathrm{B}}$ & \\
\hline
\end{tabular}

Values followed by the same letter are not significantly different. All significant differences were $\mathrm{P}<$ 0.001 . The number of chromophore cells with a specific alteration is indicated as a percentage of the total number of chromophore cells examined. "Empty" is defined as electron-translucent and "full" as electronopaque.

an apparent infiltration of chromophore cells into and aggregation within damaged tissues and areas where tissue was missing, even positioned on the seawater-exposed side of damaged epidermis (Fig. 1B). Chromophore cells were extremely pleomorphic, and size ranged up to at least $30 \mu \mathrm{m}$ in length. Granules in healthy tissue were very electronopaque even without lead citrate or uranyl acetate. In sections of type 2 lesions there were significantly more chromophore cells that had $100 \%$ of their cytoplasmic granules entirely electron-lucent ("empty") than in healthy tissue and type 1 lesions (43\% in type 2 versus $0 \%$ in both healthy and type 1 ; chi-square test, $\mathrm{p}<0.001$; Table 1 ). In sections of healthy $P$. lutea and type 1 lesions there were significantly more chromophores that had $>50 \%$ of their granules appear electron-opaque ("full") than chromophore cells in type 2 lesions (18\% versus $0 \%$ and $72 \%$ versus $0 \%$, respectively; both $\mathrm{p}<0.001)$. In both healthy and MPGA tissue an electron-opaque substance was frequently seen to be discharging from chromophore cells (Fig. 1F) onto membrane surfaces and into intercellular spaces. 
Alterations in zooxanthellae (Symbiodinium spp.) associated with MPGAs

There were significantly more starch granules and thicker pyrenoid starch caps in zooxanthellae from healthy P. lutea than in MPGA lesions (Fig. 2 and Table 2). The amount of electron-lucent granules (starch granules) in the zooxanthellae of healthy $P$. lutea was $8.1 \pm 5.5$ per algal cell, in type 2 lesions it was $0.6 \pm 0.8$ (z-test, $\mathrm{p}<0.0001$ ), and in type 1 lesions $0.1 \pm 0.3(\mathrm{p}<0.001)$. The thickness of the starch cap of the pyrenoid body was significantly greater in the zooxanthellae of the healthy $P$. lutea than in the type 2 lesions $(0.76 \mu \mathrm{m} \pm 0.38 \mathrm{SD}$ versus $0.12 \mu \mathrm{m} \pm 0.23$; U-test, $\mathrm{p}<0.001)$ or type 1 lesions $(0.10 \pm 0.03 ; \mathrm{p}<0.001)$. There were significantly more electron-opaque globules (lipid globules) in zooxanthellae in type 2 and type 1 lesions than in healthy tissue (4.6 \pm 4.3 SD per algal cell in type 2 versus $0.1 \pm 0.5 \mathrm{SD}$ in healthy $P$. lutea; z-test, $\mathrm{p}<0.0001$ and $3.3 \pm 3.0 \mathrm{SD}$ in type $1, \mathrm{p}<0.001)$. There were significantly more zooxanthellae that had signs of severe degeneration from type 2 lesions than from healthy tissue (14.5\% versus $\left.3.2 \% ; X^{2}=5.9, \mathrm{p}<0.05\right)$. There were significantly more zooxanthellae that had moderate to severe vacuolization from type 2 lesions than from healthy tissue (42.2\% of cells versus $\left.14.7 \% ; X^{2}=15.4, \mathrm{p}<0.001\right)$. Small electron-opaque lipid globules, presumably membrane breakdown products (Franklin et al., 2004), were significantly more abundant in zooxanthellae of MPGAs (Fig. 2B and Table 2). The number of zooxanthellae showing major signs of necrosis (Fig. 2D) was significantly lower in healthy $P$. lutea than in MPGA tissue (Table 2). In contrast with healthy P. lutea, zooxanthellae in diseased $P$. lutea generally had much paler staining intensity, 


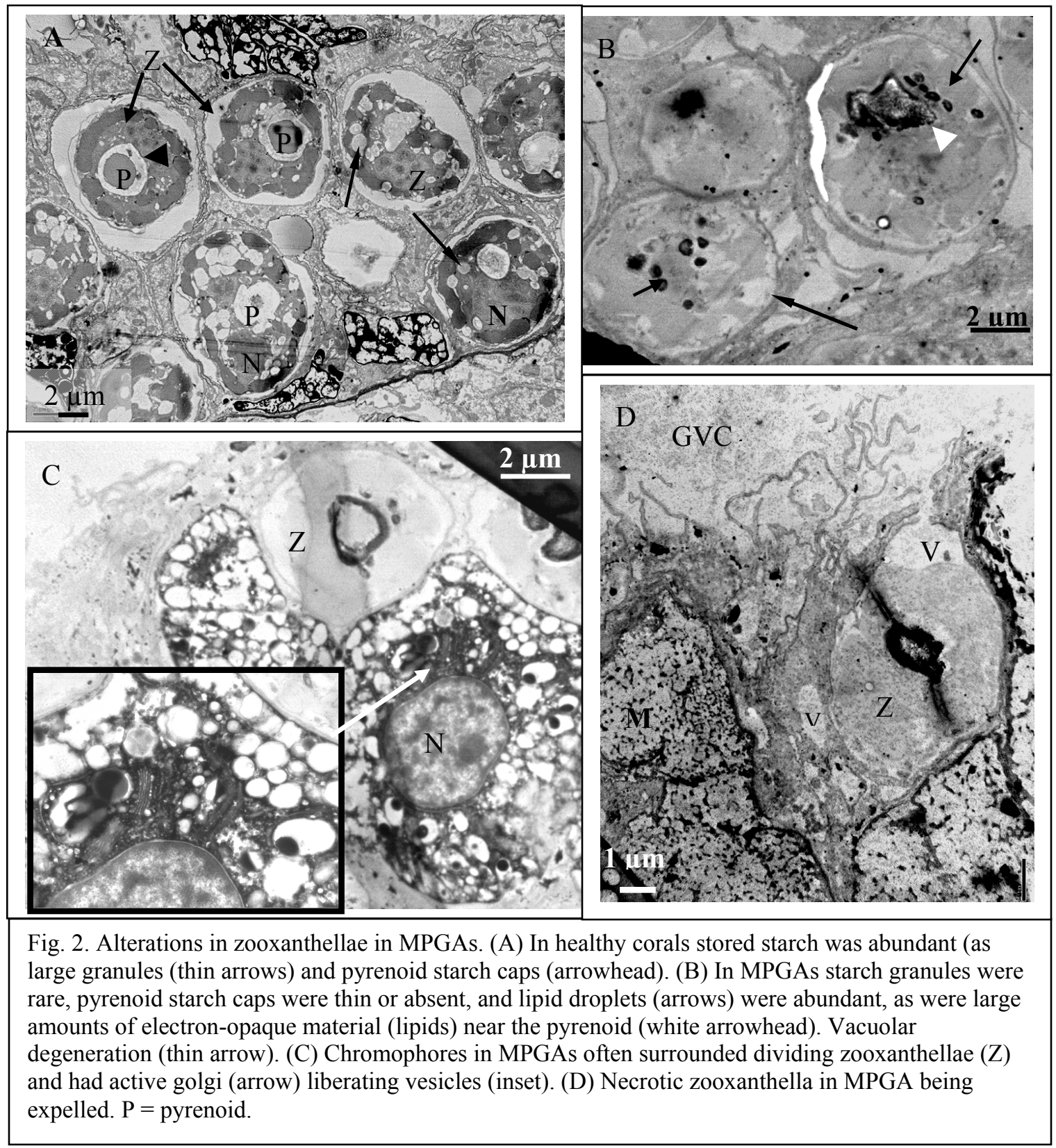

very little stored starch, and a slight accumulation of lipid globules. Thylakoid lamellae

were usually tightly packed and not loose and cell walls were not ruptured, two hallmarks of early stages of zooxanthellae necrosis. More frequently than in healthy P. lutea, MPGAs had degenerated zooxanthellae that often were no longer associated with a host 
cell and appeared in the process of being expelled (Fig. 2D). Average size of zooxanthellae appeared to be approximately $8 \mu \mathrm{m}$ in diameter but a few ranged larger

\begin{tabular}{|l|l|l|l|}
\hline \multicolumn{4}{|l|}{ Table 2. MPGA associated zooxanthellae alterations. } \\
\hline & Healthy & MPGA type 1 & MPGA type 2 \\
\hline $\begin{array}{l}\text { Total number of zooxanthellae examined } \\
\text { for the parameters below }\end{array}$ & 50 & 9 & 39 \\
\hline $\begin{array}{l}\text { Number of starch granules } \\
\text { per cell (mean } \pm \text { SD) }\end{array}$ & $8.1 \pm 5.5^{\mathrm{A}}$ & $\begin{array}{l}0.1 \pm 0.3^{\mathrm{B}} \\
\mathrm{P}<0.001\end{array}$ & $\begin{array}{l}0.6 \pm 0.8^{\mathrm{B}} \\
\mathrm{P}<0.0001\end{array}$ \\
\hline $\begin{array}{l}\text { Number of lipid globules } \\
\text { per cell (mean } \pm \text { SD) }\end{array}$ & $0.1 \pm 0.5^{\mathrm{A}}$ & $\begin{array}{l}3.3 \pm 3.0^{\mathrm{B}} \\
\mathrm{P}<0.001\end{array}$ & $\begin{array}{l}4.6 \pm 4.3^{\mathrm{B}} \\
\mathrm{P}<0.0001\end{array}$ \\
\hline $\begin{array}{l}\text { Total number of zooxanthellae examined } \\
\text { for the parameter below }\end{array}$ & 27 & 3 & 27 \\
\hline $\begin{array}{l}\text { Pyrenoid starch cap width }(\mu \mathrm{m}) \\
\text { Mean } \pm \text { SD }\end{array}$ & $0.7 \pm 0.38^{\mathrm{A}}$ & $0.10 \pm 0.03^{\mathrm{B}}$ & $\begin{array}{l}0.12 \pm 0.23^{\mathrm{B}} \\
\mathrm{P}<0.001\end{array}$ \\
\hline $\begin{array}{l}\text { Total number of zooxanthellae examined } \\
\text { for the parameters below }\end{array}$ & 95 & 9 & 83 \\
\hline Percentage of vacuolated cells & $14.7^{\mathrm{A}}$ & $66.7^{*}$ & $\begin{array}{l}42.2^{\mathrm{B}} \\
\mathrm{P}<0.001\end{array}$ \\
\hline Percentage of necrotic cells & $3.2^{\mathrm{A}}$ & $22.2^{*}$ & $\begin{array}{l}14.5^{\mathrm{B}} \\
\mathrm{P}<0.05\end{array}$ \\
\hline
\end{tabular}

Values followed by the same letter are not significantly different. The number of zooxanthellae with vacuolated or necrotic cells is indicated as a percentage of the total number of zooxanthellae examined for those parameters. "Vacuolated cells" are those that are moderately to severely vacuolated. $*=$ too few cells for statistical test.

to $11 \mu \mathrm{m}$. There did not appear to be a clear size difference between zooxanthelae from healthy P. lutea and MPGAs. Recently divided zooxanthellae were often observed surrounded by chromophore cells whether in healthy or diseased P. lutea (Fig. 2C). In such instances golgi bodies appeared to be very actively secreting vesicles (Fig. 2C, inset).

\section{Histopathology associated with MPGAs}

Several departures from the ultrastructure observed in healthy $P$. lutea were seen frequently in MPGA lesions, especially type 2 . These included badly degenerated gastrodermal tissue with signs of necrosis, which included loss of normal architecture, loosely organized acellular debris and abundant vacuoles suggesting vacuolar 
degeneration and necrosis. Numerous oddly shaped nuclei and unrecognizable vesicles were also observed in this tissue with little surrounding cytoplasm and few other recognizable cell features. Strongly electron-opaque particles, of variable size, possibly of chromophore cell origin were also abundantly deposited in association with necrotic tissue. Signs of necrosis in MPGAs included large intercellular spaces between the basal gastrodermis and calicodermis in MPGAs (Fig. 1C). Bacteria were only rarely seen in sections of both healthy and diseased tissues (Fig. 4A) and mostly on the surface of the gastrodermis in the gastrovascular cavity with only one instance of being within

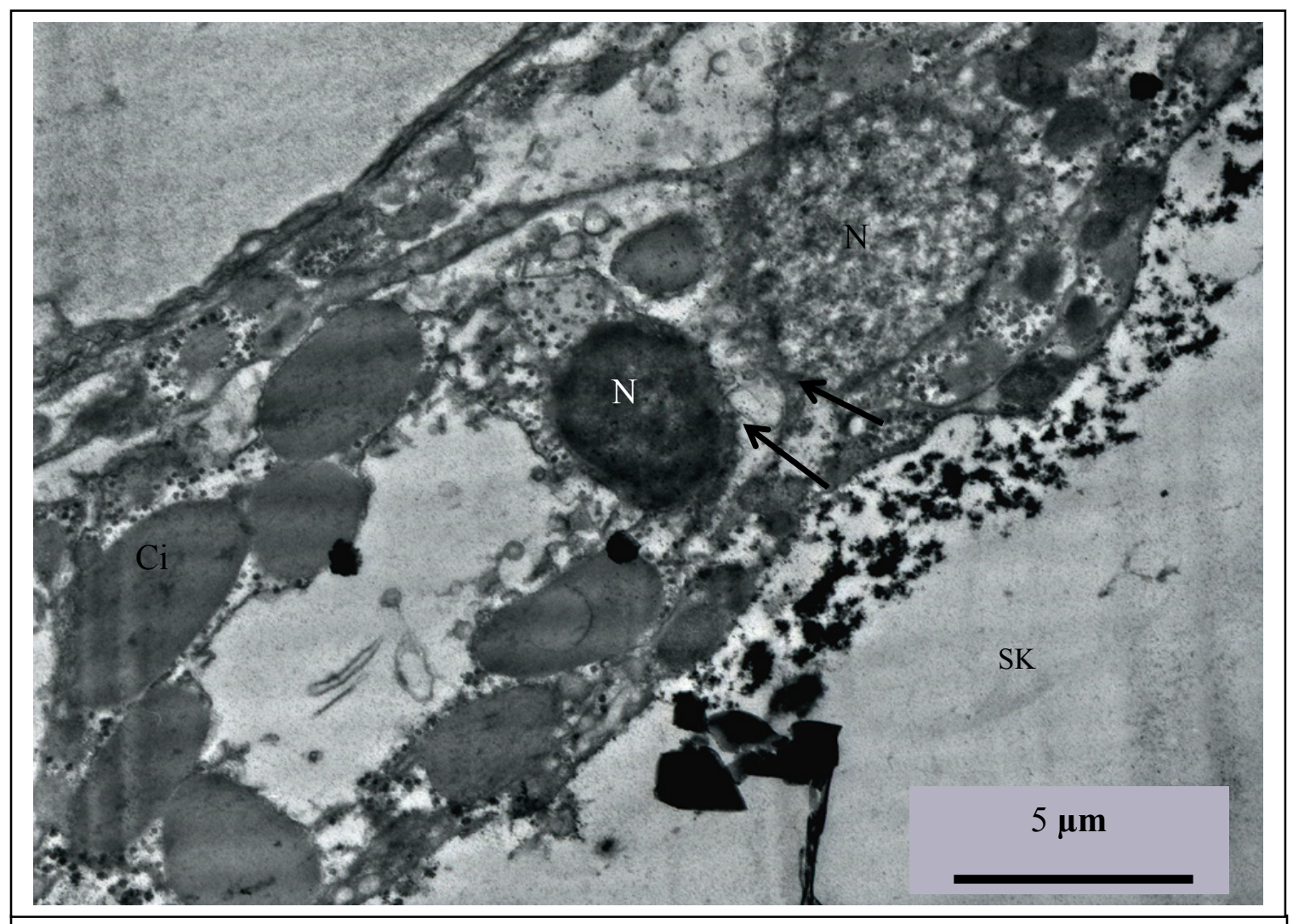

Fig. 3 Abnormally thick cuboidal calicodermal cells of type 2 MPGA with signs of necrosis: karyolytic nuclei (arrows). Most calicodermal cells contained large cytoplasmic granules (Ci). $\mathrm{N}=$ nucleus.

gastrodermal tissue, which was severely degraded. 
Calicodermal cells in MPGAs generally appeared similar to healthy samples but occasionally the MPGA calicodermal layer was abnormally thin or attenuated (Fig. 1C) and in places was absent. Less commonly, the tissue layer was abnormally thickened in which calicodermal cells were more cuboidal in shape and contained large granules (Fig. 3). Signs of necrosis (karyolytic nuclei) were also seen occasionally within the calicodermis of type 2 MPGAs (Fig. 3). In both healthy and diseased tissues, calicoblasts otherwise contained an abundance of smaller cytoplasmic granules (approx. 0.5 to $1.5 \mu \mathrm{m}$ in diameter), some membrane-bound, that appear common in calicodermal cells (Fautin and Mariscal, 1991; Isa, 1986; Goldberg, 2001a, 2001b). Presence of virus-like particles (VLPS)

VLPs occurred in both healthy and diseased tissue and were extensive. They were uniform in size, shape, and diameter, approximately $60 \mathrm{~nm}$, were spherical and did not appear to have a clear polyhedral shape (Fig. 4). They did not appear to have an envelope. They were strongly associated with calicodermal cells and intracellularly were found exclusively within the cytoplasm of these cells. There were a few resolved well enough within the cytoplasm to reveal fine filopodia-like knobs or tubular spikes resembling reoviruses (Fig. 4B, insets). They accumulated and aggregated to some extent but did not form paracrystalline arrays. They were found very frequently lined-up and adhering to membranes of cytoplasmic inclusions (Fig. 4B). They were also found occasionally in lower numbers in intercellular spaces throughout the coral (Fig. 4C). Extracellularly, they were found adhering to the membrane of chromophore cells. In 


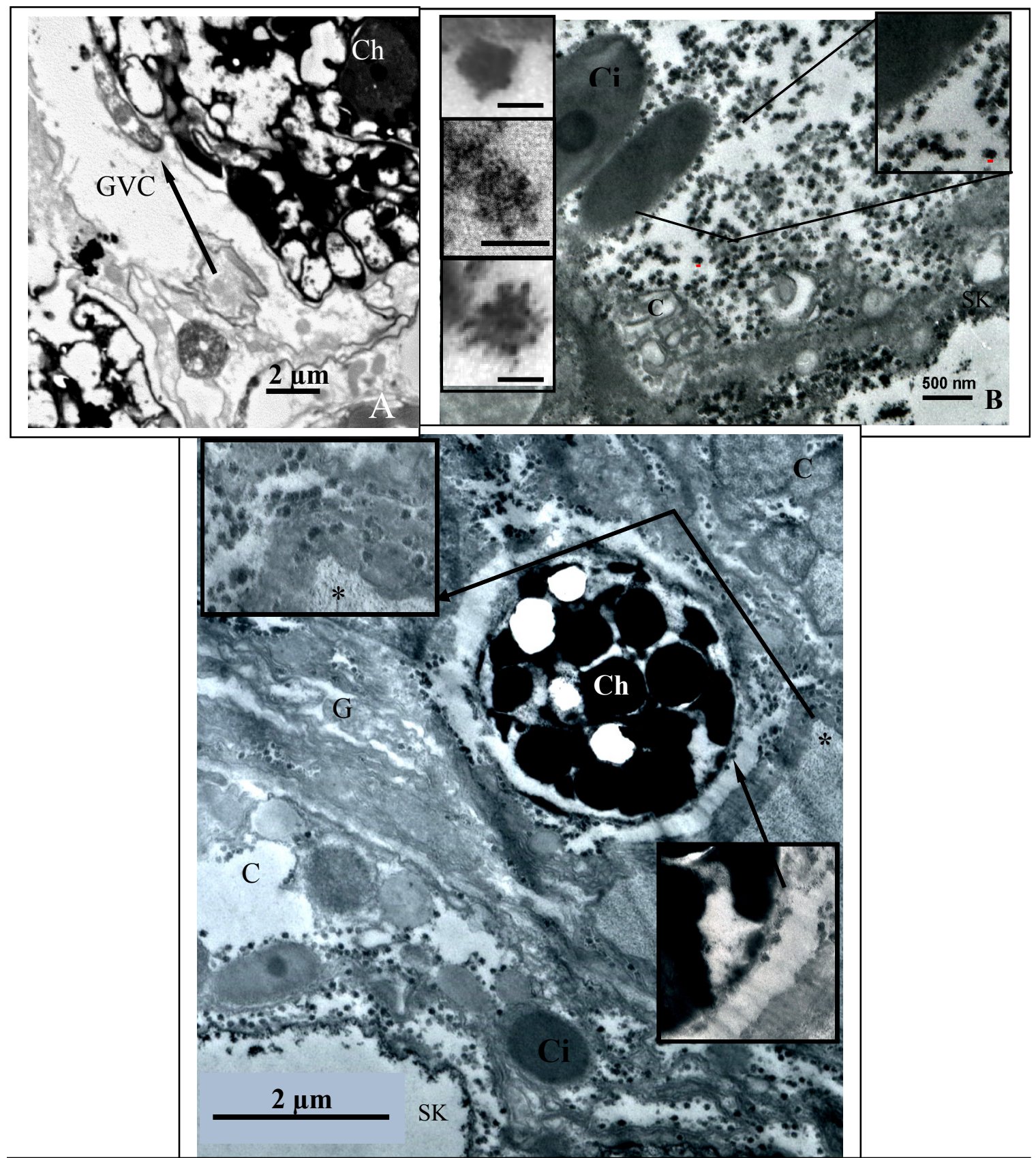

Fig. 4. Bacteria and virus-like particles (VLPs) associated with healthy P. lutea and MPGAs. (A) Rodshaped bacterium (arrow) in healthy tissue. (B) Both healthy coral and (C) MPGA lesions contained VLPs in the cytoplasm of calicodermal cells and less abundantly in (C, insets) intercellular spaces. (B, left insets) VLPs were approximately $60 \mathrm{~nm}$ and did not have a clear polyhedral shape or obvious envelopes. (C) In MPGAs, VLPs associated with membrane of rounded-up chromophore. Cytoplasmic inclusions with unknown contents were abundant in calicodermal cells in healthy $P$. lutea and MPGAs. $\mathrm{G}=$ gastrodermis, $\mathrm{C}=$ calicodermis, $\mathrm{Ci}=$ cytoplasmic inclusions. Other symbols are as in Figure 1. In $\mathrm{B}$ insets top and bottom scale bars $=50 \mathrm{~nm}$, middle bar $=60 \mathrm{~nm}$. 
MPGAs they were also seen in association with the membranes of rounded-up chromophore cells (Fig. 4C, inset). Other types of VLPs were not observed.

\section{DISCUSSION}

\section{Main alterations associated with MPGAs}

This study documents for the first time the ultrastructural differences between tissues from healthy Porites lutea and massive Porites growth anomalies of Porites lutea. Results indicate that a consistent cytopathic effect in type 2 MPGAs was an abundance of ruptured granules (that contain the melanin-like substance) within chromophore cells. The cytopathic effect was the most notable ultrastructure distinction between MPGA type 1 and type 2 and was reflected in their gross morphology (Fig. 1 in Chapter 3). When compared to type 1 MPGAs, type 2 lesions had were paler in appearance in situ, which in other coral genera could result from loss of zooxanthellae or photosynthetic pigments (bleaching). In the case of MPGA type 2, a greater depletion of granule content (i.e., fewer electron-opaque granules) in chromophore cells, compared to type 1, appears to be the reason for being paler (Fig. 1 in Chapter 3, Fig. 1B, Table 1). The two types of lesions were not very different in terms of the proportion of necrotic or degenerated zooxanthellae (Table 2), which was much higher for both type 1 and 2 than in healthy tissue. A greater amount of necrotic and degenerating zooxanthellae compared to healthy tissue would thus explain why both type 1 and 2 MPGAs were paler than healthy tissue. If chromophore cells and their contents play defensive and protective roles for Porites, as the recent literature (Bustamante et al., 1993; Smith, 1996; Rozanowska et al., 1999; Riley, 1997; Nappi and Ottaviani, 2000; Burkhart and Burkhart, 2005; Mydlarz et al., 2008; Palmer et al., 2008) and observations made in this study suggest, a more severe 
degeneration or depletion of chromophore cells in type 2 lesions than that seen in type 1 lesions may be interpreted as a potential cause of type 2 lesions grossly having a more severe effect on coral tissue (i.e., tissue sloughing). It is posited here that in type 1 lesions the coral chromophore cell population is more stable and functional.

There was little evidence of programmed cell-death (PCD), which would include condensation of cytoplasm and nucleus, presence of apoptotic bodies in the cytoplasm, and crenation of plasma membranes combined with a lack of vacuolization and lack of membrane ruptures (Cotran et al., 1999; Dunn et al., 2004). However, there was more evidence of necrosis in a number of cell types and tissues (e.g., rupture of organelle and cell membranes, degeneration of cell contents, and vacuolization of cytoplasm).

\section{Chromophore cells}

Evidence for the chemical content of chromophore cell granules indicates a melanin-like substance is an abundant component (Mydlarz et al., 2008; Palmer et al., 2008; Kaczmarsky, Chapter 3). While melanin is commonly viewed as an efficient photoprotective agent, it also has many other biological functions (Burkhart and Burkhart, 2005). Melanin and its reactive quinone intermediates (like phenoloxidase) in the melanin biosynthetic pathway exhibit antibiotic properties and the polymer itself is an important strengthening element of insect cuticle and plant cell walls (Charoensapsri, 2009). Light absorption by melanin has several biological functions, including shielding photoreceptors (like zooxanthellae) and thermoregulating. Melanin and intermediate molecules in the cascade leading to its formation are also known to be "sticky" substances (Schwahn et al., 2000) and may function to bind damaged tissue together (Thorenquist et al., 1994; Nonaka et al., 1999) and maintain tissue integrity during 
regeneration. It is also a powerful cation chelator and may act as a free radical sink and scavenger of free radicals (Bustamante et al., 1993; Riley, 1997; Rozanowska et al., 1999; Nappi and Ottaviani, 2000).

The increase in chromophore cell granules that appear to be depleted of their content in type 2 lesions may be related to the disease process in that melanin and its precursor molecules have both antimicrobial and cell binding properties (Thorenquist et al., 1994; Nonaka et al., 1999; Schwahn et al., 2000; Burkhart and Burkhart, 2005). Using light microscopy it was observed that in both types 1 and 2 lesions chromophore cell density is significantly lower than in healthy tissue (Kaczmarsky, chapter 3).

This study provided evidence that suggested phagocytic behavior by chromophore cells (Fig. 1A) which may also be associated with the disease process. Lysis of chromophore cell and granule membranes, reduction of granule contents and rounding-up of chromophore cells were all observed in MPGAs. Their behavior indicated a role in wound-healing as they appeared to infiltrate and aggregate in areas where tissue was damaged and absent. Others have reported phagocytic and wound-healing behavior by coral granular amoebocytes (Goldberg et al., 1984; Meszaros and Bigger, 1999; Olano and Bigger, 2000; Mydlarz et al., 2008; Palmer et al., 2008).

In the present study clustering of chromophore cells was observed in all tissue layers where tissue was missing, whereas in GAs of $P$. compressa chromophore cells were observed to preferentially cluster in the aboral tissues (Domart-Coulon et al., 2006). In this study clustering was only rarely seen in the TEM of healthy tissue where they were observed mainly in surface gastrodermal layers, and Domart-Coulon et al. (2006) 
suggested chromophore cells might be involved in the separation of epithelia in GAs of P. compressa. The latter was commonly observed in the present study (Fig. 1C).

Rounded-up chromophore cells were frequently observed within MPGA tissues (Fig. 1E and 4C) but were rare in healthy tissue. Rounding-up of cells associated with GAs has also been noted in acroporid GAs and thought to be suggestive of apoptosis (Work et al., 2008). Vibrio and other bacterial toxins have been observed to cause the rounding-up of cells (Martin, 2004; Rupnick et al., 2005; Li, et al., 2008). Toxin-like activity has been associated with the capsomeres of some viruses (USEPA, 1996) and thus viral toxins may be a possible factor where VLPs are seen in association with the membranes of rounded-up chromophore cells. The rounding-up of cells, which is considered a degenerative condition, is thought to be a cytopathic effect characteristic of some viral diseases, e.g., adenovirus (Bannister et al., 2006). Rounding-up of infected cells was also observed as a typical effect of enterovirus infections (USEPA, 1996). In light microscopy, these rounded-up cells were also observed freely within the gastrovascular cavity (Chapter 3).

The observations of an apparently upregulated secretory behavior among chromophore cells at sites of degenerating tissue and cells (Fig. 1F) suggests a melaninlike substance may be secreted to act as an agglutinin for disassociated cell components to maintain some degree of tissue integrity, as a potential oxygen-scavenger (of reactive oxygen species), and/or as an antimicrobial. In other invertebrates release of such substances from amoebocytes has been reported, for example, a substance in crab amoebocytes was seen to stimulate clotting of crab blood (Bang, 1971). In the intercellular spaces of MPGAs, electron-opaque particles of very variable size and shape 
were frequently observed and are posited to be a functional secretion or released via lysis (Fig. 1D, E, and F) from chromophore cells. TEM indicated discrete membrane disruptions of chromophore cells. Histochemical staining patterns (Kaczmarsky, chapter 3) supports the hypothesis that they are a melanin-like substance. They were not observed in healthy $P$. lutea. Bigger and Hildemann (1982) proposed that the granular amoebocytes of gorgonian corals might regularly lose and regenerate their granules.

The majority of granules in chromophore cells (granular amoebocytes) from healthy P. lutea (Fig. 1A) and type 1 MPGA (Fig. 1C) appeared electron-opaque or "full" whereas the majority of granules in type 2 MPGA chromophore cells were electrontranslucent or "empty" (Fig. 1B). No chromophore cells appeared completely devoid of electron-opaque granules in MPGA type 1 or healthy $P$. lutea although many were in MPGA type 2. Severely necrotic chromophore cells (Fig. 1F) were only observed in type 2MPGAs, occasionally with only the nucleus remaining unruptured. Chromophore cells with apparently $100 \%$ of their granules electron-opaque or "full" occurred more commonly in healthy coral than in type 1 lesions (not statistically analyzed). These conditions may contribute to the relative paleness of type 2 MPGA lesions compared to type 1 or healthy tissue. In unstained histological tissue sections and in fresh cell suspensions chromophore cells are normally strongly pigmented a golden brown color (Galloway et al., 2007).

Overall, the observations of chromophore cells described here are consistent with those of the granular amoebocytes described by Olano and Bigger (2000) and Palmer et al. (2008) in that they also appear as cellular (i.e., inflammatory) responses to injury in 
corals. The present study adds support to their observations of cellular defenses in anthozoans, knowledge of which is still widely lacking.

\section{Zooxanthellae}

There were significantly more zooxanthellae that had moderate to severe vacuolization (Fig. 2D and Table 2) in type 2 lesions than in healthy tissue (42\% of cells versus $\left.15 \% ; X^{2}=15.4, \mathrm{p}<0.001\right)$. Under high stress conditions (high temperature and high light) it has been shown that increased vacuolization can be a result of loss of intracellular contents and/or protoplast shrinkage (Franklin et al., 2004). Thus this feature was used as a sublethal marker in the present study. In TEM of bleached corals, zooxanthellae, like those in MPGAs in the present study (Fig. 2 and Table 2), showed a loss of starch storage granules, attenuated pyrenoid starch caps, increased vacuolization, and formation of small lipid droplets in chloroplasts (Ainsworth and Hoegh-Guldberg, 2008).

Necrotic zooxanthellae were proportionately more common in MPGAs. There were significantly more zooxanthellae that had signs of severe degeneration from type 2 lesions than from healthy tissue $\left(15 \%\right.$ versus $\left.3.2 \% ; X^{2}=5.9, \mathrm{p}<0.05\right)$. Histological examination, using LM, of the same lesions from affected colonies revealed a significant decrease in density of zooxanthellae in both types (Kaczmarsky, Chapter 3) compared to healthy coral. Substantially fewer zooxanthellae in MPGAs, which supply the main constituents of mucus (Brown and Bythell, 2005), may lead to a slower turnover rate of the surface mucus layer (SML) of the coral. A slower turnover rate of mucus could affect the diversity of microbes in the SML (O'Toole et al., 1999), which is believed to play a role in promoting coral heath (Reshef et al., 2006). 
The effect of nutrient-enriched seawater on energy storage in zooxanthellae has been measured by variations of the pyrenoid starch cap in cross-section (Ambariyanto and Hoegh-Guldberg, 1996). Taylor (1968) described the pyrenoid as normally surrounded by a thick electron-lucent sheath (or cap) of starch and pointed out that in aging or starved zooxanthellae the starch cap is lost and in degenerating zooxanthellae starch is lost from granules and the pyrenoid cap. Taylor thus suggested the starch granules seen in healthy zooxanthellae are food storage bodies.

Stored starch was significantly more abundant in zooxanthellae of healthy P. lutea (observed as large granules and sheaths around pyrenoid bodies) than in MPGAs (Fig. 2A and Table 2). Starch granules were rarely observed in zooxanthellae of MPGAs and pyrenoid starch caps were absent or very thin. A decrease in stored starch might decrease the food supply to the host coral. That there were significantly more starch granules and thicker pyrenoid starch caps in zooxanthellae from healthy coral than GA lesions strongly suggest that the stored energy reserves of the symbionts were in a depleted state in the GA lesions (Taylor, 1968).

Some degeneration and expulsion of zooxanthellae are part of a normal cyclic process (Taylor, 1968) and the normal number of degenerate or dead symbiotic zooxanthellae has been estimated to range approximately from 5 to $10 \%$ (Fitt, 1988; Gates and Muscatine, 1992; Franklin et al., 2004). A 5 to $10 \%$ range is similar to the present study where in healthy $P$. lutea the proportion of degenerating zooxanthellae was $3.2 \%$. The difference in proportions of degenerate zooxanthellae in healthy coral $(3.2 \%)$ and MPGAs (15\% in type 2 and $22 \%$ in type 1) was a similar difference as that 
observed between zooxanthellae in healthy coral and those in heat and light stressed corals by Franklin et al. (2004).

Small electron-opaque lipid droplets, presumably chloroplast membrane breakdown products, were significantly more abundant in zooxanthellae of MPGAs (Fig. 2B and Table 2) and were rarely seen in zooxanthellae from healthy tissue. Lipoidal material generally is observed as strongly electron-opaque after osmication even without the use of other cationic agents (Riemersma, 1963). Franklin et al. (2004) similarly found an apparent increase in lipid droplets in temperature and light stressed (bleaching) corals. Salih et al. (1997) not only observed an increase in lipid droplets in coral zooxanthellae under high light/high temperature conditions but also, as in MPGA lesions (Fig. 2B), thick lipid layers where the pyrenoid starch cap is normally located. But in contrast to Salih et al. (1997), the chloroplasts in the MPGAs had little degradation. The weaker osmiophilia of chloroplasts in the MPGAs may reflect a decrease in lipid content of thylakoid membranes, which normally contain large quantities of lipids (Salih et al., 1997), and thus contribute to a small observed increase in lipid globules and/or lipid deposits around pyrenoids.

The small lipid droplets observed within and between chloroplasts presumably develop within zooxanthellae as the result of degeneration of membranes (Salih et al., 1997), as opposed to smaller, diffuse lipid droplets observed in the peri-algal space of healthy zooxanthellae that are presumably the transfer products leaking to the host coral. While some lipids were undoubtedly lost during tissue processing, both healthy and MPGA tissue were processed simultaneously thus the impact would likely have been similar. 
Massive Porites growth anomalies are generally chronic. It is likely that energy for the long-term persistence of these lesions is being translocated from and burdening surrounding healthier tissues. This hypothesis is consistent with Yamashiro et al. (2001) who observed in another species, Montipora informis, that coral tissue energy stores (combined lipids of both coral and zooxanthellae) in areas surrounding GAs were depleted and suggested they are likely shunted to GA tissue to compensate for inadequate energy production within the GA. One possible process to partly explain this may involve the observed VLPs, as plants infected with virus have also been shown to have chloroplasts that had far less starch than chloroplasts from healthy tissue (Gao and Nassuth, 1993). The possible burdening of surrounding tissues is also consistent with histological observations that full tissue thickness of tissue surrounding MPGAs were significantly thinner than tissue from healthy colonies (Kaczmarsky, chapter 3).

It has been observed that coral growth rates can be many times faster in injured than in uninjured corals (reviewed in Henry and Hart, 2005), which might possibly explain, at least in part, the protruding morphology of type 1 lesions (and other GAs). Furthermore, during regeneration of damaged tissue, colony pattern formation (astogeny) may be altered due to altered gastrovascular flow during the regeneration process especially if it is chronic and widespread. In addition, if interstitial or reserve cells are depleted during chronic regeneration altered morphology might result because of altered levels of gene expression since genes that regulate colonial development are likely expressed in interstitial cells (Henry and Hart, 2005). 


\section{Partial characterization of VLPs in Porites lutea}

This is the first study to visually demonstrate the presence of VLPs in healthy Porites tissues and in growth anomaly lesions of a scleractinian coral. One type of VLP observed in aquarium-kept corals (Pavona danai) by Wilson et al. (2005) was in a similar size-class as those in the present study and, similarly, were non-enveloped, cytoplasmic, uniform in size and spherical (i.e., did not have conspicuous polygonal shapes). Interestingly, in the surface mucus layer of massive Porites from Australia (P. lobata, $P$. lutea, and P. australiensis), Davy and Patten (2007) detected a high diversity of VLPs. Patten et al. (2008) also detected non-enveloped, cytoplasmic VLPs of a similar shape and size as those in the present study in healthy and diseased tissues of an Australian acroporid.

The characteristics of the observed VLPs (i.e., uniform size, morphology, distribution, location, and lack of envelope) resemble members of two RNA virus families believed to infect other marine invertebrates (Johnson, 1984; Renault and Novoa, 2004; Lang et al., 2009). These are the Birnaviridae and Reoviridae. Like other RNA viruses the VLPs observed in this study were located exclusively in the cytoplasm (of calicodermal cells) and intercellular spaces. Using metagenomic analyses (not TEM) Wegley et al. (2007) and Vega-Thurber et al. (2008) both detected numerous types of DNA viruses in non-diseased corals of the same genus, Porites. Their methods focused on DNA viruses, which may not detect RNA viruses. RNA viruses recently discovered in association with diseases of marine bivalves that were similar in size and shape to those found in the present study and also without envelopes included Birnaviridae and 
Reoviridae (Renault and Novoa, 2004). Some recent data suggest that viruses might have a role in coral bleaching (Wilson et al., 2001; Davy et al., 2006; Lohr et al., 2007).

The observed VLPs were approximately $60 \mathrm{~nm}$ and were regularly found in extracellular spaces. These two characteristics are further evidence that the VLPs were not ribosomes, which are also much smaller (approximately $20 \mathrm{~nm}$ ). That the VLPs were not membranebound and very uniform and small in size excludes them as peroxisomes or microsomes, both of which tend to be larger, not so uniform in size and membrane-bound. They were also too uniform in size to be glycogen particles.

Although viral diseases have been reported for a wide variety of marine organisms (Munn, 2006), there are still only a few observations of VLPs in Anthozoa. The identity of the VLPs observed here cannot yet be made and the significance of VLPs for involvement in MPGAs is mostly speculative at this point. Clear instances of phagocytosis, viropexis, adsorption, or viral budding of the VLPs were not observed nor were any instances of viral release from the cells. However, these are very short-term events and not easily encountered in TEM. Molecular characterization of VLPs observed in MPGAs is needed.

\section{Additional ultrastructure observations}

Zooxanthellae, degenerated gastrodermal cells, and rounded-up chromophore cells were regularly seen liberated into the gastrovascular cavities of MPGAs (consistent with necrosis) but only rarely in healthy corals. In MPGAs, vacuoles in cells and tissues were common suggesting vacuolar degeneration (Fig. 1C). A near complete loss of cell membranes and tissue architecture occurred in some areas of MPGAs. TEMs of GAs of the coral Pavona clavus from the west coast of Costa Rica also showed a similar 
vacuolarization of tissues (Gateño et al., 2003). Like in GAs of $P$. compressa from Hawaii (Domart-Coulon et al., 2006), large intercellular spaces were also observed between the basal gastrodermis and calicodermis in MPGAs (Fig. 1C). No clear signs of programmed cell death (e.g., apoptosis) were detected in the present study. Thus this does not seem a major process of MPGAs.

Based on comparisons with healthy tissue, the ultrastructure analyses presented here provided evidence that there is a disruption in normal activity associated with the calicodermis in MPGAs that included observations of missing and attenuated (or atrophied) calicodermis, karyolytic and karyorrhexic nuclei, and vacuolization. Although the rare observation of abnormally thick calicodermis with more cuboidal shaped cells containing large granules (Fig. 3 and 4) was consistent with the thick, granular calicodermis of GAs observed with LM described by Domart-Coulon et al. (2006), it appeared a thinning and complete loss of calicodermis were also common in MPGAs. Thus this could partly explain why, in contrast to the normal but enlarged corallite organization of $P$. compressa GAs in Hawaii (Domart-Coulon et al., 2006), the skeletal architecture of MPGAs was highly irregular and had some skeletal areas that were thicker and more dense and others that were thin and more porous.

Along with signs indicating necrosis in the badly degenerated gastrodermal tissue of MPGAs, this study revealed some signs consistent with dysplasia. These included loss of normal architecture, numerous oddly shaped nuclei with little surrounding cytoplasm, loosely organized acellular debris, abundant vacuoles, unrecognizable vesicles, and few other recognizable cell features. While hyperplastic tissues in MPGAs usually involved the characteristic abnormally abundant but normal-looking cells, sometimes within the 
hyperplasia the cells looked abnormal. These epthelial cells appeared dysplastic, were disorganized with odd shapes and sizes, had high nuclear to cytoplasm ratios, and nuclei with abnormal shapes.

In conclusion, this study documents severe tissue irregularity and abnormal cell behavior associated with both type 1 and type 2 MPGAs of $P$. lutea. Confirmation of true neoplasia remains to be accomplished for any coral GA. 


\section{REFERENCES}

Ainsworth, T.D., Fine, M., Roff, G., Hoegh-Guldberg, O., 2007a. Bacteria are not the primary cause of bleaching in the Mediterranean coral Oculina patagonica. ISMEJ 2, 67-73.

Ainsworth, T.D., Kvennefors, E.C., Blackall, L.L., Fine, M., Hoegh-Guldberg, O., $2007 b$. Disease and cell death in white syndrome of acroporid corals on the Great Barrier Reef. Mar. Biol. 151, 19-29.

Ainsworth, T.D., Hoegh-Guldberg, O., 2008. Cellular processes of bleaching in the Mediterranean coral Oculina patagonica. Coral Reefs 27, 593-597.

Ainsworth, T.D., Hoegh-Guldberg, O., 2009. Bacterial communities closely associated with coral tissues vary under experimental and natural reef conditions and thermal stress. Aquat. Biol. 4, 289-296.

Ambariyanto and Hoegh-Guldberg, O., 1996. Nutrient enrichment and the ultrastructure of zooxanthellae from the giant clam Tridacna maxima. Mar. Bid. (Berl.) 125, 359-63.

Bang, F.B., 1971. A factor in crab amoebocytes which stimulates in vitro clotting of crab blood. J. Invertebr. Pathol. 18, 280-283.

Bannister, B., Gillespie, A.S.H., Jones, J., 2006. Infection: Microbiology and Management. Blackwell Publishers, Malden, Massachusetts, U.S.A.

Berner, T., Izhaki, I., 1994. Effect of exogenous nitrogen levels on ultrastructure of zooxanthellae from the hermatypic coral Pocillopora damicornis. Pac. Sci. 48, 254-62.

Bigger, C.H., Hildemann, W.H., 1982. Cellular defense systems of the coelenterata. In: Cohen and Sigel, (Eds.), The Reticuloendothelial System: A Comprehensive Treatise Volume 3: Phylogeny and Ontogeny. pp. 59-87.

Brown, B.E., Bythell, J.C., 2005. Perspectives on mucus secretion in reef corals. Mar. Ecol. Prog. Ser. 296, 291-309.

Burkhart, C.G, Burkhart, C.N., 2005. The mole theory: primary function of melanocytes and melanin may be antimicrobial defense and immunomodulation (not solar protection). International journal of dermatology 44, 340-342.

Bustamante, J., Bredeston L., Malanga, G., Mordoh, J., 1993. Role of Melanin as a Scavenger of Active Oxygen Species. Pigment Cell Research 6, 348 - 353. 
Bythell, J.C., Barer, M.R., Cooney, R.P., Guest, J.R., O'Donnell, A.G., Pantos, O., Le Tissier, M.D.A., 2002. Histopathological methods for the investigation of microbial communities associated with disease lesions in reef corals. Letters in Appl. Microbiology 34, 359-364.

Cervino, J.M., Hayes, R., Goreau, T.J., Smith, G.W., 2004. Zooxanthellae regulation in yellow blotch/band and other coral diseases contrasted with temperature related bleaching: in situ destruction vs expulsion. Symbiosis 37, 63-85.

Chapman, G., 1974. The skeletal system in Muscatine L., Lenhoff H.M. (Eds.), Coelenterate Biology: Reviews and New Perspectives. Academic Press, New York.

Charoensapsri, W., 2009. Gene silencing of a prophenoloxidase activating enzyme in the shrimp, Penaeus monodon, increases susceptibility to Vibrio harveyi infection. Dev. Comp. Immunol. 33, 811-820.

Cotran, R.S., Kumar, V., Collins, T. (Eds.), 1999. Robbins Pathologic Basis of Disease 6th Ed. W.B. Saunders Company, Philadelphia, Pennsylvania, U.S.A.

Couch, J.A., Fournie, J.W. (Eds.), 1993. Pathobiology of Marine and Estuarine Organisms. CRC Press, Boca Raton, Florida.

Crossland, C.J., Barnes, D.J., Borowitzka, M.A., 1980. Diurnal lipid and mucus production in the staghorn coral Acropora acuminata. Mar. Bid. (Berl.) 60, 81-90.

Domart-Coulon I.J., Traylor-Knowles, N., Peters, E., Elbert, D., Downs, C.A., Price, K., Stubbs, J., McLaughlin, S., Cox, E., Aeby, G., Brown, P.R., Ostrander, G.K., 2006. Comprehensive characterization of skeletal tissue growth anomalies of the finger coral Porites compressa. Coral Reefs 25, 531-543.

Danovaro, R., Bongiorni, L., Corinaldesi, C., Giovannelli, D., Damiani, E., Astolfi, P., Greci, L., Pusceddu, A., 2008. Sunscreens Cause Coral Bleaching by Promoting Viral Infections. Environmental Health Perspectives 116, 441-447.

Davy, S.K., Burchett S.G., Dale, A.L., Davies, P., Davy, J.E., Muncke, C., HoeghGuldberg, O., Wilson, W.H., 2006. Viruses: Agents of coral disease? Dis. Aquat. Organ. 69:101-110.

Davy, J.E., Patten, N.L., 2007. Morphological diversity of virus-like particles within the surface microlayer of scleractinian corals. Aquat. Microb. Ecol. 47, 37-44.

Dunn, S.R., Thomason, J.C., Le Tissier, M.D.A., Bythell, J.C., 2004. Heat stress induces different forms of cell death in sea anemones and their endosymbiotic algae depending on temperature and duration. Cell. Death Differ. 11, 1213-1222. 
Elston, R., 1997. Special topic review: bivalve mollusc viruses. World J. Microbiol. Biotechnol. 13, 393-403.

Fautin, D.G., Mariscal, R.N., 1991. Cnidaria: Anthozoa. In: Harrison, F.W., Westfall, J.A. (Eds.), Microscopic Anatomy of Invertebrates, Vol. 2. Placozoa, Porifera, Cnidaria, and Ctenophora. Wiley, N.Y.

Fitt, W.K., 1988. Regulation of zooxanthellae in a marine hydroid. Endocyt. Cell Res. 5, $111-131$.

Franklin, D.J., Hoegh-Guldberg, O., Jones, R.J., Berges, J.A., 2004. Cell death and degeneration in the symbiotic dinoflagellates of the coral Stylophora pistillata during bleaching. Mar. Ecol. Prog. Ser. 272, 117-130.

Galloway, S.B., Work, T.M., Bochsler, V.S., Harley, R.A., Kramarsky-Winters, E., McLaughlin. S,M., Meteyer, C.U., Morado, J.F., Nicholson, J.H., Parnell, P.G., Peters, E.C., Reynolds, T.L., Rotstein, D.S., Sileo, L., Woodley, C.M., 2007. Coral Disease and Health Workshop: Coral Histopathology II. NOAA Technical Memorandum NOS NCCOS 56 and NOAA Technical Memorandum CRCP 4. National Oceanic and Atmospheric Administration, Silver Spring, MD.

Gateño, D., Leon, A., Barki, Y., Cortes, J., Rinkevich, B. 2003. Skeletal tumor formations in the massive coral Pavona clavus. Mar. Ecol. Prog. Ser. 258, 97-108.

Gates, R.D., Muscatine, L., 1992. Three methods for isolating viable anthozoan endoderm cells with their intracellular symbiotic dinoflagellates. Coral Reefs $11,143-145$.

Gao, J.G., Nassuth, A. 1993. Alteration of major cellular organelles in wheat leaf tissue infected with wheat streak mosaic rymovirus (Potyviridae). Phytopathology 83, 2 06-213.

Glynn, P.W., Peters, E.C., Muscatine, L., 1985. Coral tissue microstructure and necrosis: relation to catastrophic coral mortality in Panama. Dis. Aquat. Org. 1, 29-37.

Goldberg, W.M., Makemson, J.C., Colley, S.B., 1984. Entocladia endozoica sp nov., a pathogenic Chlorophyte: structure, life history, physiology, and effects on its coral host. Biol. Bull. 166, 368-383.

Goldberg, W., 2001a. Acid polysaccharides in the skeletal matrix and calicoblastic epithelium of the stony coral Mycetophyllia reesi. Tissue Cell 33, 376-387.

Goldberg, W., 2001b. Desmocytes in the calicoblastic epithelium of the stony coral Mycetophyllia reesi and their attachment to the skeleton. Tissue Cell 33, 388-394. 
Goldberg, W., 2002a. Gastrodermal structure and feeding responses in the scleractinian Mycetophyllia reesi, a coral with novel digestive filaments. Tissue Cell 34, $246-$ 261.

Goldberg, W., 2002b. Feeding behavior, epidermal structure and mucus cytochemistry of the scleractinian Mycetophyllia reesi, a coral without tentacles. Tissue Cell 34, 232-245.

Henry, L., Hart, M., 2005. Regeneration from Injury and Resource Allocation in Sponges and Corals - a Review. Internat. Rev. Hydrobiol. 90, 125-158.

Hunter, C.L., Peters, E.C., 1993. Effects of stress-induced necrosis and 'tumors' on the scleractinian coral, Porites lobata, in Hawaii. Am. Zool. 33, 19.

Houlbrèque F., Ferrier-Pagès, C., 2009. Heterotrophy in Tropical Scleractinian Corals. Biological Reviews 84, $1-17$.

Isa, Y., 1986. An electron microscope study on the mineralization of the skeleton of the staghorn coral Acropora hebes. Mar Biol 93, 91-101.

Johnson, P.T., 1984. Viral diseases of marine invertebrates. Helgol. Meersunters 37, 6598.

Kaczmarsky, L., Draud, M., Williams, E.H., 2005. Is there a relationship between proximity to sewage effluent and the prevalence of coral disease? Caribb. J. Sci. $41,124-137$.

Kaczmarsky, L., 2006. Coral disease dynamics in the Central Philippines. Dis. Aquat. Org. 69, 9-21.

Kaczmarsky, L., Richardson, L.L., 2007. Transmission of growth anomalies between Indo-Pacific Porites corals. J. Invertebr. Pathol. 94, 218-221.

Khanobdee, K., Chumporn Soowannayan, Flegel, T.W., Sukathida Ubol, Boonsirm Withyachumnarnkul, 2002. Evidence for apoptosis correlated with mortality in the giant black tiger shrimp Penaeus monodon infected with yellow head virus. Dis. Aquat. Org. 48, 79-90.

Kurstak, E., (Ed.) 1991. Viruses of Invertebrates. Marcel Dekker, NewYork.

Lang, A.S., Rise, M.L., Culley, A.I., Steward, G.F., 2009. RNA viruses in the sea. FEMS Microbiol. Rev. 33, 295-323.

Li, L., Rock, J.L., Nelson, D.R., 2008. Identification and Characterization of a Repeat-inToxin Gene Cluster in Vibrio anguillarum. Infection and Immunity 76, 26202632. 
Lightner, D.V., 1999. The penaeid shrimp viruses TSV, IHHNV, WSSV, and YHV: current status in the Americas, available diagnostic methods and management strategies. J. Appl. Aquaculture 9, 27-52.

Lohr, J., Munn, C.B., Wilson W.H., 2007. Characterization of a Latent Virus-Like Infection of Symbiotic Zooxanthellae. Appl. Environ. Microbiol. 73, 2976-2981.

Martin, G.G., Rubin, N., Swanson, E., 2004. Vibrio parahaemolyticus and V. harveyi cause detachment of the epithelium from the midgut trunk of the penaeid shrimp Sicyonia ingentis. Dis. Aquat. Org. 60, 21-29.

Meszaros, A., Bigger, C.H., 1999. Qualitative and quantitative study of wound healing processes in the coelenterate, Plexaurella fusifera: spatial, temporal, and environmental (light attenuation) influences. J. Invert. Pathology 73, 321-331.

Miller, S.E., 1986. Detection and identification of viruses by electron microscopy. J Electron Microscopy Technique 4, 265 - 301.

Muller-Parker, G., 1987. Seasonal variation in light-shade adaptation of natural populations of the symbiotic sea anemone Aiptasia pulchella (Carlgren, 1943) in Hawaii. J. Exp. Mar. Btol. Ecol. 112, 165-183.

Muller-Parker, G., Lee, K.W., Cook, C.B., 1996. Changes in the ultrastructure of symbiotic zooxanthellae (Symbiodinium sp., dinophyceae) in fed and starved sea anemones maintained under high and low light. J. Phycology 2, 987-994.

Munn, C.B., 2006. Viruses as pathogens of marine organisms-from bacteria to whales. J. Mar. Biol. Ass. U.K. 86, 453-467.

Muscatine L., Lenhoff H.M., 1974. Coelenterate Biology: Reviews and New Perspectives. Academic Press, New York.

Mydlarz, L.D., Holthouse, S.F., Peters, E.C., Harvell, C.D., 2008. Cellular responses in sea fan corals: granular amoebocytes react to pathogen and climate stressors. PLoS ONE 3, 1-9. (doi:10.1371/journal.pone. 0001811)

Nappi A.J., Ottaviani, E., 2000. Cytotoxicity and cytotoxic molecules in invertebrates. BioEssays 22, $469-480$.

Nonaka, M., Azumi, K., 1999. Opsonic complement system of the solitary ascidian, Halocynthia roetzi. Dev. Comp. Immunol. 23, 421-428.

Olano, C.T., Bigger, C.H., 2000. Phagocytic activities of the gorgonian coral, Swiftia exserta. J. Invert. Path. 76, 176-184. 
O’Toole, R., Lundberg, S., Fredriksson, S., Jansson, A., Nilsson, B., Wolf-Watz, H., 1999. The chemotactic response of Vibrio anguillarum to fish intestinal mucus is mediated by a combination of multiple mucus components. J. Bacteriology 181, 4308-4317.

Paillard, C., Le Roux, F., Borrego, J.J., 2004. Bacterial disease in marine bivalves, a review of recent studies: Trends and evolution. Aquat. Living Resour. 17, 477498.

Palmer, C.V., Mydlarz, L.D., Willis, B.L., 2008. Evidence of an inflammatory-like response in non-normally pigmented tissues of two scleractinian corals. Proc. R. Soc. B 275, 2687-2693.

Patten, N.L., Harrison, P.L., Mitchell, J.G., 2008. Prevalence of virus-like particles within a staghorn scleractinian coral (Acropora muricata) from the Great Barrier Reef. Coral Reefs 27, 569-580.

Perkins, F.O., 1996. Shell disease in the gold lip pearl oyster, Pinctuda maxima and the Eastern oyster, Crassostrea virginica. Aquat. Living Resour. 9, 159-168.

Peters, E.C., Halas, J.C., McCarty, H.B., 1986. Calicoblastic neoplasms in Acropora palmata, with a review of reports on anomalies of growth and form in corals. J. Natl. Cancer Inst. 76, 895-912.

Renault, T., Novoa, B., 2004. Viruses infecting bivalve molluscs. Aquat. Living Res., 17, 397-409.

Renegar, D.A., Blackwelder, P.L., Gochfeld, D.J., 2007. Ultrastructural Analysis in the Elucidation of Disease in Corals. Microsc. Microanal. 13, 272-273.

Riemersma, J.C., 1963. Osmium tetroxide fixation of lipids: nature of the reaction products. J. Histochem. Cytochem. 11, 436.

Riley, P.A., 1997. Molecules in Focus: Melanin. Int. J. Biochem. Cell Bioly. 29, 12351239.

Roff, G., Kvennefors, E.C.E., Ulstrup, K.E., Fine, M., Hoegh-Guldberg, O., 2008. Coral disease physiology: the impact of acroporid white syndrome on Symbiodinium. Coral Reefs 27, 373-377.

Rózanowska, M., Sarna, T., Land, E.J., Truscott, T.G., 1999. Free radical scavenging properties of melanin: Interaction of eu- and pheo-melanin models with reducing and oxidising radicals. Free Radical Biology and Medicine 26, 518-525. 
Salih, A., Hoegh-Guldberg, O., Cox, G., 1998. Bleaching Responses of Symbiotic Dinoflagellates in Corals: The Effects of Light and Elevated Temperature on their Morphology and Physiology In: Greenwood, J.G., Hall, N.J., (Eds.), Proceedings of the Australian Coral Reef Society 75th Anniversary Conference, Heron Island October 1997. School of Marine Science, The University of Queensland, Brisbane. pp. 199-216.

Sánchez-Martínez, J.G., Aguirre-Guzmán, G., Mejía-Ruíz, H., 2007. White Spot Syndrome Virus in cultured shrimp: A review. Aquaculture Res. 38, 1339-1354.

Schwahn, D.J. 2001.Tyrosine Levels Regulate the Melanogenic Response to [alpha]Melanocyte-Stimulating Hormone in Human Melanocytes: Implications for Pigmentation and Proliferation. Pigment Cell Research. 14, 32-39.

Sparks, A.K. 1985. Synopsis of Invertebrate Pathology Exclusive of Insects. Elsevier Science Publishers, N.Y.

Strychar, K.B., Sammarco, P.W., 2009. Exaptation in corals to high seawater temperatures: Low concentrations of apoptotic and necrotic cells in host coral tissue under bleaching conditions. J Experimental Marine Biology and Ecology $369,31-42$.

Taylor, D.L. 1968. In situ studies on the cytochemistry and ultrastructure of a symbiotic marine dinoflagellate. Journal of the Marine Biological Association of the United Kingdom 48, 349-366.

Thorenquist, P., Johansson, M.W., Soderhall K., 1994. Opsonic activity of cell adhesion proteins and b-1,3-glucan binding proteins from two crustaceans. Dev. Comp. Immunol. 18, 3-12.

USEPA (1996). EPA/600/R-95/178 ICR Microbial Laboratory Manual.

Vega-Thurber, R.L., Barotta, K.L., Halla, D., Liua, H., Rodriguez-Muellera, B., Desnuesa, C., Edwards, R.A., Haynesa, M, Anglya, F.E., Wegley, L., Rohwer, F.L., 2008. Metagenomic analysis indicates that stressors induce production of herpes-like viruses in the coral Porites compressa. PNAS 105, 18413-18418.

Walker, P.J., Mohan, C.V., 2009. Viral disease emergence in shrimp aquaculture: origins, impact and the effectiveness of health management strategies. Rev. Aquaculture $1,125-154$.

Wegley, L., Edwards, R., Rodriguez-Brito, B., Liu, H., Rohwer, F., 2007. Metagenomic analysis of the microbial community associated with the coral Porites astreoides. Environ. Microbiol. 9, 2707-2719. 
Wilson, W.H., Francis, I., Ryan, K., Davy, S.K., 2001. Temperature induction of viruses in symbiotic dinoflagellates. Aquatic Microbial Ecology 25, 99-102.

Wilson, W.H., Dale, A.L., Davy, J.E., Davy, S.K., 2005. An enemy within? Observations of virus-like particles in reef corals. Coral Reefs 24, 145-148.

Work, T.M., Aeby, G.S., Coles, S.L., 2008. Distribution and morphology of growth anomalies in Acropora from the Indo-Pacific. Dis. Aquat. Org. 78, 255-264.

Yamashiro H., Hirosuke, O., Onaga, K., Iwasaki, H., Takara, K., 2001. Coral tumors store reduced levels of lipids. J. Exp. Mar. Biol. Ecol. 265, 171-179.

Yee, A., Dungan, C., Hamilton, R., Goedken, M., De Guise, S., Sunila., I., 2005. Apoptosis of the protozoan oyster pathogen Perkinsus marinus in vivo and in vitro in the Chesapeake Bay and the Long Island Sound. J. Shellfish Res. 24, 10351042 .

Yellowlees, D., Alwyn, T., Rees, V., Leggat, W., 2008. Metabolic interactions between algal symbionts and invertebrate hosts. Plant, Cell and Environment 31, 679-694. 
CHAPTER 5

\section{SUMMARY AND FUTURE DIRECTIONS}


Coral reefs are ecosystems characterized by immense beauty, fascinating adaptations, and rich biodiversity. They also provide many critical ecosystem services to humans, which includes providing a majority of the dietary protein to a majority of people living in many tropical countries like the Philippines. Much of the beauty and services are dependent upon sustainable and diverse populations of coral. Unfortunately, diseases have reduced many coral populations. Along with diseases are other threats that may act synergistically with disease or induce disease, such as global-warming, soil erosion, run-off, sewage effluent, ocean acidification, coastal construction, and destructive fishing practices. Disease epizootics can result in ecosystem phase shifts in coral reefs, from communities dominated by corals to those dominated by algae as has happened in many Caribbean reefs. In over 30 years of studying numerous Caribbean reefs I have observed this shift in a majority of locations with only one instance of recovery to a coral dominated state (albeit one with much lower coral diversity).

Amazingly, for an area of the world considered to be the center of global coral diversity, very little is known about coral diseases of the Philippines. The research presented here makes substantial contributions to help fill that void.

The data presented in this dissertation are the combined results of field and laboratory studies of the two most common diseases in the Philippines, massive Porites growth anomalies (MPGAs) and ulcerative white spot disease (UWS). These studies revealed new connections between disease prevalence and environmental conditions and yielded new descriptions of tissue and cell alterations associated with disease. The study also provided the first evidence of virus-like particles (VLPs) in healthy Porites tissues and in growth anomaly (GA) lesions of scleractinian corals. 
Chapter two describes the first study to quantitatively detect positive correlations between MPGA prevalence and colony density, and organic carbon and nitrogen concentrations. It is also the first study to detect a positive correlation between UWS prevalence and phosphorous levels. In studies of other coral diseases similar positive correlations with disease prevalence were observed involving density-dependence (Bruno et al, 2007) and nutrients (Kuta and Richardson, 2002; Bruno et al., 2003; Baker et al., 2007).

Reef sites with diseases at chronic high levels that appear to be the result of a chronically degraded environment, such as those in the present study, may act as disease reservoirs that perpetuate and/or facilitate the spread of coral disease. The potential for the diseases to spread from such reservoirs would likely increase during periods of heightened environmental stress (e.g., severe warming events).

Chapter three describes the first study to quantitatively show, using light microscopy, significant and consistent histologic alterations associated with coral growth anomalies. These alterations included reductions in zooxanthella densities, changes in chromophore cell (granular amoebocytes) densities associated with the time of day, thickening of coral tissue that indicated proliferation of gastrovascular canals and associated cells, swelling of the surface epidermis, widening of the most basal gastrovasular canals, and thickening of the most basal skeleton. In MPGAs, a significant decrease of symbiotic zooxanthellae, which supply nutrients to the coral, likely diminished physiological functions (e.g., mucus production, reproduction, and tissue repairs). 
Qualitatively, the gastrodermis appeared swollen, tissue necrosis was abundant, many mucocytes in the surface epidermis and gastrodermis were hypertrophied (swelling) and lysed, strong eosinophilia was associated with the calicodermis, gastrovascular canals in the more oral regions were constricted by mucus, cell debris, and hypertrophied mucocytes and gastrodermal cells. Alterations associated with both types of MPGAs (swelling and loss of cells and tissue, thinning and sloughing tissues, skeletal abnormalities, and reduction in activity of phagocytes/chromophore cells) resembled tissues of other marine animals exposed to bacterial, fungal or viral toxins.

In type 2 MPGAs, chromophore cell content appeared more depleted than in type 1 and their density distribution patterns were different. The most basal gastrovascular canals were significantly wider in type 2 than type 1 . In contrast to type 2 MPGAs and healthy P. lutea, the full tissue thickness of type 1 MPGAs was consistently thickened. The tissues in type 2 MPGAs were thinner than healthy P. lutea.

A notable characteristic of both types of MPGAs was that the sporadically located swollen mucocytes (singly and in clusters) microscopically resembled blisters and resulted in an overall thickening of the surface epidermis. These swollen tissues, combined with a massive infiltration of chromophore cells into these tissues, fulfill the definition of an inflammatory response. This inflammatory pattern is a new observation in corals with the only other similar description being that of Domart-Coulon et al. (2006) who observed the infiltration of chromophore cells into thickened basal epithelia of GA lesions in the branching Hawaiian species, $P$. compressa.

Gastrovascular canals (GVCs) are conduits for waste and nutrient exchange and in MPGAs were frequently constricted or blocked by swollen cells, mucus and cell 
debris. The full tissue thickness of type 1 MPGAs was consistently thickened because of a proliferation of GVCs and associated cells, which I surmised may be a means to compensate for a reduction in overall exchange via the gastrovascular canals. Type 2 lesions were more variable and had many very thin degraded areas. Based on the histology, type 1 MPGAs appeared in a more stabilized state than type 2 and are perhaps a strategy to deal with localized stressors.

One of the most notable, previously undescribed, cellular phenomena involved the apparent nocturnal migration of chromophore cells into the surface epidermis and basal calicodermis in MPGA lesions where they appear to conduct wound-healing activities. These activities include forming layers in degraded epithelia and secreting a melanin-like substance. During the day they migrate to the interior away from the layer of zooxanthellae in the surface epithelia possibly to maximize photosynthate production (i.e., reducing their shading affect) since the zooxanthellae population is significantly reduced in MPGAs.

Further first time observations included: (1) chromophore cells, en masse, exhibiting phagocytic-like behavior upon abnormal growths, necrotic cells, bacteria, and protozoa (also observed in TEM); (2) the positive correlation of chromophore cell densities with zooxanthellae densities in healthy P. lutea in the day but not in MPGAs suggesting they may modulate the rate photosynthesis in healthy $P$. lutea through shading; (3) wound-healing behavior of chromophore cells, chromophore cell granules, and secretions in damaged tissues as evidenced by their plugging of gaps en masse in degraded epithelia; (4) secretions of a melanin-like substance concentrated within the mesoglea in close proximity to necrotic tissues as well as within degrading and necrotic 
tissues (also detected with TEM) suggests the mesoglea may function as part of a humoral defense system; (5) degranulation of chromophore cell granules and attachment of these granules to protozoa and cellular structures suggests their possible role in defense since melanin is known to have antimicrobial and free radical-scavenging properties; (6) chromophore cell granules depleted of their melanin-like substance within MPGAs in combination with the previous observation supports the hypothesis that the melanin-like substance is being used up for wound-healing and defenses; (7) the association of MPGAs with an abundance of fungus-like filaments suggests possible opportunistic fungal involvement in the disease process; (8) the abundance of fungus-like filaments suggests the prevailing environmental conditions may favors fungal proliferation ; and (10) formation of a granuloma-like structure in association with neoplastic growths in a coral GA.

The histopathological component of this study also revealed a clear case of hyperplasia associated with MPGA type 1 evidenced by a significant increase in gastrovascular canals (GVCs) and the associated cells. In type 2 MPGAs, small patchy areas consisting of growths of poorly differentiated cells protruding from the tissue surface and inwardly into GVCs, resembling wart-like lesions, may be simple forms of neoplasia and not hyperplasia. Such cells were both poorly differentiated and appeared to be actively growing, seemingly unchecked, in abnormal locations. These abnormal growths may be the first observation of true neoplasia in corals. However, because coral tissue is not vascularized and each single-celled layer of epithelia in healthy coral requires contact with surrounding water for proper physiological exchanges, as these 
abnormal masses enlarge they must self-destruct from a lack of waste and nutrient exchange and probably make up part of the sloughing tissues observed in type 2 lesions.

Chapter 4 examined quantitatively and qualitatively the ultrastructural characteristics associated with MPGAs and analyses therein detected a number of significant alterations that would not have been detected using light microscopy. These included the following.

(1) Quantitative evidence that the melanin-like substance within chromophore cell granules of type 2 lesions was significantly depleted. This depleted state suggests the use of the melanin-like substance, possibly in wound-healing activities (see Chapter 3 ), is exceeding its production. Thus, type 2 MPGAs may be a more unstable disease state than type 1.

(2) The detection of significant reductions in the energy-storage (starch) organelles in the zooxanthellae of MPGA lesions.

(3) The detection of significant increases in membrane breakdown products in MPGA lesions.

(4) The detection of significantly more necrotic and vacuolated zooxanthellae in MPGA lesions.

(5) Observation of virus-like particles in coral tissues that had cell-type specificity for calicodermal cells. The presence of VLPs in type 2 lesions in combination with the detection of small patchy protuberant areas of neoplastic and/or hyperplastic growths of poorly differentiated cells suggests a possible relationship.

The apparent skeletal abnormalities consistently associated with MPGAs may simply be the result of a diminished allocation of resources to skeletogenesis in favor of 
tissue regeneration needs. But, alternatively, the observation of virus-like particles with cell-type specificity for calicodermal cells (the cell type likely responsible for skeleton production) suggests the possibility of their involvement in the development of abnormal skeleton.

The combined results of this dissertation have led to the following proposals regarding the MPGA disease process.

(1) A characteristic common to both MPGAs and sediment/light-stressed corals (Hodel and Vargas-Angel, 2007; Vargas-Angel et al., 2007) is an abundance of swollen epithelial cells, particularly mucocytes and gastrodermal cells. Histological examination qualitatively indicated that many of the gastrovascular canals in MPGAs, largely in the upper (more oral) portions, were reduced or completely blocked by swollen mucocytes and gastrodermal cells as well as large amounts of mucus and cell debris not seen in healthy coral. The mucus and cell debris appear to be a result of lysed cells and degraded tissues as evidenced by long stretches of missing gastrodermal layers, observations of cells in the process of rupturing, and abundant necrotic tissue. It is proposed here that this consistent feature contributes to the coral's hyperplasia - that it is the abnormal proliferation of gastrovasular canals to compensate for a restricted exchange of wastes and nutrients as a result of GVC blockage by tissue swelling, mucus, and cell debris.

(2) It is further proposed that type 1 lesions are a more stable state of MPGAs while type 2 lesions are more dynamic in that more active tissue loss appears to be occurring. Perhaps type 2 MPGAs experience a higher level of attack from a more diverse and 
abundant pool of invaders. MPGA lesions may simply be a natural biological strategy to adapt to difficult environmental conditions.

(3) MPGA lesions show more swelling in the upper (more oral) regions of the coral tissue suggesting that a causative agent is associated with the upper region, perhaps bacteria in the surface mucus layer. Attack from the surface mucus layer might explain the significant increase in GVC diameter in the more basal, possibly less impacted, region of the tissues. I propose it is in the more basal region, in the case of MPGAs, where the coral is compensating, with a proliferation of tissues to create wider and additional GVCs.

(4) In type 2 lesions there appeared qualitatively to be a greater abundance of fungus-like filaments associated with the most basal tissues than seen in healthy coral or type 1 lesions. It is possible that the tissues in type 2 lesions are being attacked by endolithic fungi from within the skeleton thus inhibiting to some extent a proliferative development of GVCs that may otherwise stabilize the lesion, hence the more diffuse edge and sloughing tissues observed in type 2 lesions. It appears there may be some compensatory response by both types of MPGAs by producing, as a possible defense response, a thicker basal skeleton. The putative endolithic fungi in type 2 MPGAs should be considered at least a potential secondary disease agent.

(5) Numerous studies on elevated nutrient levels and temperatures have related these to increases in marine fungi populations (Moss, 1986; Valiela, 1995; Bruno et al., 2003; Baker et al., 2007; Ward et al., 2007; Vega-Thurber, et al., 2008). The combination of the investigation of environmental correlates (Chapter 2) and histopathological studies (Chapters 3 and 4) has led me to consider that a potential relationship exists 
between elevated levels of nutrients and organic carbon, high prevalence of MPGAs, and the abundance of endolithic fungi associated with MPGAs. It is thus proposed here that these MPGA lesions may not resolve in the Philippine study site (Kaczmarsky, 2006) because of chronically elevated nutrient levels in the water column and sediments that favor the proliferation of agents that contribute to the persistence of MPGAs such as endolithic fungi and microorganisms in the surface mucus layer. Better water quality may explain why similar MPGA lesions have been seen to resolve in other locations (Hawaii; Hunter, 1999).

(6) It is proposed here that new MPGA lesions may develop not exclusively as a result of transmission but might arise in colonies that already contain an abundance of native endolithic fungi that sustain injuries. These injuries may give resident organisms an opportunity to advance to the point of overwhelming the regenerative abilities of the coral. The apparent transmission observed by direct contact experiments by Kaczmarsky and Richardson (2007) might be explained by minor injuries at the point of contact. In further support are observations that fresh fish bites can induce MPGA lesions (pers. obs.). Similarly, Moss (1986) demonstrated that a wound was required for fungal infection to occur in experiments with crustacean shell disease. In this study only a small amount of fungal material placed in the wound was necessary to produce infections. Yarden et al. (2007) suggested endolithic fungi are native residents that proliferate opportunistically after the authors detected a four-fold increase in fungi in diseased Acropora and further suggested they are secondary invaders. 
To further expand our understanding of these and other coral diseases it is recommended that more detailed, hypothesis-driven investigations of the mechanistic interactions be explored focusing on the following relationships.

(1) Chromophore cell-zooxanthellae interactions.

(2) Bacterial and fungal toxins and their histological effects on diseased and healthy coral using commercially available and newly isolated toxins. These should include the effects on zooxanthella and chromophore cell densities and on the contents and membranes of mucocytes and chromophore cells (i.e., the melanin-like substance).

(3) The relationships between diseased coral and various nutrient, organic carbon, sedimentation, turbidity, pollutant, and temperature regimes using controlled experiments and samples collected from the field.

(4) The relationships between mechanical injuries and disease inducement, especially combined with elevated environmental variables, under both field and laboratory conditions.

(5) Assessment of virus populations and various environmental regimes using higher resolution TEM.

The addition of measuring stress proteins and examining associated microbial communities using molecular and culture-dependent techniques under different experimental regimes would further enhance our understanding. Metagenomic analyses and pyrosequencing would also be informative, although knowledge gained through less expensive methods may suffice for making effective management decisions.

Research into the wound-healing aspect and other potential immunological properties provided by the population of chromophore cells, which are unique to the 
genus Porites, should be of interest to not only coral biologists but also others studying disease and immunology.

The populations of diseased corals are sufficiently large in SE Negros Island to allow for extensive experimentation that utilizes diseased coral, making this region ideal for such research. The very close proximity of laboratory facilities (literally a few meters from the reef) makes this area especially well-suited for coral disease research.

As human populations steadily climb, more sewage effluent and run-off will impact the reefs, likely worsening coral losses through disease and bio-erosion. However, mitigation to alleviate these stressors is possible through education about better gleaning practices, the addition of some sewage treatment or deep-water pipelines, and improved management of agricultural and aquacultural run-off. 


\section{REFERENCES}

Bak, R.P.M. 1983. Neoplasia, regeneration and growth in the reef-building coral Acropora palmata. Mar. Biol. 77, 221-227.

Baker, D.M., MacAvoy, S.E., Kim, K., 2007. The relationship between water quality, $\Delta 15 \mathrm{~N}$, and aspergillosis of Caribbean sea fan corals. Mar. Ecol. Prog. Ser. 343, 123-130.

Bayer, F.M., Grasshoff, M., Verseveldt, J., 1983. Illustrated Trilingual Glossary of Morphological and Anatomical Terms Applied to Octocorallia. Leiden: E.J. Brill, Dr. W. Backhuys.

Bruno, J.F., Petes, L.E., Harvell, C.D., Hettinger, A., 2003. Nutrient enrichment can increase the severity of coral diseases. Ecol. Lett. 6, 1056-1061.

Bruno, J.F., Selig, E.R., Casey, K.S., Page, C.A., Willis, B.L., Harvell, C.D., Sweatman, H., Melendy, A.M., 2007. Thermal stress and coral cover as drivers of coral disease outbreaks. PLoS Biol. 5, 1-8.

Carson, F.L. 1997. Histotechnology: A Self-Instructional Text. American Society of Clinical Pathologists.

Coris, 2006. NOAA's Coral Reef Information System, Glossary.

Domart-Coulon, I.J., Traylor-Knowles, N., Peters, E., Elbert, D., Downs, C.A., Price, K., Stubbs, J., McLaughlin, S., Cox, E., Aeby, G., Brown, P.R., Ostrander, G.K., 2006. Comprehensive characterization of skeletal tissue growth anomalies of the finger coral Porites compressa. Coral Reefs 25, 531-543.

Dorland, W.A.N. 2006. Dorland's Illustrated Medical Dictionary. Saunders, W.B.

Duerden, J. 1902. West Indian madreporarian polyps. National Academy of Sciences 7: 399-648.

Fautin DG, Mariscal RN (1991) Cnidaria: Anthozoa. In: Harrison FW, Westfall JA (eds) Microscopic Anatomy of Invertebrates, Vol. 2. Placozoa, Porifera, Cnidaria, and Ctenophora. Wiley, NY. 474 pp

Galloway, S.B., Work, T.M., Bochsler, V.S., Harley, R.A., Kramarsky-Winters, E., McLaughlin. S,M., Meteyer, C.U., Morado, J.F., Nicholson, J.H., Parnell, P.G., Peters, E.C., Reynolds, T.L., Rotstein, D.S., Sileo, L., Woodley, C.M., 2007. Coral Disease and Health Workshop: Coral Histopathology II. NOAA Technical Memorandum NOS NCCOS 56 and NOAA Technical Memorandum CRCP 4. National Oceanic and Atmospheric Administration, Silver Spring, MD. 
Goldberg, W.M. 2001. Acid polysaccharides in the skeletal matrix and calicoblastic epithelium of the stony coral Mycetophyllia reesi. Tissue and Cell 33, 376-387.

Goldberg, W. 2002a. Feeding behavior, epidermal structure and mucus cytochemistry of the scleractinian Mycetophyllia reesi, a coral without tentacles. Tissue and Cell $34,232-245$.

Goldberg, W. 2002b. Gastrodermal structure and feeding responses in the scleractinian Mycetophyllia reesi, a coral with novel digestive filaments. Tissue and Cell 34, 246-261.

Hodel, E.C., Vargas-Ángel, B., 2007. Histopathological Assessment and Comparison of Sediment and Phosphate Stress in the Staghorn coral, Acropora cervicornis. Microsc. Microanal. 13(Suppl. 2), 220-221.

Hunter, C.L. 1999. First records of coral disease and tumors on Hawaiian reefs. In: Maragos, J.E., Grober-Dunsmore, R. (Eds.), Proc. Hawaii Coral Reef Mon. Workshop. pp 73-97.

Hyman, L.H. 1940. The Invertebrates: Protozoa through Ctenophora. McGraw-Hill Book Company.

Kaczmarsky, L., 2006. Coral disease dynamics in the Central Philippines. Dis. Aquat. Org. 69, 9-21.

Kaczmarsky, L., Richardson, L.L., 2007. Transmission of growth anomalies between Indo-Pacific Porites corals. J. Invertebr. Pathol. 94, 218-221.

Kaiser, H. (Ed.) 1981. Neoplasms - Comparative Pathology of Growth in Animals, Plants and Man. Williams and Wilkins, Baltimore.

Kuta, K.G., Richardson, L.L., 2002. Ecological aspects of black band disease of corals: relationships between disease incidence and environmental factors. Coral Reefs 21:393-398

Leggat, W., Badger, M.R., Yellowlees, D., 1999. Evidence for an Inorganic CarbonConcentrating Mechanism in the Symbiotic Dinoflagellate Symbiodinium sp. Plant Physiol. 121, 1247-1255.

Mariscal, R. N. 1984. Cnidaria: Cnidae, In: Bereiter-Hahn, J., Matoltsy, A., Richards, K. S. (Eds.), Biology of the Integument. Springer-Verlag. New York p. 57-68.

Moss, S.T. (Ed.), 1986. The biology of marine fungi. Cambridge University Press. 
Palmer, C.V., Mydlarz, L.D., Willis, B.L., 2008. Evidence of an inflammatory-like response in non-normally pigmented tissues of two scleractinian corals. Proc. R. Soc. B 275, 2687-2693.

Peters, E.C. 1984a. A survey of the normal and pathological histology of scleractinian corals with an emphasis on the effects of sedimentation stress, chap 1. Doctoral Dissertation, Graduate School of Oceanography, University of Rhode Island, Kingston, RI, pp 1-145.

Peters, E.C. 1984b. A survey of cellular reactions to environmental stress and disease in Caribbean scleractinian corals. Helgol Meeresunters 37, 113-137.

Petes, L.E., Harvell, C.D., Peters, E.C., Webb, M.A.H., Mullen, K.M., 2003. Pathogens compromise reproduction and induce melanization in Caribbean sea fans. Mar. Ecol. Prog. Ser. 264, 167-171.

Pharma. 2006. Medi-Lexicon, Medical Terms Dictionary.

Puverel, S., Tambutte E., Zoccola, D., Domart-Coulon, I., Bouchot, A., Lotto, S., Allemand, D., Tambutte, S., 2005. Antibodies against the organic matrix in scleractinians: a new tool to study coral biomineralization. Coral Reefs 24, 149156.

Stedman, T. 1995. Stedman's Medical Dictionary, 26th Edition ed. Williams \& Wilkins.

Smith, C.B. 2004. Water clarity flux due to variable light intensity and its effects on fluorescent proteins of Porites porites: A hard coral from the tropical Western Atlantic. PhD dissertation. George Mason University.

Sparks, A.K., 1985. Synopsis of Invertebrate Pathology Exclusive of Insects. Elsevier Science Publishers.

Stachowitsch, M. 1992. The Invertebrates: An Illustrated Glossary. Wiley-Liss.

Upton, S.J., Peters, E.C. 1986. A new and unusual species of Coccidium (Apicomplexa: Agamococcidiorida) from Caribbean scleractinian corals. J. Invertebr. Pathol. 47, 184-193.

Valiela, I. 1995. Marine Ecological Processes. Springer-Verlag, New York.

Vargas-Ángel, B., Peters, E.C., Kramarsky-Winter, E., Gilliam, D.S., Dodge, R.E., 2007. Cellular reactions to sedimentation and temperature stress in the Caribbean coral Montastraea cavernosa. J. Invertebr. Pathol. 95, 140-145. 
Vega-Thurber, R.L., Barotta, K.L., Halla, D., Liua, H., Rodriguez-Muellera, B., Desnuesa, C., Edwards, R.A., Haynesa, M, Anglya, F.E., Wegley, L., Rohwer, F.L., 2008. Metagenomic analysis indicates that stressors induce production of herpes-like viruses in the coral Porites compressa. PNAS 105, 18413-18418.

Wobeser, G.A. 1981. Diseases of Wild Waterfowl. Plenum Press, New York.

Ward, J.R., Kim, K., Harvell, C.D., 2007. Temperature affects coral disease resistance and pathogen growth. MEPS 329, 115-121.

Yarden, O., Ainsworth, T.D., Roff, G., Leggat, W., Fine, M., Hoegh-Guldberg, O., 2007. Increased Prevalence of Ubiquitous Ascomycetes in an Acropoid Coral (Acropora formosa) Exhibiting Symptoms of Brown Band Syndrome and Skeletal Eroding Band Disease. AEM 73, 2755-2757. 


\section{APPENDIX}

\section{GLOSSARY}

Aboral - region of polyp directly opposed to, away from, or remote from the mouth; the terms Basal or Proximal can also be used to describe this region. (Dorland, 2006)

Amoebocyte - a cell possessing pleomorphic form and high elasticity, the principal cellular defense element of Cnidaria and typically found in the mesoglea. Granular amoebocytes contain small, dense, acidophilic granules in the cytoplasm, may secrete collagen fibers or sclerites, phagocytize and digest particulate matter, or differentiate into other cell types. (Fautin and Mariscal, 1991)

Apoptosis (a form of programmed cell death) - a morphologic pattern of cell death formation of cytoplasmic blebs, and fragmentation of the cell into membrane-bound affecting single cells, marked by shrinkage of the cell, condensation of chromatin, apoptotic bodies that are phagocytosed by other cells. (Dorland, 2006; Stedman, 1995)

Atrophy - diminution of tissues, organs, or entire body, as from death and reabsorption of cells, diminished cellular proliferation, decreased cellular volume, malnutrition, or lessened function. (Stedman, 1995)

Attenuated - thinned or weakened, cause unknown. (Stedman, 1995)

Basal - situated near the base of a structure in relation to a specific reference point, opposite of apical. (Stedman, 1995)

Body Wall - the three layers of tissues (epidermis, mesoglea, gastrodermis) that form the surfaces of the polyp, enclosing the gastrovascular cavity and, in colonial corals, the gastrovascular canals. (Bayer et al., 1983; Goldberg, 2002b)

Surface Body Wall - in contact with seawater, covering the coenenchyme, tentacles, oral disk, peristome, and polyp neck zone and column (hexacoral).

Basal Body Wall - the calicodermis, mesoglea, and gastrodermis that covers the exoskeleton of the scleractinian coral, surrounding the gastrovascular cavity and canals.

Calicoblast - primary cell type of the calicodermis that secretes the organic matrix involved in calcification and formation of the skeleton in the scleractinians. (Puverel et al., 2005)

Calicodermis (= Calicoblastic Epithelium) - the thin but complex layer of ectodermally derived cells around a scleractinian polyp whose primary function is building the exoskeleton. In a colonial coral, as new polyps are formed, the calicodermis 
continues as the cell layer immediately adjacent to the skeleton of the interconnecting gastrovascular canals in imperforate corals and completely surrounds the gastrovascular canals embedded in the exoskeleton in perforate corals. Most of the cells are modified to secrete an organic matrix that may have a crucial role in the formation of aragonite crystals to form the exoskeleton. These cells, currently referred to as calicoblasts, do not form aragonite intracellularly. Other cells in the calicodermis are modified to attach the tissue to the exoskeleton. This epithelium can also contain mucocytes, pigment cells, or amoebocytes, but usually lacks cnidocytes. (Goldberg, 2002b; Goldberg, 2001; Peters, 1984a, Galloway et al., 2007)

Chromophore Cell - amoeboid cell containing cytoplasmic pigment granules in the scleractinian genus Porites. The granules appear yellow to tan when stained with hematoxylin and eosin using incandescent light microscopy and are bright green in unstained polyp sections when using a filter for green fluorescent protein with epifluorescence microscopy. (Duerden, 1902; Smith, 2004)

Cnidocyte - epithelial cell that can produce a cnida in the Cnidarians. (Mariscal, 1984)

Coccidian - a single-celled organism belonging to the protistan Phylum Apicomplexa, characterized by merogony and a life cycle comprising both sexual and asexual stages, parasitic in epithelial cells of invertebrates and vertebrates. (Upton and Peters, 1986)

Coenosarc (or Coenenchyme) - the tissues between and continuous with the polyps in a colonial anthozoan, consisting of the surface body wall and gastrovascular canals found either on the surface of or penetrating the skeleton (in hexacorals) or consisting of the surface body wall, gastrovascular canals, and solenia penetrating through the thick mesoglea stiffened with sclerites (in octocorals). The edge zone of the coenenchyme is that portion extending outside the peripheral polyps at the edge of a colony or outside the theca in a solitary coral. (Bayer et al., 1983; Stachowitsch, 1992)

Degeneration - a nonspecific term applied to retrogressive but sometimes reversible pathological change in cells or tissues, resulting in impairment or destruction of functions; deterioration; preferably the specific changes observed should be fully described. (Dorland 2006; Stedman 1995)

Disease - any deviation from, or interruption of, the normal structure or function of any body part, organ, or system that is manifested by a characteristic set of signs and whose etiology, pathology, and prognosis may be known or unknown (Dorland, 2006); any impairment that interferes with or modifies the performance of normal function, including responses to environmental factors such as nutrition, toxicants, and climate; infectious agents; inherent or congenital defects, or combinations of these factors. (Wobeser, 1981)

Endolithic - growing within a rock or any other hard inorganic substratum, e.g., coral skeleton. (Coris, 2006) 
Eosinophilic - cell or tissue elements staining readily with eosin dyes, appear pink to red when using a hematoxylin and eosin staining procedure; sometimes referred to as "acidophilic." (Pharma, 2006)

Epidermis - external epithelium of coral polyps and coenenchyme derived from the ectoderm, may be composed of columnar supporting cells (with apical specializations such as microvilli, cilia, or flagella), ciliated sensory cells, mucocytes, epitheliomuscular cells, cnidocytes, pigment cells, neurons, amoebocytes. (Fautin and Mariscal, 1991; Hyman, 1940)

Epithelium - layer of cells covering both ectodermally and endodermally derived tissues of the polyp body and canals, bound together by various junctions and cementing substances to provide strength and mediate the exchange of metabolic and messenger molecules, and bound to and supported by basement membrane or basal lamina. (Dorland, 2006; Stedman, 1995)

Gastrodermis - the inner epithelium of a coral polyp derived from the embryonic endoderm, lining the gastrovascular cavity and polyp-connecting canals. Some cells in this epithelium are phagocytic to digest food particles, absorb nutrients, and release waste products; zooxanthellae often reside within membrane-bound vacuoles in these cells. The gastrodermis may also contain ciliated or flagellated supporting cells, cnidocytes, amoebocytes, sensory cells, mucocytes, and pigment cells. (Fautin and Mariscal, 1991; Goldberg 2002a; Hyman, 1940; Peters, 1984b)

Gastrovascular Canal - a system of tubes lined with gastrodermis that connect the gastrovascular cavities of colonial coral polyps. The canals extend along the surface of the coenosteum in all colonial scleractinians; in some species (e.g., Porites) additional canals extend from the gastrovascular cavities to penetrate through the coenosteum between polyps, forming a porous or perforated skeleton. (Bayer et al., 1983; Peters, 1984a)

Gastrovascular Cavity - the interior space of a coral polyp, also referred to as the coelenteron in anthozoans, the saclike cavity within a polyp connected to the mouth by the actinopharynx. (Bayer et al., 1983; Fautin and Mariscal, 1991)

Hyperplasia - an increase in the number of normal cells in normal arrangement in a tissue or organ, increasing its size. (Dorland, 2006; Stedman, 1995)

Hyphae - the fine, branching tubes which make up the body (or mycelium) of a multicellular fungus. (Pharma, 2006)

Inflammation - a fundamental pathological process aimed at destroying, diluting, and walling off the injurious agent. The process generally consists of a dynamic complex of cytological and chemical reactions that occur in affected tissues in response to an injury or abnormal stimulation caused by a physical, chemical, or biologic agent, including the 
local reactions and resulting morphologic changes, the destruction or removal of injurious material, and the responses that lead to repair or healing. (Dorland, 2006; Sparks, 1985; Stedman, 1995)

Karyolysis - swelling of the nucleus of a cell and gradual loss of its chromatin, indicated by paling of the basophilic reaction in hematoxylin and eosin staining. (Dorland, 2006; Stedman, 1995)

Karyorrhexis - rupture of the nucleus of a cell and the chromatin disintegrates into small pieces, which are extruded from the cell. (Dorland, 2006)

Lesion - a wound or injury, or any pathologic change in the tissues. (Stedman, 1995)

Massive - a term used by coral biologists to describe the growth form of a coral colony, not its size. This form is semi-hemispherical in shape. Other terms to describe the growth form of a coral species include "branching", "laminar", "encrusting", etc. (Veron, 2000).

Melanin - high molecular weight polymer of indole quinone produced by animals, this pigment can be black, brown, yellow, red, or violet. It is produced by gorgonian cells (corticocytes) to encapsulate infectious agents. (Petes et al., 2003; Pharma, 2006)

Melanized - characterized by deposition of melanin. (Stedman, 1995)

Mucocyte - modified columnar epithelial cell with basal nucleus containing basophilic granules or spumous inclusions, also referred to as a mucous secretory cell or mucosecretory cell. The cell synthesizes and secretes mucus through an apical pore to aid in feeding, protection, and sediment removal. (Peters, 1984a)

Mucus - protective secretion of mucocytes consisting of a polysaccharide-protein-lipid complex; it traps particles non-selectively, removes sediment, lubricates the passage of food within the actinopharynx (ciliary-mucus feeding) and helps digest it, provides protection against desiccation, and presents a barrier against environmental stresses, including salinity and temperature changes and exposure to UV radiation. Mucus may also be involved in self-recognition and the immune response of cnidarians. Some of the properties of mucus can be distinguished in histology by using a staining procedure involving alcian blue, periodic acid, and Schiff's reagent (AB/PAS). (Brown and Bythell, 2005; Carson, 1997; Fautin and Mariscal, 1991; Goldberg, 2002a)

Necrosis - cell death characterized by irreversible damage, the earliest of which is mitochondrial. Changes visible with light microscopy are nuclear (pyknosis, karyolysis, or karyorrhexis) and generally accompanied by cytoplasmic hyper-eosinophilia, shrinkage, or fragmentation. After such changes, the outlines of individual cells are indistinct and affected cells may become merged, sometimes forming a focus of coarsely granular, amorphous, or hyaline material. (Stedman, 1995) 
Neoplasia - the pathological process that results in the formation and growth of a neoplasm. (Stedman, 1995)

Neoplasm - an abnormal tissue that grows by cellular proliferation more rapidly than normal and continues to grow after the stimuli that initiated the new growth cease. A neoplasm is often characterized by partial or complete lack of structural organization and functional coordination with the normal tissue, usually forming a distinct mass. (Stedman, 1995)

Perforate coral - coral that has a porous skeleton with gastrovascular canals that connect the gastrovascular cavities of the polyps along the surface and through the skeleton. (Coris, 2006)

Pyknosis - a condensation or reduction in size of the cell or its nucleus. Nuclear pyknosis is contraction of the nucleus to a deep staining irregular or round mass, a stage of necrosis or sign of cell death. (Pharma, 2006; Stedman, 1995)

Pyrenoid - a small proteinaceous body found within the cytoplasm of zooxanthellae (and other phytoflagellates) and closely associated with the chloroplasts. It contains the enzyme ribulose-1,5-bisphosphate carboxylase/oxygenase (RubisCO), which adds carbon dioxide to the sugar ribulose-1,5-bisphosphate as it synthesizes and deposits polysaccharides. The pyrenoid is visible in fixed, stained sections of zooxanthellae as a small round refringent body surrounded by a pale staining starch sheath. (Dorland, 2006; Leggat et al., 1999)

Vacuole - a tiny fluid-filled cavity or a membrane-bound vesicle formed in the protoplasm of a cell. (Dorland, 2006; Stedman, 1995)

Zooxanthellae - dinoflagellates (unicellular photosynthetic organisms) that live within the gastrodermal cells of some scleractinians, octocorals, sea anemones and other animals (not cnidarians), which give corals a characteristic brown coloration. Zooxanthellae provide energy in the form of photosynthate, use animal wastes (nitrogenous ones and carbon dioxide) and, in calcifying organisms, enhance calcification. (Peters, 1984a) 
VITA

\section{LONGIN KACZMARSKY}

August 29, 1959

1983

1983-1984

1984-1986

1985

1986-1990

1990-2002

1992-2000

2000-2002

2002

2002-2003

2003

2002

2004-2008

2004 Certifications: Motorboat Operator (U.S. Dept. of the Interior), AAUS Scientific Diver and Rescue Diver, Crew Chief (FIU), Nitrox Diver (NAUI)

2006

2008-2009

2008-2009

Born, Morristown, NJ

B.S. Biology, Montclair State University, NJ Lab Technician. Polycast Corp., Hackensack, NJ

Lab Technician. Raychem Corp., Menlo Park, CA courses in statistics and management. Univ. of California, Berkeley Commercial fisherman. St. Croix, USVI Executive Director and Curator. St. Croix Aquarium and Marine Education Center. St. Croix, U.S. Virgin Islands

U.S. Dept. of Commerce. Caribbean Fisheries Management Council Graduate teaching assistant. C.W. Post College, NY

M.S. Environmental Science. Thesis: "Coral Diseases and Anthropogenic Influences in St. Croix, U. S. Virgin Islands” C.W. Post College, NY GPA 4.0 Fulbright Research Fellowship. Silliman University, Philippines Field Biologist. World Bank Coral Disease survey, Philippines

Adjunct Professor. C.W. Post College, NY (Ecology, Anatomy and Physiology II Lecture \& Lab)

Graduate teaching assistant. (Laboratory: Ecology, Microbiology, Marine Biology, General Biology, Human Biology and Microbial Ecology)

rincipal Investigator. HOVENSA. Largest coral population survey of St. Croix, USVI to date Committee member for Amanda Sabol, M.S., C.W. Post College, NY Florida International University Miami, FL Doctoral Candidate in Biology 


\section{PUBLICATIONS AND PRESENTATIONS}

Kaczmarsky L, Draud M, Williams EH (2005) Is there a relationship between proximity to sewage effluent and the prevalence of coral disease? Caribbean Journal of Science 41:124-137

Kaczmarsky L (2006) Coral disease dynamics in the Central Philippines. Dis. Aquatic Org. 69:9-21

Kaczmarsky L and Richardson LL (2007) Transmission of Growth Anomalies between Indo-Pacific Porites corals. Journal of Invertebrate Pathology 94:218-221

Raymundo LJ, Reboton CT, Rosell KB, Kaczmarsky L (2005) Coral diseases on Philippine reefs: genus Porites is a dominant host. Diseases of Aquatic Organisms 64:181-191

Richardson LL, Sekar R, Myers JL, Gantar M, Voss JD, Kaczmarsky L, Remily ER, Boyer GL, Zimba PV (2007) The Presence of the Cyanobacterial Toxin Microcystin in Black Band Disease of Corals. FEMS Microbiology Letters 272:182-187

Sekar R, Kaczmarsky L, Richardson LL (2008) Microbial community composition of black band disease on the coral host Siderastrea siderea from three regions of the wider Caribbean. MEPS 362:85-98

Richardson LL, Miller AW, Broderick E, Kaczmarsky L, Gantar M, Stanić D, Sekar R (2009) Sulfide, Microcystin, and the Etiology of Black Band Disease. Dis. Aquat. Org. In press.

Sekar R, Kaczmarsky L, Richardson LL (2009) Effect of Freezing on PCR Amplification of 16S rRNA Genes from Microbes Associated with Black Band Disease of Corals. AEM 75: $2581-2584$

"Gorgonian coral diseases in the Caribbean". Weir J, Weil E, Kaczmarsky L, Harvell CD, Kim K, Smith G 29 ${ }^{\text {th }}$ Annual Benthic Ecology Meeting. 2000.

"Dynamics of Coral Diseases and Syndromes in the Central Philippines ". Oral presentation. 10 $0^{\text {th }}$ Int. Coral Reef Symp. Okinawa, Japan. 2004.

"Etiology of the Caribbean coral disease white plague". Richardson LL, Mills DK, Foley J, Kaczmarsky L, Remily E, Voss JD. ASLO meeting. Salt Lake City. 2005. p 91

"Coral Community Composition in St. Croix, U. S. Virgin Islands in Relation to Sources of Major Anthropogenic Impacts". Poster presentation. $11^{\text {th }}$ Int. Coral Reef Symp. 2008. Ft. Lauderdale, FL 